\title{
Creating a Relational Participatory Space: \\ Insights from a Youth Participatory Action Research \\ Project
}

\author{
By \\ Eddy Davis-Rae
}

\begin{abstract}
A thesis submitted to the
Victoria University of Wellington

In partial fulfilment of the requirements for the degree of Master of Education
\end{abstract}

Victoria University of Wellington

2021 


\section{Abstract}

Since the ratification of Article 12 of the United Nations Convention on the Rights of the Child, there has been a heightened focus on youth participation as a way of upholding young people's right to have their say on decisions that affect them. However, programmes that attempt to engage young people in decision-making processes have often been poorly enacted and have failed to adequately address the barriers that limit young people's ability to participate meaningfully and therefore rarely result in sustained change. This study examined processes with a youth participatory action research [YPAR] project in order to identify and explore processes and practices that might serve to sustain young people's involvement and support authentic and meaningful participation. The research used an instrumental case study approach to examine an 18-month-long YPAR project operated through an existing youthwork programme. Data were collected through autoethnography, artefact analysis and participant interviews and reflections with youth participants.

The study found that peer-to-peer and peer-to-leader relationships were foundational to youth participants' ongoing involvement over the 18-month period. Such relationships appeared to drive much of the momentum of the action research and enable at times dynamic flows of power between youth participants and adults that encouraged an inter-generational space within the YPAR project. Young people stepped into leadership roles at different phases of the project while adult leaders managed the pace and progress of the project. The study identified five factors that helped to create this relational participatory space: reduced leader direction; valuing youth voice; openness of other participants, reworking adult-centric processes and the implementation of a variety of sharing activities. A number of factors that constrained youth voice were also identified. The study highlights how strong relationships were an integral part of the processes and practices of YPAR, rather than merely a positive outcome of participatory processes. These findings challenge traditional individualistic models of youth participation that frequently fail to acknowledge the importance of intergenerational and collective relationships within youth participatory action research projects. The study therefore calls for a heightened focus on relationship building within participatory processes both at a policy and practical level. 


\section{Acknowledgements}

There are a number of people who have contributed hugely to this piece of research that I would like to acknowledge.

First, I would like to thank the young people that have participated in this project. They are an absolute credit to their generation and have made a huge contribution to their city, to the lives of other young people and to myself. Seeing their enthusiasm and passion for change has been a continual source of inspiration and joy in my life.

Second, I would like to thank my supervisor, Bronwyn Wood who has encouraged, supported and challenged me throughout this project. Her expert advice and her approach to supervision that drew out and expanded my interest and passion for youth participation is so appreciated.

Third, I would like to thank my colleagues at BGI who have helped to support the young people involved in this project by being friendly and welcoming to every young person who walks through the door. In particular, I would like to acknowledge my boss Ross, who encouraged me to enrol in the Masters programme and who has allowed my learnings to shape and contribute to BGI processes. I would also like to thank my colleague Rose, who has worked alongside me as a volunteer to co-facilitate this project and has offered myself and the young people so much support and encouragement along the way.

Finally, I would like to thank my friends and family for their love and patience during this time. Thank you Meg, for your unwavering support for me through stress, late nights and sacrificed weekends and your ability to make me feel calm and confident every day. Thank you to my brothers, Micah and Luke, who have offered words of encouragement and have celebrated the various milestones along the way and thank you Mum and Dad for your support, your enthusiasm for my work and your unconditional love.

This thesis is dedicated to all of you. 


\section{Table of Contents}

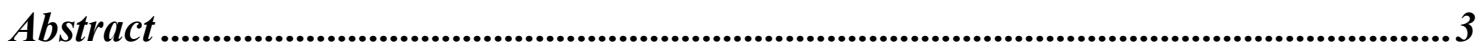

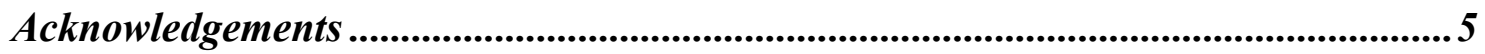

Chapter One: Introduction.......................................................................................11

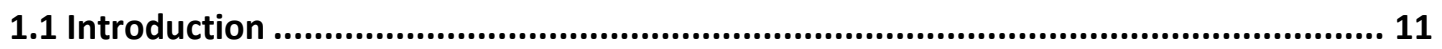

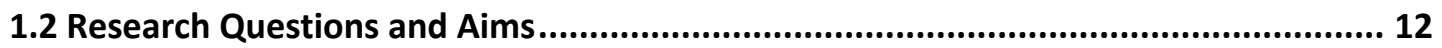

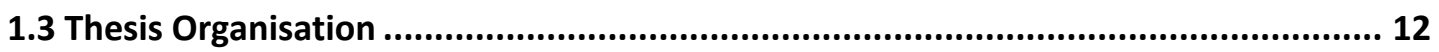

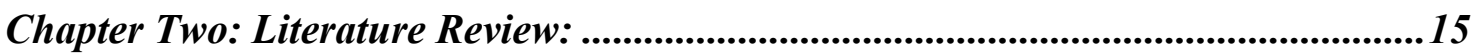

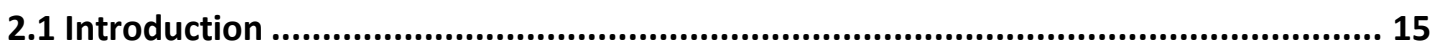

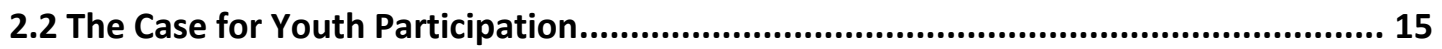

2.3 Applied Youth Participation: Examples and Limitations .......................................... 18

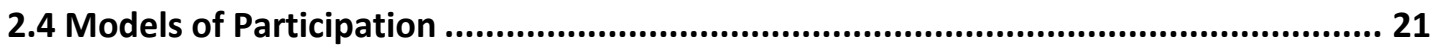

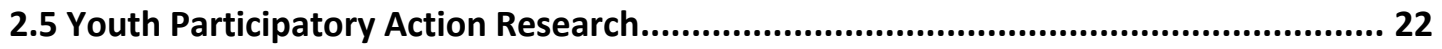

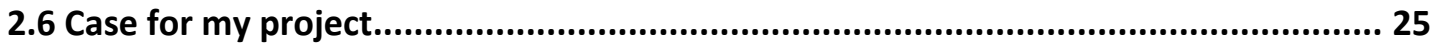

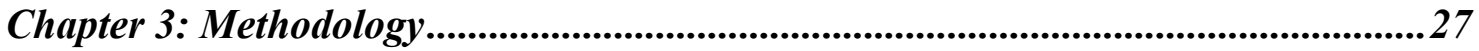

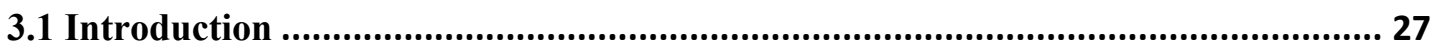

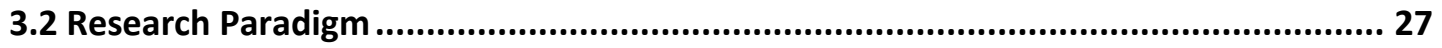

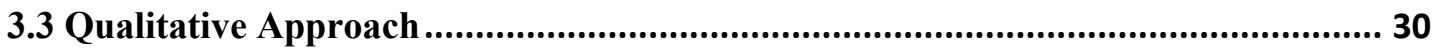

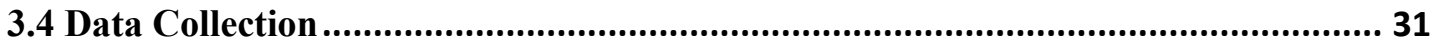

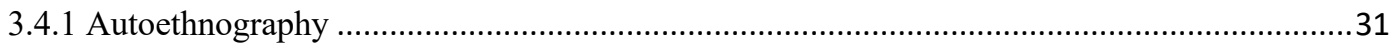

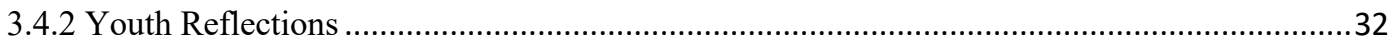

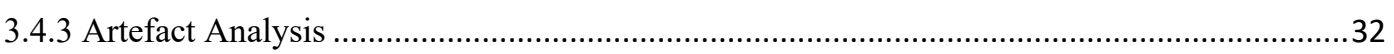

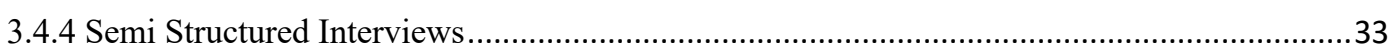

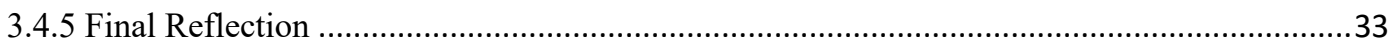

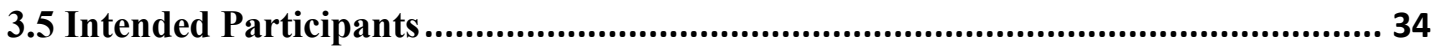

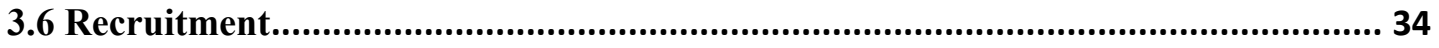

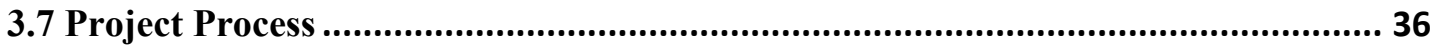

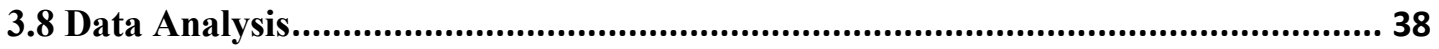




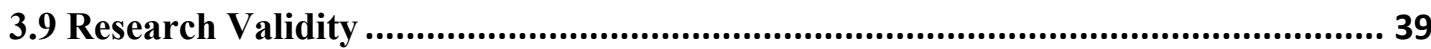

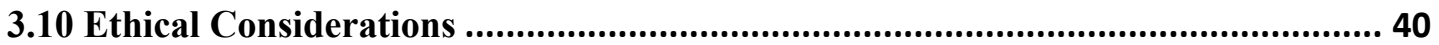

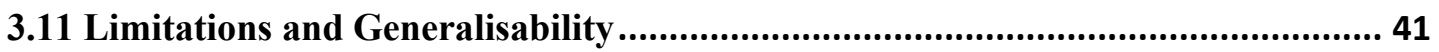

Chapter 4: Factors Influencing Participant's Involvement in the YPAR Project...... 43

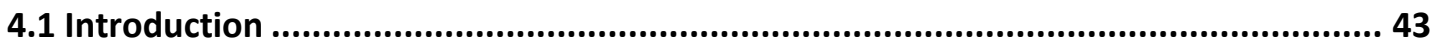

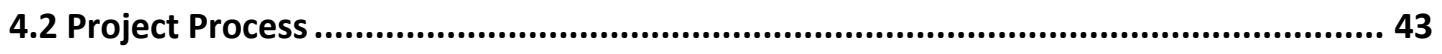

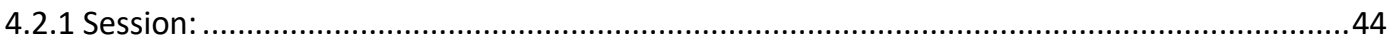

4.2.2 Whakawhanaungatanga (relationship building) ………....................................................4

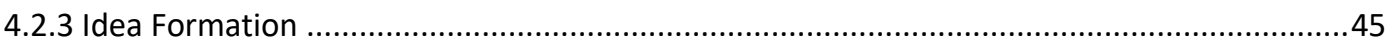

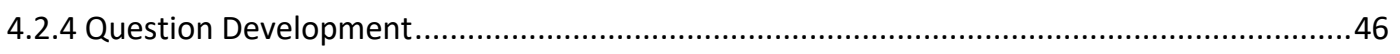

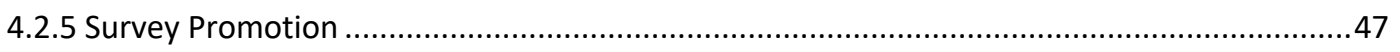



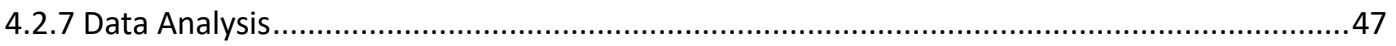

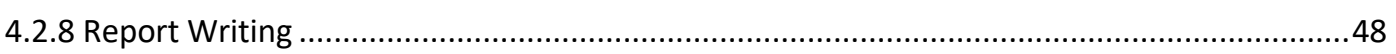

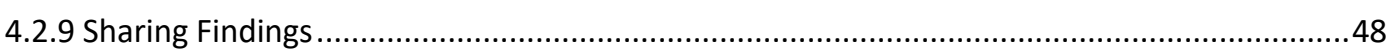

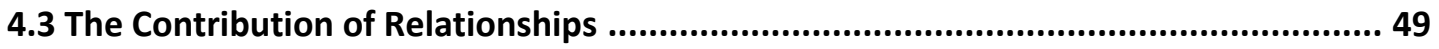

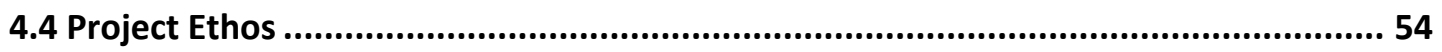

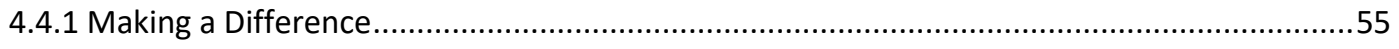

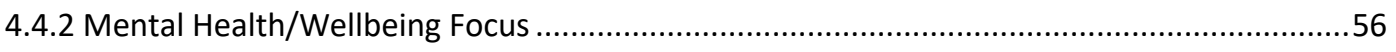

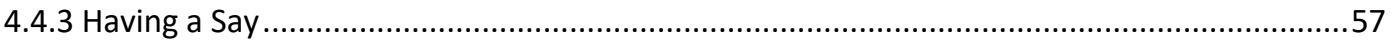

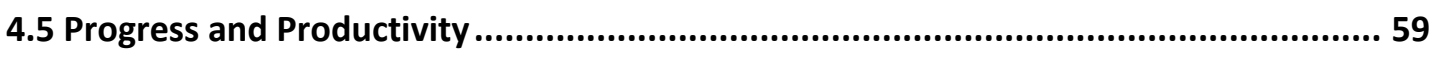

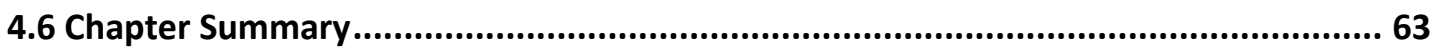

Chapter 5: Exploring the Amplification of Youth Voices........................................65

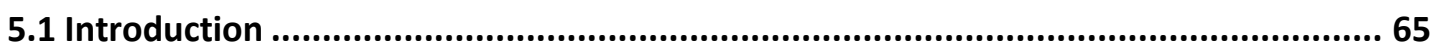

5.2 The Contribution of Relationships ............................................................................. 66

5.3 Creating a Participatory Space ….............................................................................. 70

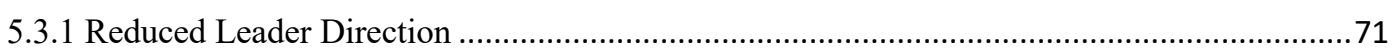

5.3.2 Other Participants' Openness...........................................................................................

5.3.3 Variety of Sharing Activities ............................................................................................

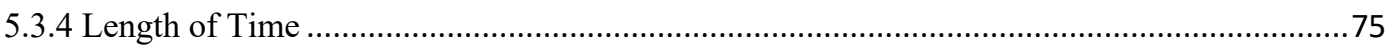

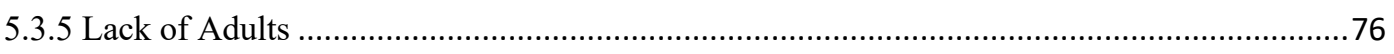

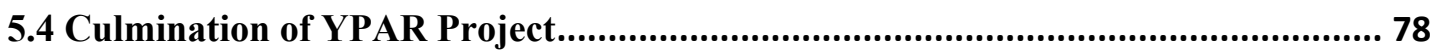




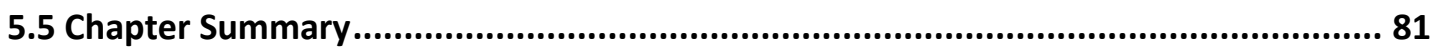

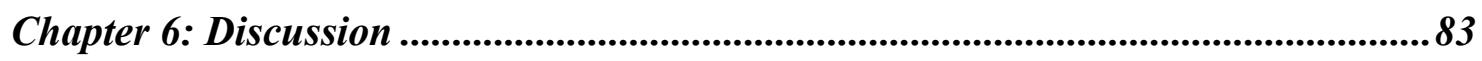

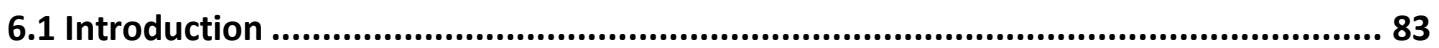

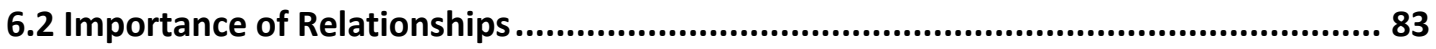

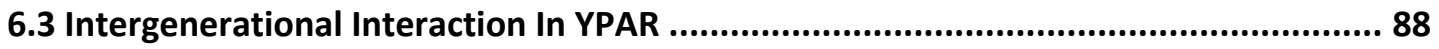

6.5 Implications for Youth Participation Models ......................................................... 93

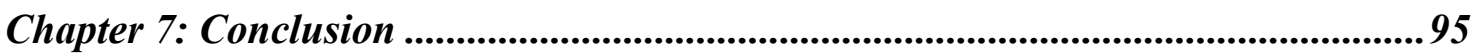

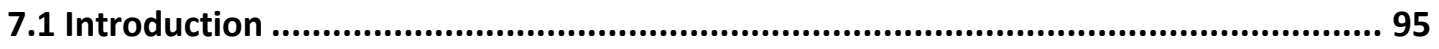

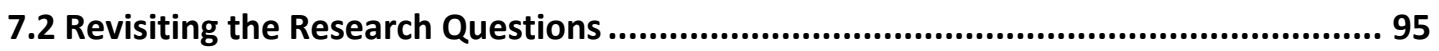

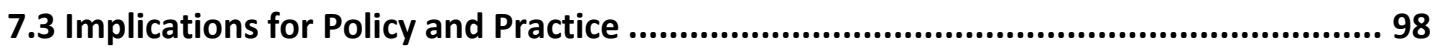

7.4 Implications for Further Research ............................................................................. 99

References.................................................................................................................................. 101

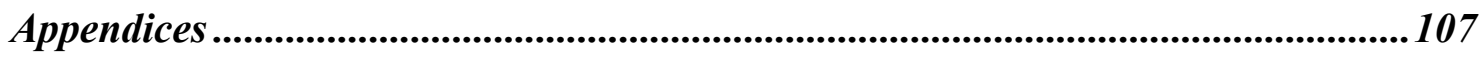

Appendix 1: Observation Protocol.............................................................................107

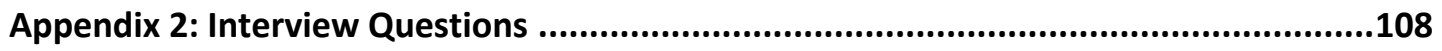

Appendix 3: Post Launch Reflection Sheet ..................................................................109

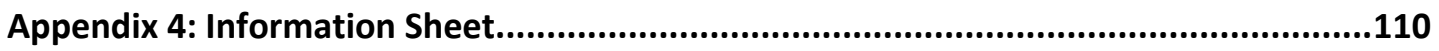

Appendix 5: Consent Form ....................................................................................112






\section{Chapter One: Introduction}

\subsection{Introduction}

Since the ratification of Article 12 of the United Nations Convention on the Rights of the Child [UNCROC], which gave children and young people the right to have their say on decisions that affect them (UN General Assembly, 1989), youth engagement has become highly sought after in decision-making-processes (Woodhead, 2010). This, coupled with the growing perception that young people are capable and have valuable contributions to make (Hart, 1997; Lansdown, 1995; Lundy, 2007; Malone, 1999; Woodhead, 2010), as well as a number of developmental benefits that young people gain from being involved in participatory projects (Mitra, 2004; Serido, Borden, \& Perkins, 2011; Wagaman, 2015) have increased the focus on youth participation across multiple sectors.

An increased focus on youth participation has in turn illuminated a number of barriers that young people face to ensuring their voices are heard in traditional decision-making processes. Systemic issues such as age restrictions on voting, adult centric language used within engagement processes, and a view that young people's voices are not valued or taken into consideration even if they are able to navigate these barriers, work to limit young people's ability to participate in decision making (Harris, Wyn, \& Younes, 2010).

An understanding that these traditional forms of engagement such as voting, town hall style meetings and submissions are not accessible for young people (Bermudez, 2012) has encouraged those working with young people to consider other forms of engagement that include young people's perspectives. Examples include Youth Councils and Parliament programmes, student voice and civic education initiatives in schools as well as YPAR. However, attempts to encourage youth engagement and participation have often been poorly performed (Freeman, Nairn, \& Sligo, 2003). Many of these initiatives still involve adult centric processes and do not sufficiently respond to the power dynamics that work to limit young peoples' ability to participate meaningfully and authentically (Fitzgerald, Graham, Smith, \& Taylor, 2010; Nir \& Perry-Hazan, 2016).

Identifying the various barriers that young people face has paved the way for youth participation models such as Hart's (1992) Ladder, Treseder's (1997) Wheel and Westhorp's (1987) Continuum (see Section 2.5) to offer frameworks for characterising, defining and evaluating participation. While useful as evaluative tools for participation, these models have been critiqued for their simplistic and linear approach to participation (Fitzmaurice, 2016) and have led to the emergence of other models such as Le Va (Le Va, 2016) and Ngā Uri O 
(Lifehack, 2016) which present participation with less focus on the individual and western inspired values. Drawing inspiration from these more relational models as well as the participation Star developed by Wierenga, Wood, Trenbath, Kelly, and Vidakovic (2003), my study also works to explore the effects of these relational processes within YPAR and thereby to interrogate and expand upon dominant frame works in youth work.

\subsection{Research Questions and Aims}

As mentioned,YPAR is one methodology that practitioners and researchers have utilised to enable deeper involvemeng of young people in research. In light of the barriers that young people face when trying to participate, as well as the shortcomings of engagement processes that have attempted to involve young people in decision making, in this project I sought to identify and understand processes within YPAR that support effective and authentic youth participation. The aim of this study was to gain deeper understandings about these processes which support effective youth participation in order to provide insights that can shape and improve youth engagement in decision-making processes across multiple sectors of society. In order to explore how YPAR can be a methodology that facilitates meaningful and authentic youth participation I developed the following research questions.

1) What factors might sustain youth involvement in an extended YPAR project?

2) What processes of YPAR can enable and constrain the amplification of youth voices in a youth engagement project?

Here I consider the term voice in broad terms to include not just their ability to share their perspectives but also their deep involvement and participation within the project.

\subsection{Thesis Organisation}

In the following chapter I will consider these issues surrounding YPAR with reference to literature and research in this area in order to examine previous research that has explored young people's experience in decision-making processes, the structures that work to limit or encourage the representation and authenticity of young people's involvement. I then go on to analyse the current tensions within the literature and the case for YPAR as one option for 
achieving meaningful youth engagement and how my project sought to make a contribution to the ongoing literature around youth participation. In Chapter 3, I will describe my methodology and the theoretical lenses that have influenced my approach to this thesis. This is followed by my findings. Chapter 4 presents the evidence for process that enabled sustained involvement and Chapter 5 explores how young people's voices were amplified and constrained within the project. Chapter 6 discusses these findings in greater detail and establishes the reflexive, dynamic relationship between sustained involvement, amplified youth voices and relationships. Finally, Chapter 7 concludes this thesis by revisiting the research questions, and considering the implications for policy and practice as well as further research. 


\section{Chapter Two: Literature Review:}

\subsection{Introduction}

In this chapter I provide an overview of the current literature around youth participation and YPAR as a method for listening to young people's perspectives. I begin the chapter by building the case for meaningful and authentic youth participation and describing how and why it has become a focus within policy and literature. Next, I identify examples of youth participation initiatives and critique the extent to which they have reduced the various barriers and power dynamics that limit young people's participation within decision making processes. I then shed light on YPAR as a methodology for enabling youth participation before identifying a number of models that work to characterise, evaluate and define youth participation. Finally, I build the case for my own project by identifying gaps within the literature and suggesting how my research questions will explore some of these gaps.

\subsection{The Case for Youth Participation}

In the last 30 years there has been a heightened focus on youth participation in the academic literature across multiple sectors. This can, in part, be attributed to the United Nations Convention on the Rights of the Child (UNCROC) which Martin Woodhead (2010) refers to as "unquestionably the most significant milestone for development of current child policies" (p. xx). Article 12 of UNCROC (ratified by New Zealand in 1993) provided young people with the right to express their views freely and be heard on matters that affect them (UN General Assembly, 1989). This Article has both been informed by and proven a catalyst for the growing case for youth participation within literature and praxis. As well as this right provided to them by the ratification of Article 12, there is growing evidence to suggest that young people themselves want to contribute to decision-making processes (Harris et al., 2010), have valuable perspectives to share (Hart, 1997; Lansdown, 1995; Lundy, 2007; Malone, 1999; Woodhead, 2010) and can be empowered by and develop through their involvement in the process of sharing their perspectives (Mitra, 2004; Serido et al., 2011; Wagaman, 2015). Fitzgerald et al. (2010) suggest an evolution of the case for (youth) participation through three distinct movements, equality - a claim based on rights and equal 
representation, difference, a claim based on the value of diversity of knowledge and understanding and dialogue, facilitating conversation and negotiation between decision makers and young people. These three movements have been influential factors in the broad realm of youth participation.

Against this backdrop of heightened awareness of youth participation, there has been a parallel discourse noting increasing 'apathy' of youth. Research has shown a significant decrease among young people in traditional methods of participation in recent years (Harris et al., 2010), and has led to the popular narrative that young people are disengaged as a result of disinterest, apathy or even incompetence (Ball, 2019; Lock, 2019). However, critics have argued that this perspective undervalues both the 'everyday' and unconventional forms of participation that young people now engage in, (Cammaerts, Bruter, Banaji, Harrison, \& Anstead, 2016; Harris et al., 2010; Wood, 2015). The perceived crisis of youth disengagement in formal democratic processes has only increased global interest in encouraging young people to have their say (see Cammaerts et al. (2016)) and this, along with the various benefits of including young people in decision-making, has contributed to the introduction of a swathe of policies that aim to rectify the low levels of youth engagement and better uphold their right to have their say (Lawy \& Biesta, 2006; Wood \& Black, 2014)..

The desire to increase youth participation has been a feature of New Zealand policy in recent years - especially since the $7^{\text {th }}$ Labour government of 2017. Their Child and Youth Wellbeing Strategy [CYWS] released in 2019, for example, includes "children as involved and empowered" among the strategy's key outcomes (Department of the Prime Minister and Cabinet, 2019, p. 17). This particular outcome aims to ensure that young people are supported to, contribute within their various spaces, to have their perspective listened to and considered, and to become autonomous and "responsible citizens" (p. 17).

Policy within schools has also attempted to increase students' ability to shape their school and learning environment. In 1989 for example, the Government made it mandatory for schools to include a student representative on Boards of Trustees through the establishment of The New Zealand Education Act. This initiative instructs school Boards to provide a voice for the student body and attempts to allow a student to have an impact on the vision and direction of their school. Student leadership positions such as prefects and school councils are other examples of initiatives that can encourage certain young people to have their say. While these positions focus on providing opportunities for young people to provide their perspectives on school processes and structure, educators, policy creators and researchers have used notions of participation within the New Zealand Curriculum to 
champion student voice research within the classroom (Ministry of Education, 2007; Wood, Taylor, \& Atkins, 2018). This has been used both as a tool for improving the education experience for students while also upholding their right to have their say on issues that affect them and increase young people's agency and autonomy (Loveridge \& Bourke, 2018). The vision section of the New Zealand curriculum which articulates "what we want for our young people" uses language such as "actively involved", and young people who are "participants in a range of life contexts" and "contributors to the well-being of New Zealand." (Ministry of Education, 2007, p. 8). "Participating and contributing" again feature in the key competencies section (pp. 12-13) and a subject overview shows that social science subjects aim to allow students to explore how they can "participate and take action as critical, informed and responsible citizens" (p. 17).

Within the New Zealand youth development sector, the mandate for youth participation is particularly strong. UNCROC is explicitly referred to in the Code of Ethics for Youth Work in Aotearoa New Zealand [CEYWA] meaning that youth work that does not adequately allow and encourage young people to have a say in the decisions that affect them is considered to be unethical (Ara Taiohi, 2020). Youth participation was also a key principle within the Youth Development Strategy Aotearoa (2002) which has contributed to the increased Ministry of Youth Development [MYD] funding for community organisations that encourage young people to be: "connected to communities," "contributing to society" and to ensure their "opinions (are) listened to and valued" (Ministry of Youth Development, 2019). Furthermore, in the newly developed Mana Taiohi framework, ${ }^{1}$ youth participation has been named whai wahitanga which poetically translates to the pursuit of place (Finlay-Robinson, Baxter, \& Dunlop, 2019). It is a principle that encourages youth workers to recognise youth participation as mana enhancing process for the young people involved and also value the contributions that they can and do make to their community.

The use of Te Reo and kaupapa Māori approaches to describe youth development principles signals the sector's attempt to honour Te Tiriti o Waitangi and this commitment provides a further impetus to ensure that young people can participate and are heard within decision-making processes. There is evidence to suggest that pre-colonial Māori included young people in various tribal activities in a way that reflects participatory values that the sector holds today. Urungatanga, for example is a pre-colonial principle which has been translated to 'education through exposure. It involved young people participating in various

\footnotetext{
${ }^{1}$ https://arataiohi.org.nz/resources/training-and-resources/mana-taiohi/mana-taiohi-principles/
} 
activities in order to learn their role within the iwi, hapū and whānau structures (Hemara, 2000). Baxter, Caddie, and Cameron (2015) suggest that this principle of urungatanga, is evidence of a pre-colonial commitment to youth participation and that, perhaps, the lack of youth engagement within Pākeha dominated decision-making processes or at least, the lack of consideration of principles such as urungatanga, has been normalised in New Zealand society through colonisation. This perspective is furthered by Skerrett \& Ritchie (2018) who use this quotation from Reverend Samuel Marsden's (a member of the Church Missionary Society who travelled to New Zealand in the early 1800s) diary to highlight the different position that young people held in pre-colonial Māori society to those held by children in western society:

The chiefs in general are very sensible men, and wish for information upon all subjects. They are accustomed to public discussions from their infancy. The chiefs take their children from their mothers' breast, to all their public assemblies. They hear all that is said upon politics, religion, war etc by the oldest men. Children will frequently ask questions in public conversation, and are answered by the chiefs. I have often been surprised, to see the sons of the chiefs at the age of 4 or 5 years sitting amongst the Chiefs, and paying such close attention to what was said.

Evidence of this pre-colonial commitment to youth participation adds further weight to the case for including young people in decision-making processes. A key principal of Te Tiriti o Waitangi is tino rangatiratanga or self-determination which in effect is what youth participation is all about (Williams, Edlin, \& Beals, 2010). Therefore, an organisation interested in honouring Te Tiriti must (among other things) work to uphold the tino rangatiratanga of tangata whenua and consider the ways in which certain practices or principles such as urungatanga can work as a vehicle for decolonisation.

\subsection{Applied Youth Participation: Examples and Limitations}

While the motivation behind this cross-sector commitment to encouraging youth participation varies, it is clear that there are strong global and national forces making the case for young people to be able to have their say. However, despite this, in 2017 Children's Commissioner, Andrew Becroft condemned New Zealand's commitment to upholding the rights of children by outlining the lack of practical steps the Government had taken to comply with the 
convention (The UN Convention on the Rights of the Child Monitoring Group, 2017). In the report the monitoring group make three recommendations to the New Zealand government one of which concerned the lack youth engagement in decision-making processes or specifically, "Ensure(ing) children and young people's views are taken into consideration in the development of legislation and policies in line with the Children's Convention" (The UN Convention on the Rights of the Child Monitoring Group, 2017, p. 8). This critique has provided further motivation for those whose work impacts young people to consider how they can encourage young people to provide their perspectives on issues that affect them and reduce the various barriers that work to reduce young people's active participation in their lives. This leads policy makers to consider how adult-centric or traditional democratic processes enable (or prevent) young people to participate in society.

An analysis of these sectors of society illuminates barriers to participation including, age restrictions on voting, language and discourse commonly used in government and decision-making spheres and even the perception, among young people, that their voice is not listened to by decision makers (Harris et al., 2010). These barriers work to reduce young people's participation within these traditional civic engagement systems and therefore does not appropriately provide young people with the opportunities to have their say on issues that affect them. As Fitzgerald et al. (2010) state, authentic youth participation requires more of adults and the government than just a proclaimation of their rights to participate. It requires extending young people an invitation to the dialogue that shapes decision-making. This is also true for youth participation within schools and student voice initiatives in the classroom.

Understanding this has prompted the current government to establish initiatives through "Youth Voice Project" to investigate other ways that they can engage young people and gather their perspectives on issues that affect them (Department of the Prime Minister and Cabinet, 2019, p. 19). This has led to the development of Hiver ${ }^{2}$ a website that aims to make policy decisions accessible for young people and invites them to provide feedback as well as implementing youth advisory groups in various Government departments and rolling out a programme to encourage civic participation activities such as volunteering, engaging with local and national government and voting in ethnic communities (Department of the Prime Minister and Cabinet, 2019). Other organisations such as Rock Enrol, ${ }^{3}$ Youth Councils, UN Youth and New Zealand Youth Parliament have also attempted to increase young people's

\footnotetext{
${ }^{2}$ www.hive.nz

${ }^{3}$ http://www.rockenrol.org.nz
} 
engagement within traditional forms of public engagement. However, while these initiatives technically invite young people to dialogue, many fail to appropriately engage and respond to the various power structures and barriers that exist within dialogical processes between adults and young people (Fitzgerald et al., 2010; Nir \& Perry-Hazan, 2016).

One limitation of youth versions of democratic processes such as Youth Councils and youth Parliament is diversity of voice. While these initiatives attempt to recruit diverse young people that accurately represent the population, the adult centric nature of these systems often attract 'high achievers' who are able to operate in spaces that effectively mimic adult systems (McGinley \& Grieve, 2010; Tukie, 2010). Nairn, Sligo, and Freeman (2006) propose that even attempts to address this issue by adding 'trouble makers' to these processes can result in the exclusion of 'ordinary' young people. The result is that these processes afford certain young people the opportunity to contribute and participate in decision-making processes but can work to homogenise youth voice in a way that may not only inaccurately represent many young people, but also works to further adult ideas (Lansdown, 2010; Spicer \& Evans, 2006), support neoliberal agendas (Arnot, 2006) or merely maintain the status quo (Hart, 1992; McGinley \& Grieve, 2010).

Such processes can also fall short of effective participation if adult facilitators lack the steadfast commitment to reduce the power dynamics that exist between young people and adults (Pain \& Francis, 2003). These power imbalances can be accentuated by common physical settings of participatory processes such as classrooms or government offices where young people may feel intimidated (Wood et al., 2018) or impose (often unstated) expectations to perform to adult expectations (Arnot \& Reay, 2007). Furthermore, even a process that addresses the various limitations of youth participation within the confines of the Youth Council or Parliament itself, can still be limited by adult authorities that do not respect or value the perspectives put forward through this youth participatory process (Hickey $\&$ Pauli-Myler, 2019). An example would be a Youth Council developing various recommendations on how a particular council decision might affect young people, only for the city councillors who own the real mandate and authority with which to make change to reject their perspectives. The result is a process that does not uphold the rights of young people to have their say but rather provides a lesson about unfair democratic process. Adult facilitators of such processes thus need to be wary of the potentially demotivating effects for young people of experiencing exclusionary and oppressive practices, especially when attempting to address these inequalities. 
Consideration of the various inequalities and barriers that young people face both to participate and then be listened to within participation processes, has led some scholars to conclude that young people's apparent decision to disengage from traditional processes is a logical one (Harris et al., 2010). Regardless of young people's motivation for doing so, Pain and Francis (2003) identified that their unwillingness to participate, has become another issue for those hoping to engage young people in decision-making processes. While some may point to this unwillingness as further evidence of youth apathy, others have considered how youth engagement processes can be an empowering and motivating experience for young people by ensuring that their perspectives can effect change.

\subsection{Models of Participation}

There are a number of models that aim to categorise and conceptualise effective youth participation. Hart's (1992) Ladder, Treseder's (1997) Wheel and Westhorp's (1987) model, for example, are three of many that describe a continuum of participation (Graham, Whelan, \& Fitzgerald, 2006). Hart's Ladder is perhaps the most well-known and presents eight rungs of participation and describes the first three rungs (manipulation, decoration and tokenism) as "non- participation". The delineation of these three concepts indicate that adults have attempted to pass these forms of youth-involvement as participation (Hart, 1992). Hart's higher rungs (5-8) are the levels of young people's involvement which should be aimed for. For example, Level Five projects are adult initiated but young people are consulted and informed while level six projects are adult initiated but involve young people in the implementation and design. Level Seven and Eight represent youth-initiated projects that are supported by and participated in by adults. Hart's Ladder has been critiqued for its simplistic and linear presentation of youth participation that suggests a hierarchy of participatory approaches (Wood et al., 2018). Treseder's Wheel partly addresses this critique simply by presenting his suggested "degrees of participation" in a less hierarchical wheel format (Treseder, 1997).

Another model is Wierenga et. al's star, which describes seven concepts for meaningful youth participation loosely under the headings of 'meaning,' 'control' and 'connectedness' (Wierenga et al., 2003). While Hart's model provides a way to critique and evaluate levels of participation within various processes, Wierenga et. al's star works as a planning tool to illuminate various considerations for would-be youth participation facilitators. It offers methods to reduce barriers in participatory processes by suggesting among other things that 
facilitators: "listen" to young people in order to ensure that young people are invited to participate and will be heard; "recognise the strengths" of young people, in order to critically engage with the idea that young people's perspectives are not as valuable as adults or that they are incapable of participating and "rework structure and processes" to ensure that an organisations and processes are set up in a way that enables young people's participation and that their contributions can impact decision-making (Wierenga et al., 2003). Shier's (2001) 'Pathways to Participation' is similar in that it works as a checklist for would be practitioners but similar to Lundy's (2007) model, it also works to conceptualise the necessary factors needed to uphold the rights afforded to children and young people through UNCROC. These models act as evaluative tools and challenge those interested in upholding these rights to consider how they are providing space for and facilitating youth perspectives through policy and practice and how to ensure those perspectives are heard and acted on within decisionmaking processes.

Few of the influential models within the literature give much consideration to how relational (barring Wieringa et al's Star) or cultural factors influence participatory processes. However, closer to home an organisation called Le Va (2016) have developed a Pasifika youth participation guide which is centred on traditional Pasifika values. The model describes nine concepts under the headings 'absolute inclusion', 'radical acceptance' and 'full participation' as guidelines for those working alongside Pasifika young people. Similarly, Lifehack (2016) developed a model called Ngā Uri $\bar{O}$ which uses a Māori concept of sharing whakapapa and identity to help facilitate a participatory and collaborative space. It also presents the idea of whakawhanaungatanga or relationship building as a necessary prerequisite for youth adult collaboration by asking participants to answer three questions: ko wai au? (Who am I?) ko wai koe? (who are you?) and ko wai tatou? (who are we?). These models challenge the more widespread previous models by removing participation from the context of western individualist values and towards collective, relational, and interdependent understanding that Abebe calls for in his (2019) study. These models are of particular interest to my study given the context of New Zealand.

\subsection{Youth Participatory Action Research}

YPAR is one process that has been used by schools and community organisations to gather and understand youth perspectives. It is a process that allows young people to be part of the design of a research project and in doing so accepts and responds to the notion that young 
people not only have the right to be listened to, but also hold valuable perspectives on issues that affect them (Lansdown, 1995). Furthermore, it can be a process for young people to provide authentic and in-depth perspectives because of its inclusivity, defined by young people themselves (Cahill, 2007b). These two factors position YPAR as a participatory process that can facilitate young people's right to participate by providing them with 'space', 'voice' 'audience' and 'influence' through the internal process (Lundy, 2007). These are four concepts that Lundy (2007) describes as necessary for upholding the rights afforded to them through UNCROC. The action component of YPAR can then work to ensure that these perspectives are heard and acted on externally through the implementation of projects and campaigns that seek to address the issues illuminated through the project. In short, YPAR is a commitment to an assertion made by Torre and Fine (2006) that,

people especially those who have experienced historic oppression (in this case young people) hold deep knowledge about their lives and experiences and should help shape the questions, frame the interpretations and style the research products that ultimately effect [sic] them most intimately. (p.458)

Empirical research on YPAR projects has identified a number of benefits to participants including increased self-efficacy, motivation, skill development and conflict resolution. These studies position YPAR not only as a process for critiquing existing power structures, but also an effective pedagogical tool (Ardoin, Castrechini, \& Hofstedt, 2014; Ozer \& Douglas, 2013; Scott, Pyne, \& Means, 2015; Wagaman, 2015; Warren \& Marciano, 2018). YPAR's ability to empower research participants while providing opportunities for youth representation in decision-making, have made it a popular methodology for those committed to amplifying youth voices. However, YPAR does not automatically address the various limitations of other youth engagement processes described above. It too requires adult facilitators to hold a deep commitment to the values of participatory research and the amplification of youth voice to ensure that their project doesn't use young people as tokens or decorations to perpetuate adult ideas or maintain the status quo (Hart, 1992). It requires a commitment to reducing power imbalances a continual evaluation of their own place within the project. These issues, if not addressed, can work to limit the authenticity of youth voice and participation. As well as issues of power, other barriers such as a focus on quantifiable outcomes, financial restrictions and time pressure (Freeman et al., 2003) can also limit the effectiveness of YPAR and dissuade adults from resourcing such projects. These factors have in part contributed to a tendency for short term, go-nowhere youth participation projects that 
do not provide opportunities for sustained involvement (Matthews, 2001) and participation nor do they work to create meaningful change (Nir \& Perry-Hazan, 2016).

However, done well, PAR can be a tool that helps raise consciousness necessary to bring about change at personal, societal or institutional level (Cammarota \& Romero, 2011). It involves addressing these barriers directly with the aim to challenge and reduce their effect for future generations. At times raising this consciousness is a painful process which illuminates the fact that research participants are living under oppressive systems and that these systems have affected their own world views, opportunities and behaviours (Cahill, 2004). Facilitators of YPAR thus need to be wary of the potentially demotivating effects of uncovering exclusionary and oppressive practices, especially when attempting to address these inequalities. Examples include young people of colour feeling discouraged when confronted with the reality that they were less likely to be able to attend college, (Scott et al., 2015) and young urban women being negatively affected by learning how gentrification had impacted their lives (Cahill, 2004). Similarly, Norton and Sliep (2019) discuss how young refugees' feeling of hopelessness upon encountering xenophobia through a research project in South Africa was overcome through strong bonds with other youth researchers. Furthermore, in a New Zealand example, young people's attempt to present the findings of a youthparticipatory-photo-voice-project was blocked partly by the very exclusionary practices and attitudes that they sought to illuminate (Wood, 2016). Scott et. al (2015) and Cahill (2004) all acknowledge the importance of the collaborative process and the relationships and trust within the research group that allowed the young people to move forward despite coming to understand these harsh realities.

While these studies illuminate the protective benefits of relationships within YPAR, there is also evidence to suggest that young people's participation is enhanced through strong relationships with adults. Cossar, Brandon and Jordan's (2014) study emphasises that young people within state care need to have a strong trusting relationship with their social worker in order to participate and effect change within their lives. Similarly, Tisdall and Davis (2004) suggest that young people are more likely to be heard by adults who they have a supportive relationship with and Mannion (2007) emphasises the effect of intergenerational relationship on the success and sustainability of youth participation projects. 


\subsection{Case for my project}

While youth participation and YPAR has become more popular as a methodology for engaging young people in decision making, the implementation of effective youth participation processes has been more difficult than recognised. A reliance on adult-centric processes, the difficulty of reducing unstated adult-youth power hierarchies and the tendency for short term projects have limited the effectiveness of youth participation initiatives and thus necessitate research that explores how these limitations may be addressed.

Furthermore, the idea of relationships as a catalyst for participation rather than merely a positive outcome, is one that has been identified in the literature (Abebe, 2019; Body \& Hogg, 2019; Mannion, 2007) and through a variety of participation models (Le Va, 2016; Lifehack, 2016; Wierenga et al., 2003). However, there is little empirical research on the nature and detail of a relational approach that responds to critiques of western individualism's influence within youth participation.

The various limitations and barriers within participatory processes and the current tensions within the literature set up the case for a YPAR project informed by PYD strategies. By acknowledging and responding to these shortcomings in a number of ways, my study attempted to increase the authenticity of and amplify youth perspectives and encourage sustained involvement through YPAR. 


\section{Chapter 3: Methodology}

\subsection{Introduction}

In this chapter I describe the methodology that I utilised to investigate processes within my YPAR project with urban teenagers to investigate how these processes might enable youth engagement and potentially amplify youth perspectives. This led me to employing a qualitative instrumental case study to gather data that provided a thorough and nuanced description of the project. In this chapter I begin by describing critical theory and how it has informed thinking around youth engagement and participation. I then describe how YPAR stems from this theoretical paradigm and the implications and appropriateness of its use for this this study. I also briefly describe positive youth development theory because of its influence on processes within the case study. Next, I outline my methods of data collection and justify my approach for each method before introducing my participants and approach to recruitment. The chapter then goes on to describe my analysis process again detailing and justifying each analytical decision. Finally, I raise any issues that threaten the validity of the project and delineate my approach to mitigating any ethical dilemmas before addressing the limitations of my findings.

\subsection{Research Paradigm}

As discussed in Chapter 2, this study is predominantly interested in YPAR, a methodology underpinned by a critical theory approach to youth research (Fielding, 2004). In this section I will explain how critical theory encourages researchers to think about youth participation and how this impacted the approach to my own study when applied to youth.

Critical theory is an emancipatory paradigm that views reality as constructed within a system of power. It accepts a multiplicity of truths and works to amplify truths of those who have been oppressed (Lather, 2006). Within the context of my own study, researching with a critical lens calls for a consideration of the processes and systems that prevent young people from having their say as well as the need to critique my own project's ability to reduce these systems and power structures. A critical approach also illuminates an understanding of how knowledge held about youth engagement is constructed within power structures that exclude young people's voices (Cahill, 2007a; Cerecer, Cahill, \& Bradley, 2013). It encourages researchers to challenge the legitimacy of existing power structures by illuminating exclusionary practices put in place and upheld by those who maintain and benefit from these 
structures (Apple, Au, \& Gandin, 2009). Furthermore, critical theory seeks to be emancipatory by nature and even to liberate those who are oppressed by these structures (Freire, 1970). Therefore, as a researcher influenced by critical theory, I must consider how my project might assist in amplifying knowledge held by young people whose voices have not been heard well by decision makers as well as how it might work to reduce the various structures that marginalise them in society.

As referenced in Chapter 2, there are some who believe young people are apathetic, disinterested and unable to provide valuable perspectives (Ball, 2019; Lock, 2019). If these perceptions are widespread, then those in power can justify the various practices that exclude young people's voices from decision-making processes. Young people's experiences, understandings and perspectives are lacking in the creation of this knowledge and thus youth participatory researchers argue that including young people would make for a more rounded understanding of young people's lives. This paves the way for youth participatory research methodologies to check the validity of widespread perceptions and include young people's perspectives in order to develop evidence of young people's capabilities, willingness and interest as well as the value and perspectives that young people can generate about other issues that affect them.

YPAR is one such methodology acknowledges these issues illuminated by critical theorists and offers a process that allows young people to be part of the design of a research project. Ozer and Douglas (2015) draw upon Baum, MacDougall and Smith's (2006) definition of participatory action research to define Youth led PAR as:

a form of community-based participatory research (CBPR) that guides young people through an iterative process of collective research and reflection to understand the situations in which they find themselves, and use that knowledge to take action to improve those settings. (Ozer \& Douglas, 2015, p. 30)

As I articulated in Section 2.4, YPAR acknowledges that young people hold a "deep knowledge" of their own lives experiences and understanding (Torre \& Fine, 2006, p. 458). Adult researchers who seek to understand young people, lack this "deep knowledge" and therefore may struggle to replicate the subtlety and depth of young people's perspectives in their research findings. By including young people in the research process, participatory researchers aim to ensure young people's authentic understanding, perspectives and experiences inform knowledge creation and advocate for it to be included in decision making. 
However, as I outlined in my literature review, various power dynamics are at play between young people and adults, as well as barriers that work to prevent young people from having their say. Therefore, participatory researchers are also tasked with removing barriers and interrupting systems of power to allow young people's knowledge about their own lives to guide and frame the research process in order to illuminate youth perspectives about issues that affect them(Freire, 1970; Rodríguez \& Brown, 2009). This informed my study by encouraging me to constantly reflect on the power that I held as an adult youth worker and researcher within this space, rework adult centric systems and language that young people might not engage with so easily (Freeman et al., 2003) (see also Section 5.31).

While Positive youth development [PYD] draws predominantly on psychological frameworks and not necessarily critical theory, it helps shape many practices I used that relate to strong approaches when working with young people. I include it here because of its influence on the strategies and approaches used throughout this project. PYD is a theory of practice for youth work which encourages youth workers to base their practice around five key constructs: competence, confidence, character, connection and caring (Eccles \& Gootman, 2002). While YPAR sits within the broad critical theoretical landscape, considering the 5 C's of PYD when developing the YPAR project helped me centre young people's needs and rights as well as explore the developmental and relational factors that can benefit or limit the effectiveness of YPAR. By centring the young people within this project, PYD provides a mandate to ensure that the research participants are not merely considered as objects of investigation but rather that the project is based on a "reciprocity of action" (Freire, 1970, p. 107). That is, the young people benefit from their involvement within the project personally and their contribution to the research is reciprocated. These factors help to position PYD as an appropriate and interesting theory of practice through which to explore youth participation. However, there are few studies that explore the use of this PYD approach within a sustained YPAR project.

In sum, this qualitative enquiry uses a critical theory approach to explore factors such as process, product and relationship within an extended 18-month long YPAR project that applied many practices associated with PYD. In doing so it hopes to ascertain the effect of these factors on sustained youth participation. Informed by both the emancipatory, critical theory and the strengths-based positive youth development, this study also aims to add to the wealth of evidence that positions young people as competent, interested and valuable contributors to society. It is a commitment to the idea that ethical participatory researchers should be responsible for illuminating these issues of exclusion as well as being committed to 
actioning change (Cahill, 2007c). Figure 3.1 provides a visual representation of how this study was influenced by an intersection of the various theoretical approaches described above.

\section{Figure 3.1: Theoretical Approach Model}

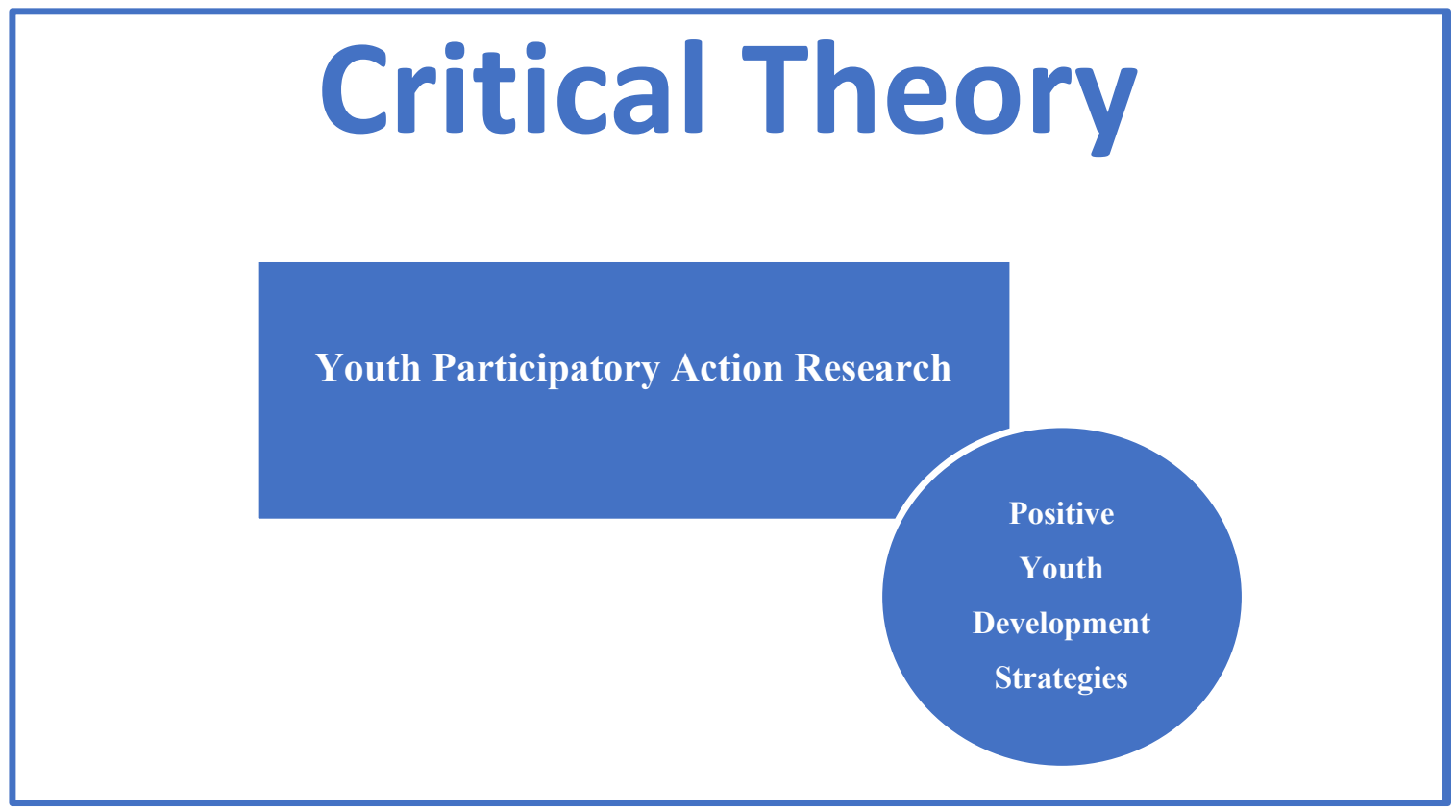

\subsection{Qualitative Approach}

The aims of the project and various paradigms that influence this study all point it towards a qualitative approach to the research. Qualitative researchers seek to explore and understand the experiences of research participants beyond that which is quantifiable (Johnson \& Christensen, 2012). They consider social interactions, roles and symbols within certain spaces and situations (Berg, 2009) and seek to explore how these factors contribute to create meaning for the various actors within these same spaces and situations (Davidson \& Tolich, 2003). This makes it an appropriate approach within the context of critical theory which works to understand more deeply, the perspectives of those who are marginalised by systems of power which, in this case, are young people.

The specific methodology I utilised within the qualitative approach is an instrumental case study. A case study uses multiple data collections to build an in depth understanding of a particular case, while an instrumental case study seeks to consider the case as a way of understanding something more general than the case itself (Johnson \& Christensen, 2012). In this instance, the case in question is an extended YPAR project with Wellington teenagers. I 
hoped to recruit an ethnically diverse group of ordinary young people in order to include differing perspectives within the project that Nairn et al. (2006) suggest are often excluded.. This study sought to explore processes within an extended YPAR project and therefore also required participants to commit to at least one year. While the case is interesting in and of itself, this study will provide insight for participatory research beyond the specific case in question. For example, the importance of processes such as relationship building, facilitation techniques and nature of end product as catalysts for participation within the YPAR project that will be of most interest to myself as researcher and the youth participation literature.

\subsection{Data Collection}

Using multiple processes to collect data acknowledges that one mode of data collection will not be able to tell the whole story (Patton, 2015). Different forms of data collection will inevitably uncover different types of data that will enrich and strengthen the researchers understanding of the topic (Berg, 2009). The use of multiple data collection is particularly common place within a case study methodology because it allows for a more in depth understanding of the case in question than if only one data source was analysed. I used several methods of data collection including autoethnography, youth reflections, interviews, and artefact collection. I used triangulation to ascertain the reliability of my data and add validity to my findings by comparing the various themes that emerged from each data set to determine their accuracy and significance (Scott \& Morrison, 2005). I discuss each of these data collection methods in turn in the following section.

\subsubsection{Autoethnography}

I gathered qualitative data through autoethnography; a process where the researcher explores the case by creating field notes from within the project as well as recording and collating personal reflections (Adams, Ellis, \& Jones, 2014). I documented the processes within the project by observing and collecting personal field notes and reflections during the weekly youth sessions. This form of data collection was particularly useful in ascertaining how engaged young people were within the sessions and how successful my attempts to facilitate their participation were. Throughout the YPAR project I had to find a balance between my role as a youth worker and as a researcher and to document the process (refer to Section 3.9 for more on this balance). During data collection this meant that I recorded my observations and reflections after each session so that during the session I remained present and able to 
facilitate, listen and be part of the meeting. In order to ensure my observations were consistent week to week, I followed Creswell's (2019) recommendation and developed an observation protocol and recording template which gave structure and parameters to my observations and recordings (see Appendix 1). My observations and reflections were focussed on the YPAR process and how it enabled or inhibited young people within the group to share their perspectives. It also allowed me to gauge how the young people engaged with the different tasks within the overall YPAR project. For example, while some participants were enthusiastic about data analysis, others found this phase of the project to be slightly repetitive (see Section 4.5 and Houghton (2015)). This insight enabled me to manage the pace of this phase to ensure that the group did not lose interest and remained involved.

\subsubsection{Youth Reflections}

I also collected weekly reflections from the young people themselves using a variety of youth appropriate debrief activities used in PYD. For example, after one session young people were asked to use an object in the room as a reflection tool while at another session, they were asked to use three words that summarised their feelings about that week's meeting. These reflections took place in a group setting after each session and often involved young people going around the circle and sharing one after another. I recorded these reflections with the young people's permission next to a description of that session which gave me another tool to gauge how the young people were feeling at different stages of the project. This also served as a reflexive tool that allowed me to make changes to the process or pace based on the group's regular feedback and energy for different parts of the project.

\subsubsection{Artefact Analysis}

I also collected secondary data by analysing project artefacts including photos, videos, resources and brainstorms produced during the YPAR process. While this data did not directly answer the research questions, it helps to build up a more complete picture and understanding of the case which informed my analysis. Specifically, the artefacts helped me gain a stronger understanding of the young people's experience within the project and ascertain to what extent they engaged with various activities within the project. For example, some brainstorm posters were laden with writing and information while others were relatively bare. By utilising a process of triangulation, these artefacts help to shed light on an idea when considered alongside other data sources and thus strengthened and adds validity to 
a particular piece of evidence. For example, both my observations and the young peoples' interviews identified a benefit to the young people's developing relationships and their ability to contribute and share within the context of the group (see Section 5.2). The two data sources here work together to strengthen the evidence for this idea.

\subsubsection{Semi Structured Interviews}

Eight months into the YPAR project, I conducted semi-structured individual interviews with 14 members of the group who opted in to this opportunity. A semi-structured interview utilises a set of prewritten yet open ended questions (see Appendix 2). This semi-structured and open-ended interview style enables the participants to share perspectives that were not directly linked to the question. This helps to reduce the chances of an interviewer steering the interviewees towards a particular perspective and allows the participants the space to share information that the researcher may not have considered pertinent or relevant to the project (Berg, 2009). This is useful within a case study where a researcher seeks to build a comprehensive picture of the case in question. The interviews were recorded and young people were told that the recording device could be switched off at any time. This data collection technique allowed me to hear directly from the participants about their experience and feelings about the project (Johnson \& Christensen, 2012). The nature of interviewing young people meant that I needed to ensure the questions were appropriately worded and able to be understood by all of the participants. I wrote various prompts which enabled me to guide the discussion where necessary and clarify my question if the young person had not understood.

\subsubsection{Final Reflection}

In October 2020, after the research project was finished, the young people ran an event at New Zealand Parliament to share their findings (see Section 4.3). This was not part of the original project plan but, as described in Chapter 5, it became a possibility as the project developed and worked to contribute to the more transformative hopes of the project. Because this event was a culmination of the YPAR project and led by the youth participants, I added this additional form of data collection in order to document this and explore how such an event effected the participants' feelings towards the project as a whole. I asked the participants to fill out a brief questionnaire (see Appendix 3) that asked them to consider how they felt having reached that stage of the project and what it meant for young people's voices. 
A questionnaire, like an interview, helped to gain a deeper understanding of the young people's feelings about the project (Johnson \& Christensen, 2012). The two-week proximity of this questionnaire to the event was purposeful in order for the young people to consider how the event had impacted them and what they felt it meant to them and others.

\subsection{Intended Participants}

Young people between the age of 14 and 20 were recruited to be part of a Wellington Boys' and Girls' Institute ${ }^{4}$ [BGI] YPAR project and could then opt in to my own research study which explored their experience with these processes. The long-term commitment requirement necessitated a strong relational approach from the start in order to attract committed participants and ensure the group were able to work together for an extended period. The nature of working with young people with busy schedules and a variety of commitments meant that I expected some participants to opt out during the project and so I hoped to recruit enough young people to ensure that the project could continue if and when some chose to opt out. 10 participants who attended at least one session chose not to continue their involvement with the project. While a year-long commitment was required by some young people to ensure that the project could progress, I also stressed that individuals could leave at any time (see Section 3.10).

\subsection{Recruitment}

The project involved recruiting a group of young Wellingtonians (ages 14-20) utilising BGI's existing relationships with young people, community organisations schools and the local Youth Council. I started by describing the project to youth workers at BGI and other organisations so they could suggest the opportunity to young people they were connected to. I also described the project to young people I was personally connected to, to give them the opportunity to be involved. This initial contact came from myself or someone the young person had an existing relationship with rather than random recruitment and allowed them to indicate whether they were interested or not. If they were interested, I asked their youth worker to pass on their contact details before inviting them to meet with me to ask any questions. I also gave each young person the opportunity to bring along a friend or two who might be interested in being part of the project. I asked them not to decide straight away but

\footnotetext{
${ }^{4}$ A youth development organisation in Wellington through which the YPAR project was run
} 
let them know the details of the first information meeting which they were welcome to attend. At this meeting I spoke more about the project before handing out the information sheet (see Appendix 4) and consent form (see Appendix 5). I advised young people to discuss the opportunity with their parents and youth workers before deciding whether to commit to the project. To reduce the effect of coercion I requested that all participants indicate their decision to be involved or not through a person of trust such as a youth worker, mentor or another BGI staff member. I intentionally left the room if they were considering this invitation while I was present (see Section 3.10). I was aware that some young people may find it difficult to tell me directly if they were not interested and was pleased that some utilised a relationship with another youth worker to pass on their decision not to be involved.

As described in Chapter 2, participatory processes have often been criticised for their tendency to involve only high achieving young people (Nairn et al., 2006). This project sought to recruit diverse participants in order to uphold everyday young people's right to have their say. BGI works with and has existing relationships with young people across a 'continuum of need,' 5 an approach to youth development that aims to provide programmes and support for young people regardless of their capability or needs. By utilising these relationships in the recruitment phase I was able to offer the opportunity to a range of young people including the often excluded 'ordinary' young people that I referenced in the literature review (Nairn et al., 2006).

Twenty four young people came along to at least one session with an average of 8-12 each time. 14 chose to take part in the interview at the end of the project. Table 3.1 describes the ethnicity, age, gender and occupation of the participants as well as how they came to be involved with the project.

${ }^{5}$ The continuum of need is based on pre-colonial Māori principles of pukengatanga, loosely translated to mentoring, whare wānanga, skill development and urungatanga, or education through exposure (Baxter et al., 2015) 
Table 3.1: Participant's Biographical Details

\begin{tabular}{|l|l|l|l|l|l|}
\hline Pseudonym & Age & $\begin{array}{l}\text { Education or } \\
\text { Occupation* }\end{array}$ & Gender & Ethnicity & Recruitment \\
\hline Ben & 17 & Red College & M & Pākeha & $\begin{array}{l}\text { Came with } \\
\text { friend }\end{array}$ \\
\hline Charlotte & 19 & University & F & Pākeha & Youth Council \\
\hline Em & 17 & Blue College & F & Pākeha & $\begin{array}{l}\text { Different Youth } \\
\text { Organisation }\end{array}$ \\
\hline Clive & 16 & Red College & F & Pākeha & BGI connection \\
\hline YP8 & 17 & Pink College & M & Pākeha & BGI connection \\
\hline Bubbles & 18 & Work & F & Māori Indian/Fijian & BGI connection \\
\hline Stamaloa & 16 & Yellow College & F & Samoan & $\begin{array}{l}\text { BGI connection } \\
\text { /Youth Council }\end{array}$ \\
\hline Raihaan & 16 & Green College & M & South African & Youth Council \\
\hline Sarah & 16 & Green College & M & Indonesian Arabic & $\begin{array}{l}\text { Came with } \\
\text { friend }\end{array}$ \\
\hline Chantelle & 16 & Maroon College & F & Sri Lankan & BGI connection \\
\hline Shelly & 16 & Green College & F & Chinese & $\begin{array}{l}\text { Came with } \\
\text { friend }\end{array}$ \\
\hline Lil Wayne & 18 & $\begin{array}{l}\text { Unemployed-- } \\
\text { PWork }\end{array}$ & F & Māori & $\begin{array}{l}\text { Came with } \\
\text { friend }\end{array}$ \\
\hline YP16 & 17 & Pink College & F & Māori & BGI connection \\
\hline Felix & 16 & Red College & M & Pākeha & BGI connection \\
\hline
\end{tabular}

* Schools were given a pseudonym to protect the identity of the participants who wished to remain confidential.

\subsection{Project Process}

Within case study research it is important for a researcher to give an in-depth description of the case so the reader knows the parameters of what is being researched in (Merriam, 1988). In this study it was particularly important because my research questions directly consider the processes within YPAR that might work to amplify youth perspectives. Furthermore, the findings may have implications for practitioners wishing to develop such processes for use within their own organisations and therefore needed to be outlined in detail. Because the case I was studying was also a research project, there is the potential for the case and my own research for the purpose of this study to become confused. The project process is described in 
detail in Chapter 4 but here I will briefly outline the project in this section to clarify how the case differs from my own research and vice versa.

The young people were recruited through existing relationships as discussed above and were tasked with developing a research project that explored an issue facing young people in Wellington City. Phase 1 (see Figure 3.2) involved forming the group building expectations around the project and establishing relationships with one another. Phase 2 involved identifying prominent issues for young people before selecting one that they wished to research in depth. The young people chose mental wellbeing as their key issue and after considering the issue within the confines of the group decided to develop a survey to test some of their assumptions across youth in the wider Wellington City. Phase 3 involved collecting and analysing the data through this survey before writing up the findings and Phase 4 involved sharing their findings through various channels including a report launch event held at Parliament (which happened at the end of the project).

This YPAR project described above developed its own findings, implications and action plan around mental wellbeing. However, my thesis is concerned with exploring the various processes activities and decisions around the YPAR case and how these processes enabled and constrained the amplification of youth perspectives. I describe this in more detail in Chapter 4.

\section{Figure 3.2: Phases of YPAR Project}

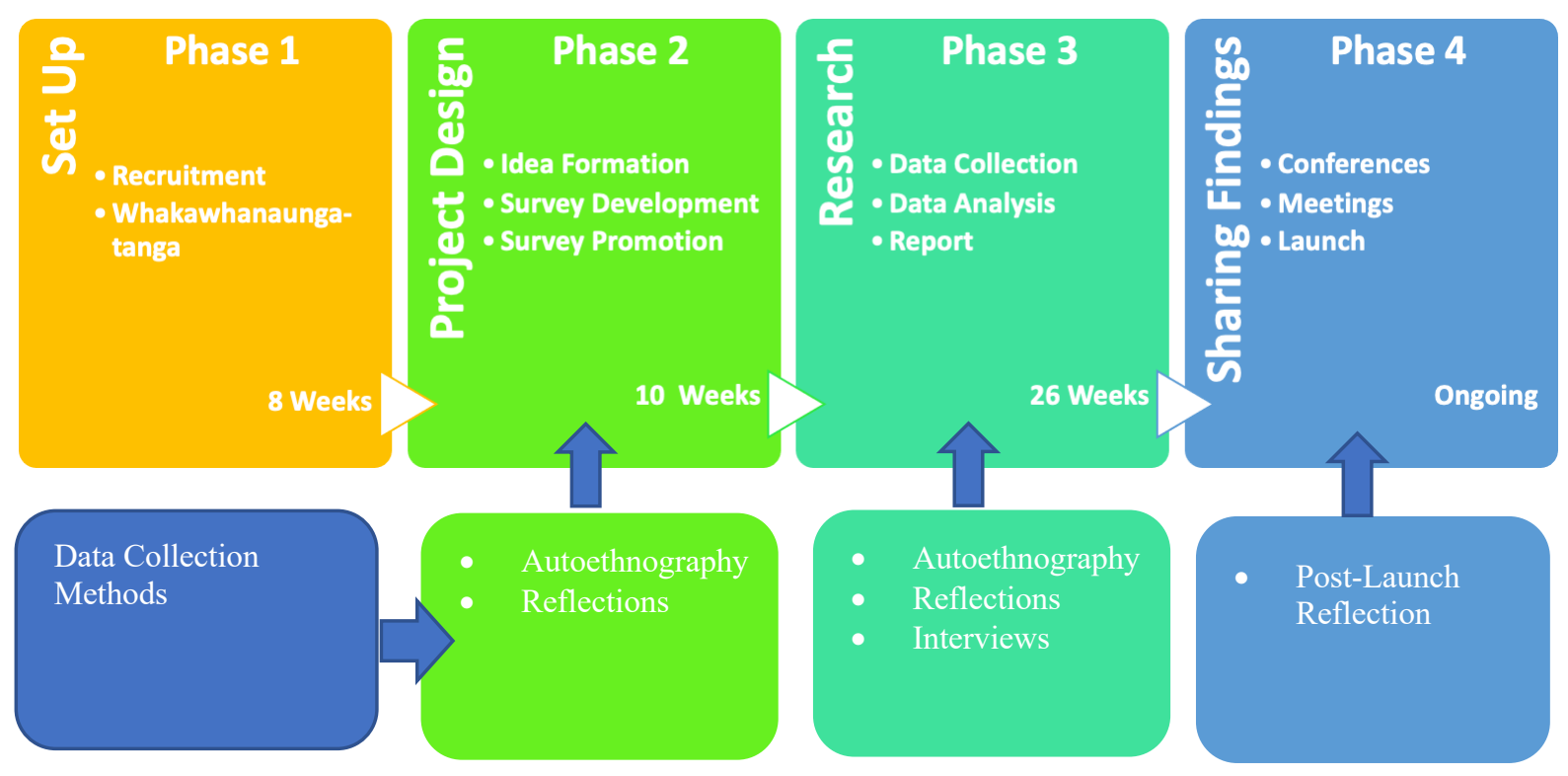




\subsection{Data Analysis}

For this study I employed thematic analysis as my method for analysing the data sets. Braun and Clark (2006) outline a six-part process for thematic analysis and stress the importance of acknowledging the decisions that a researcher makes when identifying themes. Outlining my process for drawing themes from the data as well as naming the various limitations will ensure a reader can consider the validity of my inquiry and identify biases that may have led me to certain conclusions.

The first part of the analysis was to organise the various data sets in sequential time order. I put the observation notes from each session alongside the young people's reflections as well as my own post session reflections and a run sheet from that session in order to understand how different focusses, activities and facilitation techniques were received by the young people in the group. I organised the recorded interview data by creating word-for-word transcripts. I then read over the transcripts in order to familiarise myself with the data and make notes that outlined my initial interpretation.

Once I had read over each data set I began my coding process (Corbin \& Strauss, 2008). The coding process was slightly different for each data set. For the interview data, I began by highlighting parts of the texts that I deemed were significant or that summed up a young person's answer to the specific question within the interview. I then began a second phase of coding in which I generated codes that were related to my broader research questions. This second phase of coding was applied to my observation notes, personal reflections and the young people's reflections. The initial interpretation notes that I took after reading through the data sets in part one of my analysis, informed the codes and were extended upon in order to draw out as much detail from each data set as possible. For example, the pride the young people had in their work came through as a code when considering the young people's sustained involvement. This second phase of coding was repeated for each of my research questions.

Next, I began to identify sub-themes within the codes. This process involved grouping the codes into broader subthemes before extracting raw data from each data set, such as quotes from the young people or my own observations related to the research question, and organising them under the heading of each subtheme. For example, the code associated with 'pride the young people had in their work' was combined with other codes such as the idea of 'working towards something' to create a subtheme around "the value of product." 
I then began to generate major themes by creating a thematic map which allowed me to visually consider how the various subthemes were connected to each other and physically place subthemes under the major themes they most closely related to. These major themes are discussed further in the subsequent chapters and include ideas such as relationships, progress and momentum and the project ethos. I used my research questions to ensure the themes collected focus on processes and also analysed the proposed community action project and evaluated it against youth participation models, such as Hart's Ladder (1992). The key themes generated from this analysis informed the findings of my study.

\subsection{Research Validity}

A number of issues threaten the validity of qualitative research (Johnson \& Christensen, 2012). Although I have attempted to reduce the effect of these issues, it is difficult to remove them entirely and therefore it is worth naming them so the reader can judge the validity of the findings.

Researcher bias is threat to many research projects and manifests itself through a researcher's inadvertent or purposeful selective observation and recording (Johnson \& Christensen, 2012). Because I was researching a project that I was running myself, the threat of researcher bias is particularly prominent. As a youth worker at BGI my observations might be selective in order to paint BGI or myself as a youth worker in a better light. In attempt to reduce this I had to navigate between my role as a youth worker and my role as a researcher by employing a strategy called reflexivity. Johnson and Christensen (2012) indicate that reflexivity is a process of critical reflection that encourages the researcher to consider how their perspectives and preconceived ideas may influence the research. As described in Section 3.8, I utilised Braun and Clark's (2006) six part guide to thematic analysis. This process helped to develop reflexive thinking about my identification and reporting of key themes by highlighting the need to regularly check that the themes I identified were not merely reflections of my own bias and perspectives. In addition, I discussed the process at length with my supervisor in order to remain critical rather than rosy in my analysis.

The power dynamic that exists between youth worker and young people is another issue that may have affected the validity of this research. Youth work that adheres to the CEYWA (Ara Taiohi, 2020) and Mana Taiohi (Tuhaka \& Zintl, 2019) helps to reduce the power imbalance that exists between an adult and a young person somewhat but it is difficult to remove this completely. Youth workers often become role models for young people and this 
can cause them to feel hesitant about disclosing ideas, perspectives or actions that they believe the youth worker may disagree with. Encouraging honesty and openness is a large part of a youth worker's relationship with young people, there are a number of reasons why they might not feel comfortable sharing their perspectives including; previous experience in disclosing information to adults, a lack of trust in a particular youth worker and differing ideas of what should and should not be shared within the context of a youth work relationship. One way I tried to combat this issue was by stressing that anything they said would remain confidential and developing a group agreement that ensure that other members of the group understood that conversations had within the context of the group sessions would not leave the room. That being said, some things still may not have been raised by youth participants which is a limitation to the data.

\subsection{Ethical Considerations}

I was granted ethical approval from the Human Ethics Committee at Victoria University of Wellington (Reference no. \#27762 see Appendix 6). There are particular ethical considerations that need to be taken into consideration when working with young people, such as the Code of Ethics for Youth Work in Aotearoa New Zealand. This includes knowledge of boundaries, informed consent, transparency, confidentiality and cultural safety (Ara Taiohi, 2020). These were acknowledged as additional frameworks in my ethics application.

The nature of a sustained YPAR project meant there are some specific ethical considerations. Traditionally consent is negotiated for what is often a short term research encounter. In my study, consent was a particularly important consideration for this project because of the length of time that participants were poetntially engaged for. I collected signed consent forms (see Appendix 5) from all young people and parents of those who were under 16. However, young people's consent had to be regularly renegotiated throughout the project (Cullen \& Walsh, 2019). While young people were messaged to remind them about the session and check if they were attending, there were no consequences for not turning up. And therefore, each meeting served as additional opt in points and some participants who had originally opted in, chose to opt out by not showing up to meetings for a number of different reasons. Others declined the interview towards the end of the project but were still able to attend the majority of the meetings. These decisions were all respected and go some way to 
providing evidence for a space that allowed young people the freedom and agency to decide whether they provided consent at multiple points throughout this extended project.

One other issue was confidentiality. I ensured artefacts used in the analysis did not identify the young people involved and allowed each young person to choose a pseudonym for themselves so they remain confidential in the write up of the findings. Some young people decided against choosing a pseudonym, preferring to be referred to by their own name within the thesis (see Table 3.1.). While confidentiality of participants has long been a nonnegotiable for human ethics research, some participatory researchers make the claim that participants who chose to be named deserve to be given credit for their contribution to the research (Yanar, Fazli, Rahman, \& Farthing, 2016). In my study three participants wished to be named in recognition of their sustained involvement.

A further ethical consideration was the fact that I was researching alongside young people that I had an existing relationship with. While the case for doing this has been consistently made throughout the thesis already, it does still pose some limitations that may affect the findings. Similar to the issues that arise with regards to power, there may certain things that the young people may not wish to say to someone that they have a positive or prior relationship with. They may be more inclined or feel obligated to say positive things about the project, perform to certain perceived expectations or be less inclined to critique various aspects because they know me as a youth worker as well as the researcher. I also had to consciously adopt a more critical perspective as a researcher. I attempted to reduce the impact of this limitation by telling young people that they were free to say whatever they liked about the project and in the interviews, I included questions that allowed them to talk about the challenges associated with the project. However, I am aware these are issues that may prevent the findings from being totally reliable.

\subsection{Limitations and Generalisability}

This project was a small-scale case study that explored the specific experiences of a particular group of Wellington teenagers involved in a YPAR project. There are a couple of features of this project that mean that it cannot be so easily replicated just anywhere.

First this project was housed within an established youth development organisation with existing relationships with young people and the funding necessary to provide the group with additional resources, time and energy. This is not the case for all YPAR researchers nor 
is it realistic for all youth organisations to have access to the resources needed to sustain such a project.

Second was the type of young people that opted into the study. Many of the young people involved were from high decile schools and thus there may be different findings for projects where the group was made up of young people from different backgrounds.

Furthermore, the nature of Wellington as a capital city meant that the young people involved had proximity and access to Parliament. The significant drain on resources needed to fly or drive a group to Wellington for a launch event hosted by a non-Wellington based project may have ruled this out as a possibility. While launching the product of their research is not dependent on Parliament as a venue, in this instance it provided a certain legitimacy that may have attracted other young people, MPs and decision makers to the event. As discussed in Chapter 5, young people in the group credited the event with a number of positive benefits including increased self-efficacy and a perception that their event was an example for others of young people's voices being heard.

These factors mean that the project is not easily replicated and findings drawn from this study are not able to be generalised across all young people. However, the findings are useful in that they can provide evidence to help develop theory or frameworks around youth participation practice and illuminate opportunities for future research. I also hope that they might incentivise funders to resources extended participation processes based on a relational approach.

In the next chapter I describe the different phases of the project and explore the extent to which young people's involvement was sustained across the 18 months of this project. 


\section{Chapter 4: Factors Influencing Participant's Involvement in the YPAR Project}

\subsection{Introduction}

In this chapter I explore processes that might work to sustain youth involvement in order to investigate an answer my first research question: What factors might sustain youth involvement in an extended YPAR project? In Chapter 2 I established the tendency for shortterm youth participatory projects. As Matthews (2001) argues, young people who are involved in these processes will often have a number of other commitments and their expectations around time frames for change can differ from adults. Short term projects can limit the ability for young people to effect sustained change and can also reduce the authenticity of their participation. The extended nature of this project allowed for an exploration of various factors that may have sustained the involvement of young people.

The data from this chapter are drawn from four sources: (i): artefacts that outlined the participants' initial expectations at the start of the project; (ii): my observation notes that were written after each weekly session; (iii): records of the participant's weekly reflections after sessions; and (iv): the one on-one-interviews with participants that took place at the end of the project. One particular interview question asked the participants about their motivation for regular attendance. This, and participants' answers to the other questions in the interview as well as my observation notes, young people's reflections and artefacts allow me to consider how sustained involvement was encouraged across the different stages of the project and how this was reinforced over a period of 18 months. What follows is a cross triangulation of evidence from across these various data sets.

Because this study is interested in this process, this chapter will begin with a description of the project phases that were outlined in Section 3.7 (see Figure 3.2).

\subsection{Project Process}

This section begins by describing the various processes within a typical session before describing how these sessions sat within the wider project phases. The various processes described below are referred to within my findings and discussion chapters and so this section works to provide the reader with an understanding of the case and the processes that this study explored and analysed. 


\subsubsection{Session:}

Arrival: Every Wednesday after school the group of young people came to the BGI youth centre along with myself, my colleague, and two volunteers who made up the leadership team. The day was decided upon using a Facebook poll to ensure that everyone who had indicated their interest could attend. The official start time was $4: 15 \mathrm{pm}$ for afternoon tea but young people started turning up from about 3:30pm. Before they arrived, I set up food and games such as table tennis, giant Jenga and fußball I also put on some music and, once they arrived, I encouraged them to choose the songs they want to listen to.

'What's on top?': At 4:30pm I encouraged the group to take the food from the kitchen into our meeting room so we can begin our session. Each session started with a check in called 'What's on top'? This is facilitated slightly differently every time but allows the group to share how they are feeling in that moment. Usually, the group are asked to pick a prop or picture card from a pile in the middle of the room that they can use to help them firstly check on their own feelings at the time and secondly communicate those to the group. BGI regularly uses 'what's on top' in its youth development programmes to encourage young people to communicate their emotions and practice self-awareness. We ran the 'what's on top' activity at every meeting to create a tradition.

Introduction and Energizer: Following 'what's on top', one of the leaders would start the meeting by running through the agenda written up on the board. This would outline what phase of our project we were currently in and what the purpose of the session would be. The leader would then facilitate an energizer game if they thought the group needed a change of pace or an energy boost before starting the bulk of the work for that session. During the later stages, energizers were not as commonly used because the leaders responded to a sense among the young people of wanting to get straight into the work that was needed to keep up the momentum of the project (Observation Notes).

Content: After the introduction and energizer, the group worked towards the work needed to develop and progress the project. The content of the sessions varied depending on what stage of the project the group were up to. The different stages are listed below and outlined in figure 3.2 . 
- Whakawhanaungatanga (relationship building),

- Idea Formation

- Question Development

- Survey Promotion

- Data Collection

- Data Analysis

- Report Writing

- Sharing Findings

The activities, structure and content of each stage are explained in more detail below.

\subsubsection{Whakawhanaungatanga (relationship building)}

Although some of the young people knew each other already, we wanted to ensure that the young people in the group felt comfortable with BGI, the leaders and each other. This whakawhanaungatanga focus was continued throughout the project but especially prominent in the first three sessions. Session one started with a mihi whakatau to welcome the group to the BGI space, provide some background information on what BGI as an organisation does and to convey the value the organisation and the project placed on their voices.

Each of these earlier sessions incorporated a number of name games and ice breaker activities to help develop the relationships and trust between group members. We also used the earlier sessions to agree on the expectations for the project, of each other and of the leaders. These expectations were identified by allowing each young person to reflect on what their expectations were, and writing them down on a post-it-note and sticking them up alongside everyone else's. The leaders then grouped these expectations into themes and these were recorded and outlined so all of the group were on the same page. During these first sessions, the group also came up with a name that represented these expectations and who we were as a group. The name chosen was Te Ahi o Ngā Rangatahi (The Fire of Youth) [hereafter Te Ahi]. The use of a Te Reo name was initially suggested by some of the young Māori in the group and was unanimously voted on by the rest of the participants through a Facebook poll.

\subsubsection{Idea Formation}

After the initial relationship building stage, the group moved into an idea formation phase of the project. During this phase Te Ahi created mind maps to identify some of the important 
issues facing young people in Wellington city. We started off by doing a post-it brainstorm activity and asking the group to identify things that are important in a young person's world. These were grouped into themes before the young people split into smaller groups to identify positives and issues related to each theme.

Once each of the small groups presented back (over the course of three sessions), each young person was asked to sum up the conversations using three words. These words were then used to develop our four overarching themes that encompassed the feeling of the group's discussion. These themes were hobbies, mental health, school and relationships. The young people again split up into small groups to rate each of these topics on importance and impact out of 10. The impact rating was based on how much the group thought they could affect change on this issue for young people. After rating the themes, the group settled on mental health as the focus of their action research project.

\subsubsection{Question Development}

By reviewing the minutes of the conversations during the idea formation stage, the leaders were able to draft an overall research question that encapsulated the particular research interests of the group which was then discussed and agreed upon. The research question that was decided on was:

What does mental wellbeing mean for young people in Wellington and are there barriers that prevent young people in Wellington from managing their mental wellbeing? (Artefact Data $11^{\text {th }}$ May 2019)

One young person's thoughts within the group in particular heavily influenced Te Ahi's research focus towards positive mental wellbeing and the ways that young people can feel well mentally in their day to day lives: "We want to be asking about good mental health we know what makes bad mental health" (Meeting Minutes 22 ${ }^{\text {nd }}$ May 2019). This idea which was raised in one of the meetings generated a lot of conversation that allowed the young people to build the case for focussing on positive mental wellbeing.

After hearing about various research methodologies from a guest adult researcher, the group decided to explore young people's perspectives on mental wellbeing using a survey. They then split into small groups to develop specific questions that would allow them to answer the research questions. The leaders then collated these questions and put together a 
survey which the young people critiqued, reviewed and refined extensively over two sessions, individually and in small groups before the survey was finalised.

\subsubsection{Survey Promotion}

During the survey promotion phase of the project, the group worked to identify the various spaces that young people operate in on a day-to-day basis. The young people then split up into small groups to discuss dissemination strategies online, at schools and on the streets. These strategies were devised in small groups before each group reported back to the full group to allow for feedback and further ideas. During this time the group produced, posters, videos, letters and asked local businesses for prizes that would incentivise other young people to take the survey. The leaders entered the survey into a survey development website called survey monkey which was a time-consuming part of the process and required a level of technical knowledge to ensure the survey was user friendly.

\subsubsection{Data Collection}

Young people themselves collected survey responses outside the physical meetings. As mentioned in the survey promotion phase, the group had data collection strategies for: online engagement, including sharing the survey and videos on social media channels such as Facebook and Instagram; at school, by speaking at assembly and disseminating the link to the survey through school emails and during form class time; and on the streets by setting up weekend stalls on Cuba street at a local sports arena and at a Victoria University sustainability fair. The survey was live for six weeks and had a total of 1223 responses.

\subsubsection{Data Analysis}

The group started analysing the data at our weekly sessions as it was still being collected. The leaders split the young people into smaller groups, handed them a data set and some highlighters and they grouped the answers together in themes. Each group came up with different but similar themes and the leaders collated and streamlined the ideas. Young people were encouraged to share the findings from the small group with the larger group at the end of the session and facilitate discussion between the smaller groups. An individual worksheet activity was used to help frame the young people's analysis. Leaders then presented them with the raw data and asked them to answer the following questions:

What does this tell us? Why might this be? What does this mean for our wellbeing projects? 


\subsubsection{Report Writing}

Once the group had done some collaborative analysis, certain members chose to take the lead on writing a section of the report such as methodology or demographic data. This involved a number of smaller sessions or writing workshops where we focussed on collating the analysis that had been done in the sessions and writing up our findings. Young people also worked on their section in their own time. This process was managed through google docs where leaders and other members of the group could make comments and provide feedback for the young person in charge of each section. The group was given the option of continuing this written work during the weekly sessions or concentrating on planning projects. The group decided to focus solely on finishing the report. A leader then contacted a group of student publishers who agreed to edit and design the final report. The editors provided comments and ideas which were passed on to the young people who then approved or challenged the editor's ideas. The final report was called: What's Next for Mental Wellbeing?: Outlining Opportunities for Youth Led Change (Te Ahi o Ngā Rangatahi, 2020) a name brainstormed and decided upon by the young people themselves.

\subsubsection{Sharing Findings}

The leaders then ran an activity that allowed young people to identify decision makers, teachers, youth workers and other young people among those who would benefit from hearing the results of their research project. The group shared their findings in a number of ways including at Involve Youth Development Conference on the $17^{\text {th }}$ of August 2020, through a launch event, and a series of workshops with Wellington City Council staff which I elaborate on below.

Involve Youth Conference: Knowing that the young people wanted youth workers to hear their findings, I applied on behalf of the group to present at the Involve youth development conference. Unfortunately, the conference was moved online due to Covid 19 and was during school hours. In order to ensure that the young people's voices were heard I asked those that wanted to, to prepare a presentation based on a section of the report. This was videoed and inserted into the slideshow which I presented. 
Report Launch (Te Ahi o Ngā Rangatahi, 2020) When asked how else they might share these findings one young person suggested a launch event. This was met with enthusiasm from the rest of the group. The launch was not originally part of the project plan but was made possible for a number of reasons outlined in Chapter 5. The group began by identifying the goal of their launch: "Get decision makers and people working with young people to hear the findings and recommendations" was suggested by a participant (Artefact Data 10/06/20) and then outlining the various steps needed to ensure this goal was met. These included, meeting with a local member of Parliament (Hon. Grant Robertson) to ask him to host the event which he agreed to enthusiastically. Te Ahi developed a run sheet, sent out invitations and most importantly developed the presentation. The event took place at Parliament on the $14^{\text {th }}$ of October 2020 and over 200 people attended.

Council Workshops: Because of the success of the launch and report, in 2020 Wellington City Council asked to work alongside them to help develop their child and youth strategy. Members of the group went along to Council offices to provide advice on various wellbeing outcomes for young people and what Council could do better based on their research findings. They attended four workshops on the $30^{\text {th }}$ of November, $4^{\text {th }}$ of December, $10^{\text {th }}$ of December 2020 and $20^{\text {th }}$ January 2021.

In sum this was an 18-month YPAR project that I both helped to lead and researched alongside. As discussed in Section 3.2 this project was based within a context of PYD which influenced the facilitation style and contributed to an emphasis on relational processes within the project. This separated it from projects situated within schools and council offices that may prioritise educational or civic development over these relationships. Furthermore, the project's length set it apart from other examples of YPAR within the literature that are often more short and intense engagements. In the next section I will describe how the relationships that the young people built over the course of this project help to sustain their involvement across the 18 months.

\subsection{The Contribution of Relationships}

As discussed in the previous section, the extended nature of this project set it apart from many other YPAR projects within the literature. Eighteen months represented a significant 
commitment from the young people and as such, it is important to analyse how the young people's involvement was sustained over the course of the 18 months.

The most significant factor that participants identified as influencing their sustained involvement in the project were the positive relationships that they had with the leaders, with BGI and with each other. When I traced the evidence for how these relationships were expected, established and enacted, I found they were established at multiple points in the project. For example, some indicated that their initial motivation for being part of the project were their existing friendships and connections while others credited the connections they made as the project progressed was part of the reason they kept attending sessions.

The importance of relationships and the nature of relationships that young people expected during the project were established during the first session. Through a post-it-note activity, the young people individually and anonymously outlined their expectations for a) the project, b) each other and c) the leaders. This exercise indicated that the participants expected all the relationships they had within the group to be "supportive" "respectful" and "fun" (Expectations Artefact 06/03/19). This was reinforced by multiple participants. As many as seven wrote the word 'respect' or 'respectful', seven also wrote words such as 'supportive' or 'inclusive' and there were five who wrote that they expected the process to be 'fun'.

These themes of support and respect were consistent in the young people's expectations of both their peers and of the leaders, which highlighted some common expectations that participants had of other members of the YPAR team regardless of their age. However, the young people also expressed a desire for the leaders to enable and empower the group within their role through comments such as, they "help us do stuff" and "mentor us and allow us to strive" (Expectations Artefact 06/03/19). By acknowledging their desire for the leaders' guidance and help, the participants highlighted the value of intergenerational relationships within YPAR projects and further legitimised the adult leaders' involvement in the development of the project (Cahill, 2007a; Camino, 2000; Richards-Schuster \& Timmermans, 2017). Similarly, the young people had expectations of their peers that were different from their expectations of the leaders. They expected each other to "share ideas" and contribute to the project which signalled their desire for collaborative relationships with each other as well as basic respect fun and friendship. Although these expectations do not directly indicate why participants chose to continue their involvement in the project, understanding these expectations and considering the extent to which the young people felt they were met may be an indicator for their sustained involvement. 
When asked to look back at the project in interview, some participants were initially motivated by the potential of making friends and meeting new people. Charlotte, for example, shared that she "thought it would be a like a good way to meet groups of people I might not usually interact with at university or at UN Youth or whatever."

However, others were motivated not by the opportunity of meeting new people, but rather the fact that existing friends were also taking part in the project. Clive was explicit about this when he identified that his motivation for getting involved was "probably just to hang out with Ben and Felix really."

The importance of the relationships and friendships within the group were also a significant theme of the young people's weekly reflections. This source of data was gathered in a number of different ways at the end of each session and gave me an understanding of how the young people were feeling at different stages of the project. The young people regularly spoke of their appreciation for the other members in the group. For example, as outlined in Section 3.4.2, after one session young people were asked to use an object in the room to help articulate their reflection and Chantelle (16) chose a lightbulb "because this group is a source of light in my life." Charlotte (18) revealed a similar point of view at a different session when she expressed that "it's awesome to come somewhere where you feel cared for." These reflections shed light on the young people's appreciation for the relationships with their peers and the leaders but also with BGI as an organisation. Artefact analysis points to a great deal of emphasis being placed on care within the leadership meetings. When analysing notes from leadership meetings, leaders discussed specific conversations that they had with young people which helped to identify their interests, and personalities (Meeting Notes Artefacts 01/05/19). Furthermore, after discussing with the other leaders at a leadership meeting, I assigned each of them the task of engaging with a specific smaller group of young people at each meeting to ensure that each of them had a point of contact with an adult who cared about them at every session. The specific group that a leader was responsible for was recorded on the attendance sheet (Attendance Sheet Artefact). This was particularly important at the beginning of the project but became less necessary as the project progressed and young people became comfortable with all of their peers and adults.

Towards the end of the year, the young people's reflections began to focus more on the growth of the relationships within the group. This perspective was evident in Felix's (16) reflection, "it's so cool to see how we've come from not knowing anyone and feeling 
awkward to where we are now". Other participants echoed this appreciation for the strong relationships they built over the course of the year:

Em (17): Weird to think it's been a year. At the start I was really nervous and forced my friend to come with me. At the first session I was shaky and terrified and dropped the ball literally in the name game but now it's the highlight of my week

Sarah (16): The evolution of this group is awesome.

Bubbles (18): I love the growth of this group.

Along with the artefact and youth reflection data, my own autoethnographic observation notes were another data source that allowed me to also gauge the depth and nature of the relationships that the young people shared and how it impacted their involvement at different stages of the project. During many sessions I noted the sense of comfort the young people had within the BGI space. Although this comfort grew over time, my observation on the $13^{\text {th }}$ of March (week two of the project) that "the first part of the meeting (arrival) seem(ed) to be comfortable and unintimidating" indicates that this comfort was established fairly early on in the project. On October the $16^{\text {th }}$ towards the middle of the project I wrote:

One young person lay relaxed with his feet up on the couch. One came late but was quickly caught up by a leader and able to contribute. Some young people moved freely between the meeting room and other parts of the building to go to the toilet or charge their phone. Some shared personal jokes and laughed freely. (Observation notes: 16/10/19)

Moreover, on October the $30^{\text {th }}$, "I noticed lots of joking and more light profanity than usual" (Observation notes 30/10/19). Behaviour such as swearing or joking around during group discussion, may be considered negative or impolite, but also suggests that the young people were acting with less restraint and thus felt free to be themselves. This freedom or comfort points to a more balanced power dynamic between young people and the project leaders than might be the case within a traditional adult and young person relationship such as the one that exists between teachers and students within mainstream education. 
My observations also provide evidence for the developing relationships between group members. There were many instances where the participants exhibited their desire to build strong connections with each other. This was evident in earlier phases of the project, when I observed the young people swapping contact numbers and adding each other on social media (Observation Notes 20/03/19) and later, on November the $11^{\text {th }}$, when I noted that "(Chantelle's) relationship with Lil Wayne is really strong and the two of them and Em went down to a local cafe after the meeting to talk more about creating a Te Ahi meme format". 6 In addition, there were many sessions where I noted young people laughing and joking with one another while at others I observed how they comforted or confided in each other. For example, "Em comforted Felix and helped defuse that situation" (Observation Notes 30/10/19). and Clive stayed behind to talk to Sarah about the mental health of one of his friends (19/06/19). The range of interactions - both serious and light hearted - as well as the young people's willingness to connect further outside of the weekly sessions show the depth of the relationships that the participants shared. This further illustrates and confirms the importance of a peer-to peer relational connection for young people's sustained involvement in the project which is consistent with literature around engagement in youth programmes (Guarino, Cicognani, \& Zani, 2020).

The participant interviews were a further key data source for providing evidence for the importance of relationships and connection to the young people involved. These took place at the end of the year (about eight months into the project) and allowed the young people to reflect on the project after being involved for some time. Relationships and connection were a significant talking point for many of the participants throughout the interview and were particularly prominent when they discussed what they appreciated about the project, what initially motivated them to come along and what motivated them to come regularly.

When asked what motivated them to regularly attend meetings, seven participants explicitly mentioned the group or the people as key contributing factors. Bubbles for example referenced the "welcoming and warming" nature of the group while Charlotte expressed that she "enjoyed meeting everyone and just like seeing everyone again". These particular quotes shed light on certain young people's desire for social connection and the importance of making space for this within the context of our weekly sessions. While strong connections and liking the people who are part of the project cannot be engineered, there is value in

\footnotetext{
${ }^{6}$ An internet-based form of observational humour that assigns (in this instance) group members various
} personality traits or moods. 
creating a space in which these strong relationships are encouraged (Serido et al., 2011). Raihaan expanded on the nature of relationships that young people appreciated when he credited the opportunity of working with "bright individuals" as a reason for his regular attendance. This particular perspective raised the idea of relationships that young people wanted away from something that was purely socially motivated, towards something that allowed them to grow and learn from one another. Ben seemed to represent these two perspectives around the value of relationships when he noted that he "just liked the people who were doing it ... it was always interesting just talking to other people in this and getting to know them was a good social experience." This signalled the importance of the momentum of the project (a factor I discuss later in the chapter in Section 4.5) as well as the relationships themselves, without which, the project may not have developed to such an extent.

Similar themes were present when the young people were asked what specifically they appreciated about the project. Clive's appreciation for "everyone (being) real [sic] nice and including" and Felix's assertion that the group "quickly turned into a small family" add weight to the idea that the close relationships within the group were factors for the young people's sustained involvement. Charlotte captured the sentiments of many of the participants when she said "meeting everyone was really cool I found the dynamic of the group to be wholesome."

In sum, the value of relationships and connections to the young people involved was a key theme that was woven through the various data sets. The different stages at which this data was collected enabled me to consider how these relationships developed as the project progressed as well as the nature of the relationships that the young people appreciated. Right from the start, young people indicated that they expected fun, friendly and supportive relationships with each other and with the leaders. The data collected throughout the project shows that these expectations were met and at times exceeded. There is strong evidence to suggest that both, peer-to peer and peer-to-leader, relationships were a significant factor that contributed to the young people's sustained involvement in this project.

\subsection{Project Ethos}

A further aspect which contributed to the participants' sustained involvement appeared to be the youth participatory nature of the project, the idea of making a change and the chosen mental wellbeing theme of the research. This evidence supports findings from other studies that highlight the value young people placed on making a change and having their voices 
heard within youth participatory projects (see Body and Hogg (2019) and Houghton (2015)). The different data sets allowed me to gauge the prominence of these themes at different stages of the project. This section describes how young people identified these factors that I have grouped under the theme, project ethos as having contributed to their sustained involvement within the project.

\subsubsection{Making a Difference}

When analysing data gathered at the beginning of the project, the idea of contributing to change (see Graham et al. (2006)) was the most prominent aspect of the ethos that appealed to the participants. The young people filled out an application form that asked them to write what inspired them to be part of the project. Chantelle stated that "making a change in Wellington" was a one thing that inspired her to get involved with the project in the first place and this sentiment was shared by half of the participants. The idea was articulated and built upon by Shelly who expressed that her motivation for making a change was founded in an understanding that her experience of her hometown of Wellington was not the same to other young people's experiences: “As this is my hometown, I love this place very much and would love to do anything to give back and make this city as wonderful and enjoyable for others as it is for me." This theme of wanting to make a change was also a very significant theme of the participants' project expectations during the first session. There were as many as fifteen anonymous post-it notes within the theme of making a change that expressed ideas such as "address some issues for youth" and "create a positive significant change that will improve Wellington" (Expectations Artefact).

When asked to express her initial motivation for being part of the project in the participant interview Bubbles simply stated "the idea of making a change." This was echoed by Ben who "was keen to get involved with the survey and the and the analysis as it could it, could help others" and Shelly who said "I think just the idea of being able to help Wellington because I mean I grew up in Wellington my whole life and I feel like there aren't many opportunities to help Wellington like grow and get better." This quote suggests that the opportunities for young people to make a change in Wellington are scarce and so the prospect of being able to do this was an attractive motivating factor. Keir also touches on this idea when he stated: 
I would want to do something cos obviously like all my mates and everything, I can see them and they go through stuff and other people around me in school they're going through stuff and hardships so it was like more just like, for me, so I can do a little something to help someone and that will give me, well it wasn't even about what it would do for me it's just I would I wanted to be able to find a way to help people, and this was like a really good opportunity for me. (Participant Interview)

This idea of contributing to change is furthered throughout the participant interviews. In Raihaan's assessment of what he appreciated about the project for example, he states that "obviously through Youth Council it's a lot of youth focussed policy whereas here we're actually doing things about it which is really interesting." This positions the YPAR project's focus on action and change as something different from other things the participant has been involved with. Both the idea of making a change and the project's differentiation from other activities is echoed in Chantelle's comments:

It kind of gave me something to live for. I was like "hey I'm actually making a difference" like this actually matters. It's kind of like, with school and stuff you're like where is this taking me? How is this going to help me out? But with this project you can see what you can kind of see what who's going to be affected by it and how they're going to be affected by it. (Participant Interview)

Clive's appreciation for this idea of making a change was more pronounced once the high-level, broad idea became a specific project that was more tangible to him. He shared that, "when like we talked about like having the youth space in Wellington something like that. that was an issue that was important to me because they had something like that in Marton and it was real [sic] cool."

\subsubsection{Mental Health/Wellbeing Focus}

The mental health/wellbeing focus of the project was also a significant theme that evidently influenced the participant's involvement. It was unsurprisingly less prominent in the data sources gathered during earlier stages because it was chosen as a research topic by the group themselves later on in the project. However, as the project progressed this theme grew in significance and began to be captured in weekly reflections like Em's who said that 'it was cool and interesting seeing what people would say to their friends and if they would do that 
for themselves" (18/03/20), and Sarah's who said she was "excited to see what we can do for people who don't have friends" (14/08/19). These reflections present a relationship between young people's desire to make a change their interest the topic of mental health/wellbeing." However, Unique presented a different sort of appreciation for the mental wellbeing focus of the project saying that "it has really helped me open up about my own mental health like, I posted about it on my Instagram story the other day." This perspective supports Cammarota and Romero's (2011) assertion that PAR is a tool that helps raise the consciousness necessary to bring about change at personal, societal or institutional level. In this instance, the young people's conversations around mental wellbeing helped raise their consciousness around this topic and empowered them to be thinking constructively about their own mental health. This was further supported by Charlotte's reflection after an exercise that asked the group to consider what they would share with their friends given what they know about mental wellbeing:

I found it really interesting to see the themes that came through and how similar they were in different areas and a little self-reflection myself - am I doing the same things that I would recommend to my friends? (18/03/20)

Raihaan echoed this sentiment in his participant interview when he suggested that the project "really makes you question yourself also...is my mental wellbeing is it positive? or is it negative?" Again this positions the mental wellbeing theme as, not only important to the young people as far as how they can help others, but also how they can help themselves.

\subsubsection{Having a Say}

The youth-participatory nature of the project was another prominent theme that impacted the young people's sustained involvement which again supports findings from Body and Hogg's (2019) longitudinal study. This factor was prominent right from the beginning of the project. For example, when asked about their initial motivation for being part of the project, Stamaloa expressed "the fact that it was focussing on youth" was a key factor while Chantelle conveyed that the fact that "we actually value your opinion around here" was the thing that "clinched the deal" (Participant Interviews). Participant's responses in the application forms further indicated an appreciation for the fact that the project would be youth-led. Charlotte for example, expressed that "it's super exciting to be running a project where all young Wellingtonians can have their say not just the usual voices we hear. I 
want to contribute and be part of it." Lil Wayne stated a desire "to make a difference and have a say for Wellington youth." This comment includes two aspects of the ethos and posits a relationship between the two ideas of making a change and allowing young people to have their say. That is, making a change can be expressed both through the delivery of an outcome that benefits their peers but also systemically by inserting youth perspectives into decision making processes.

The young people further acknowledged the idea of having a say in their weekly reflections. This theme incorporated ideas such as Felix's suggestion that "it's been nice to sit in a space with everyone and share ideas and polish stuff" (19/02/20) and Ben who simply noted that the "conversations are real [sic] interesting" (13/11/19). These ideas point to the young people's appreciation for simply being asked what they thought about certain issues and being able to talk to other young people about it. Charlotte expanded on this point when she stated, "I have loved all the discussions and it's awesome to come somewhere where you feel cared for and the work is fun and interesting and worthwhile rather than just being for a grade" (27/11/19). By comparing this project to others that are just "for a grade," Charlotte creates a critique of mainstream education and suggests her sustained involvement in the YPAR project is in part down to her perception that it is "worthwhile." This reflection also captures the essence of Ben and Felix's appreciation for a space to share ideas and have discussion as well as touching on Charlotte's aspiration to make a change. While Charlotte's perspective is shared by Ben who stated he "can't wait to make a change" (16/10/19) and an anonymous ${ }^{7}$ participant who stated "I'm grateful to work with you guys and make an impact" $(12 / 06 / 19)$, this reflection also establishes a potential motive for why making a change is so significant for the young people involved.

The participant interviews also provided a wealth of evidence that helped position the participatory nature or the idea of having a say as significant factors in the participants' sustained involvement. When asked what they appreciated about the project some young people spoke of the opportunity to share their ideas. Keir suggested that "it was it was good to bounce ideas back and forward between each other as well and that brought out new ideas" while Lil Wayne stated that she "found it really empowering as a young person to be able to talk about this kind of thing with other young people.” In Felix's interview he touched on this slightly different perspective when he explained that it was:

\footnotetext{
${ }^{7}$ This particular exercise was a personal written reflection and so the identity of this participant was not
} recorded. 
cool being part of a youth-led project for the first time because this is the first group project I've done with youth so it's been really interesting to see how that differs from like projects run by adults and stuff - how there is different views and all that. (Participant Interview)

While other young people spoke of their appreciation to share their views and ideas, Felix noted the project's youth-led nature offered a point of difference from something he was used to and this in itself was something that he appreciated.

A cross triangulation analysis of the various data sets reveals a strong link between the young people's sustained involvement and the project's ethos. The young people appreciated the youth-led nature of the project, partly because it simply gave them opportunity to think about and discuss big issues. However, the fact that, by being youth-led, it was different from other things they were involved with, also created a sense of intrigue and excitement about being involved in something new and different. Further to this, was the young people's apparent strong desire to make a change. The evidence suggests that the opportunity that this project offered them to do just that was an attractive one and encouraged young people to get involved in the first place and stay connected as the project progressed. Moreover, the mental wellbeing theme that was decided on by the young people themselves presented firstly, evidence of the idea that this project would be youth-led, secondly a specific, issue within which the young people could contextualise their desire to make change. As the project progressed, it also provided the group with the opportunity to consider how the youth perspectives that brought to light the wellbeing issues facing young people also had an impact in their own lives. Each of these aspects of the ethos had an impact on the young people's experience of the project and contributed to their motivation to stay connected to the project.

\subsection{Progress and Productivity}

Participant's sustained involvement also appeared to be impacted by the perceived momentum of the project or a sense that the group was being productive. While this theme was less pronounced at the beginning of the project, some young people were able to articulate this idea of progress as an expectation from the outset. When asked to write down their expectations of the leaders, one participant wrote that "this needs to be more than just 
talking - doing is key", while another expressed that they expected "more doing - this needs to be something real." While these expectations were directed towards the project leaders, participants also expected their fellow group members to create a "highly productive environment" and to "be held accountable." These initial expectations suggest that some participants would be motivated to continue coming if they saw the project progressing towards a tangible outcome and wanted both the leaders and their peers to ensure this was prioritised.

Despite some early indications that the momentum was an important factor for keeping young people involved, his theme was most pronounced within the reflection data where the young people regularly spoke of their appreciation for the fact that the project was progressing. This was exemplified in a reflection after one session a few months into the project where the participants were asked to reflect on the session using an object in the room. Felix chose a "spring roll, because this thing is really on a roll right now" while Chantelle chose a "plant because I can really see this thing growing" (19/06/19). There were certain sessions where the project's progress was more obvious than others, for example when the group finalised their dissemination plan for their survey, every participant spoke about the progress of the project. For example, Felix shared that he was "proud of how we've actually got a plan to do the survey now and getting stuck into something practical" and Charlotte "expressed that it was cool to come back and see it all done after being away for a couple of weeks." (31/07/19) Both of these reflections show that the young people felt encouraged that the project was progressing and that the discussions were leading towards something tangible. However, Charlotte's reflection in particular suggests that some participants valued seeing the project progress above necessarily being involved in the weekto-week work that enabled that progress. Furthermore, my own observation data shows that less young people came to the extra sessions that were set aside for action such as data collection or report writing (Attendance Sheet). While there are factors such as different commitments and young people's capacity that partly explain the smaller turn out for these extra sessions this evidence shows both that the young people felt comfortable choosing the extent of their own participation but also speaks to the value of adult partnerships within YPAR projects (Wood et al., 2018). In this instance, the adult leaders recognised the young people's desire for progress and momentum and were able to progress the project in between sessions. The data suggests this progress kept the young people interested and involved throughout the YPAR process. 
Throughout the observation data I noted the group's apparent desire and appreciation for progress. This was evident in my own reflections from the meeting such as when I suggested that the group was "stuck during the question formulating time. Young people found it challenging so we need to move on to keep up the momentum" $(22 / 05 / 19)$. This was also shown through my observations of the young people themselves such as when I noted that "talk of a launch was attractive to some of the group who became excited when discussion progressed" (16/10/19). There were also times when I observed the ongoing tension between the young people's desire for progress and the importance of relationships. After the first session back after the school holidays, I wrote about the individual exercise that I had prepared stating that "most young people didn't engage with the work in a particularly meaningful way preferring to continue catching up and sharing stories and jokes" $(12 / 02 / 20)$. This illuminates a possible tension between the relational focus of the project and the desire for progress and momentum. Here young people provided evidence to suggest that at times the relational aspect of the project was more important than the outcome or momentum.

This idea of progress being an important factor for the young people involved was also evident within the participant interviews. Bubbles, for example, said she appreciated that "it wasn't all just talk and things actually got done. I think that doesn't happen often in a lot of the groups that I've been in where the mahi was actually done and it wasn't just all talk" (Participant Interview). However, Clive stated that at times "it got a little bit repetitive with the data analysis stuff" and Shelly suggested that "it was quite slow I'll say, but I think that was good to create a sort of chill, relaxed we'll go at everyone else's, pace and no one was like rushed or pressured" (Participant Interview). These critiques of the project suggest that there were times when the young people were challenged by a lack of progress. Shelly's comments in particular suggest that she understood the connection and possible tension between the idea of building and maintaining relationships (a process that takes time) and the progress of the project.

In contrast to some of the reflection and attendance data which presented progress itself as being more important for some participants than being involved in the progress, there was evidence in the participants' interviews that suggests the young people's consistent week to week involvement or "fear of missing out" was also a factor in motivating to come more often. 
Em: Probably my $\mathrm{FOMO}^{8}$ really. what if something really interesting happens in a meeting and I can't have my say and things like that? Or put in my two cents that no one really wants or something like that. I feel like if I'm not coming, I'm missing out.

Felix: I'm a person who gets really bored if they don't have something to accomplish and just seeing the group progress just wanted me to like it made me want to come more and more just cos if I missed like a week I'd miss this huge chunk of data or something and I didn't really want to miss out on seeing that progress happen so yeah.

Keir: Yeah, obviously what kept me coming was like I really wanted to continue and see how things were going. And like if I missed a week here and then I would like it would be like in my conscience like "oh I wonder what they did. I wonder how they're progressing things."

These quotes show how certain participants valued the idea of being part of the project progress. For Keir and Felix it was not enough to see the project progressing from afar while Em in particular wanted her perspective to inform the progress. This desire to be part of the progress was furthered by my observation notes showed certain participants regularly referenced the fact that they rarely missed a session (Observation Notes, 13/11/19, 27/11/19, 26/02/20).

The data suggests that progress was on the mind of both the leaders and the young people throughout the course of the project. It became apparent that the leaders needed to balance the pace at which the project progressed to cater to different participants. While some at times lost interest if they felt as if the project was dragging, some found it motivating to be involved every step of the way. This presented an interesting relationship between the idea of building relationships and the project's momentum. Both were important factors for the young people involved and thus need to be carefully managed by the leaders. In Chapter 5 I discuss this with more reflection on the role leaders played to maintain and manage pace and progress (see Section 4.5).

${ }^{8}$ Fear of missing out 


\subsection{Chapter Summary}

This chapter outlines and describes the eight stages of the project process from whakawhanaungatanga through to sharing the findings at a launch event (see Figure 3.2). It also describes a typical meeting structure before presenting evidence to illustrate how these processes worked to help sustain the participants' involvement. It was clear the strong, supportive relationships were the most significant factor that young people identified as keeping them involved within the project because of its prominence across all the data sets. However, the specific focus or ethos of this particular project such as it being youth-led, allowing young people to make a change and was concerned with mental wellbeing were also identified by young people as factors that influenced their desire to continue attending. Finally, the idea of progress and productivity was one that young people also highlighted as an important factor within the various data sets and had had to be carefully considered by the leaders to ensure that the young people did not lose interest and enthusiasm for the project. Chapter Five provides evidence for processes that helped to amplify young peoples' perspectives both internally within the YPAR project and externally as a result of their findings. 


\section{Chapter 5: Exploring the Amplification of Youth Voices}

\subsection{Introduction}

An enduring theme across the data sources was an examination of what might amplify youth voices through this project. This chapter explores the evidence related to my second research question: What processes of YPAR can enable and constrain the amplification of youth voices in a youth engagement project? There were a number of factors that the data suggested contributed to this. In this chapter I outline the various factors that enabled young people's participation and thus amplified or constrained their voices both within the context of the project and within wider decision making. In Chapter 2 I identified the various barriers that work to limit the authenticity of young people's voices even within projects that attempt to involve them in decision making. The prominence of these barriers and limitations highlights the need for research that examine how authentic youth voices can be amplified or constrained within YPAR.

As discussed in chapter 4, supportive and respectful relationships the young people had with each other and the leaders were a significant factor across the data that helped them feel comfortable sharing. Another significant aspect of the project was the creation of relational participatory space. Here I discuss five key factors that helped to create this space within the project and enhanced the young people's ability to share and participate as a result. I also identify various tensions that a relational approach to participation illuminated and how these may have inhibited young people's ability to contribute fully to the project.

A third aspect of the project that I examine in this chapter was the impact of some of the outcomes that stemmed from the findings of the YPAR project and how they might work to amplify youth voice.

The data from this chapter were predominantly drawn from the participant interviews that took place towards the end of the YPAR project. However, I also draw on my observations throughout the project as well as a youth reflection that took place after the launch event at Parliament. The following sections will describe how these data sets provide evidence both for the amplification and constraint of youth voices within this project. 


\subsection{The Contribution of Relationships}

The participants all stated that they felt encouraged to share their perspective as a result of the relationships they developed throughout the project which support's Tisdall and Davis' (2004) claim that adult support and partnership can help raise the voices of young people.

The young people credited the relationships they had with each other the leaders and BGI as an organisation as factors that enabled them to feel comfortable sharing and contributing authentically. As discussed in Chapter Four, some young people were only comfortable coming along in the first place because they had friends who were also part of the group while others felt more and more able to share as their relationships with other members strengthened. Felix captured the sentiment of many participants when he stated:

Oh, it definitely helped like I reckon you're crazy if, well not crazy, but you've got a very special skill if you find strangers very comfortable to speak to, like I don't possess that skill. If there's a stranger who comes up to me just in the middle of the street my mind goes 'oooh warning signs,' but if it was a friend who approached me in the street, I'm more likely to stop. Being friends with people made it a whole lot easier just to talk to one another because you're talking as mates rather than just co-workers. (Participant Interview)

Here, Felix presents relationships as an almost necessary factor for him personally to be able to share comfortably and authentically with others. Raihaan echoed this sentiment stating that "you feel more comfortable working with them and so, yeah, you're more likely to give your honest opinion and give, give it more frequently." His use of the second person to illustrate his point indicates that he may consider this to not just be unique to himself but something that is true of many people or at least of the other members of Te Ahi. Shelly also described this feeling as being true of the group collectively rather than just herself:

I think we're less reluctant to participate now which is the most important thing cos now that we're closer and we're more friendly. Like at the start, we might have been like worried about like speaking up or something and like really rigid with each other, but now we're super friendly and close and we can just say what we want and be really comfortable. (Participant Interview)

There is a wealth of evidence from the study that suggests the young people felt more able to share authentically thanks to the strong relationships they had with both the leaders and the 
other young people within Te Ahi. This is consistent with certain scholars who stress the importance of intergenerational partnership within participatory processes (Cahill, 2007a; Camino, 2000; Richards-Schuster \& Timmermans, 2017). When asked what helped make them feel comfortable sharing, both Shelly and Keir credited the "welcoming" and "friendly" nature of the leaders. Unique expanded on this when she touched on the importance of the relationships she had with leaders in relation to the mental wellbeing focus of the sessions when she said "...the leaders in the group like you and Elle (leader) and all that, just the support that they gave me personally I found it really easy to talk about that kind of thing" (Participant Interview).

This supportive relationship that the leaders provided was noted by eight of the 14 participants as something that helped encourage them to participate and share their perspective. While Unique touched on this with regards to mental health, others such as Charlotte noted that the support and care the leaders provided helped to establish a more authentic participatory process when she stated:

definitely having like authoritative figures who weren't like (gruff voice) "I'm experienced I know what I'm doing" that sort of relationship, like the fact that you felt cared for and that [was] super nice. You were hands off when it came to telling us what to do. It was always if they brought in their perspective, so if you Rose or Elle (leaders) brought in your perspective it was always a suggestion it wasn't a (gruff voice) "this is what we're going to do what do you think about it?" and that's you know that's super awesome. (Participant Interview)

This was echoed by Chantelle who noted that "the people who were sort of in charge so like you, Elle, Rose, (leaders) like you weren't over bearing about being in charge. You kind of, guided the discussion instead of, like, dictated it, if that makes sense, so there was a lot of flow" (Participant Interview). Through these perspectives the young people present the leaders support and guidance as contributing factors for a positive adult/youth relationship within the participatory process. They both critique an authoritarian style relationship in which the adults just tell the young people what to do, but also acknowledge the importance of the leaders as helpful facilitators and even friends. This was further emphasised by Bubbles when she said: 
I think definitely having the leaders, like, you know, we, youth, rangatahi, will talk about it but they don't really have a space or people to guide them and I think having that stability behind them, not necessarily telling them what to do but showing them what they can do, helped us make the survey. (Participant Interview)

Here, Bubbles touches on the barriers that young people face when trying to get their voices heard, or develop projects and campaigns. She too speaks of the value of the leaders' guidance and the need for young people to be given space and support to action the conversations that Bubbles suggest they are already having. Her perspective highlights the importance of recognising adults within this relational process, not as facilitators of youth autonomy, but rather as holders of a space where multiple perspectives can be put forward, examined and critiqued and the power is mobile and shared rather than held by certain adults or young people within a group (Wood et al., 2018). It also highlights the opportunity for learning and development that YPAR provides young people as they are empowered to navigate these power structures and begin creating their own space in spite of the barriers that exist.

The participants also regularly referenced their relationships with each other and used words such as inclusivity, respect and understanding to describe how these relationships helped them feel more able to share their perspective. Charlotte touched on this inclusivity when she expressed that the group "wasn't clicky ${ }^{9}[\mathrm{sic}]$ at all. There wasn't like a certain small group sitting round a table and you didn't want to go and talk to them cos they might be like, 'who are you?' yeah it was super chill with everyone.” Raihaan also noted that "everyone was so supportive everyone so caring, kind like saying hi on the street even if you ran into people, I think it's something that supported me through the whole process was everyone's kind of positive outlook on each other." When asked about these relationships Felix offered an insight into how this inclusivity and whanaungatanga was encouraged within the context of the meeting:

before everything started there would be food there, and you'd sit round a table and just talk banter about school or work or anything and that quickly helped form friendships just cos it wasn't a: 'you come in, there's the meeting you

${ }^{9}$ A phenomenon where people form small groups among themselves that are internally focussed can and exclude others from joining. 
leave.' There's: 'you can come in any time before the meeting there are going to be people here.' You can hang out with those people. You can go into the meeting having a little chat beforehand and everyone's kind of comfortable. (Participant Interview)

In Cahill's (2007a) study her emphasis on hospitality and welcome, she says, helped to establish the young women in her project as equals and Felix's perspective here works to support this idea. This inclusivity fostered an environment where young people felt respected and comfortable that they would not be judged for speaking up. This lack of judgement, also associated with strong relationships, was another significant factor for the young people feeling able to share. Stamaloa suggested that she came to understand that she wouldn't be judged as the project progressed and she got to know the other participants better: "as we went along like along in the year it just became clear that like the people surrounding me weren't there to judge, they were there to help me." Sarah also noted the lack of judgement and explicitly mentioned that it helped her to share her perspective:

they're all so kind and they're all so lovely it felt easier to talk about personal things because there was no judgement behind it and they all had something to say and everyone just respected one another and that was like the best part. (Participant Interview)

A final aspect of the young people's peer-to-peer relationships that a couple of participants noted was the understanding between certain young people within Te Ahi. Em for example, noted that "if I said things in the wrong way people would still kind of understand what I was trying to say. That kind of thing so like having those relationships really did help." Unique expanded on this point when she said:

I think it made it easier cos I'd tell Lil Wayne quite a bit anyway like outside of the group so with her being there and being like a support person for me was just easier to share and she'd elaborate on it if I couldn't finish a sentence. (Participant Interview)

These perspectives show how strong relationships can contribute to young people's ability to share more authentically. It suggests that young people can act as advocates and champions for others within the group. Especially those who may struggle to articulate their point of view. Rather than seeing this as being spoken for or having their ideas misconstrued, 
both Em and Unique suggest that this was helpful for their ability to contribute especially within the group setting. Interestingly, this role model relationship with some of the other members of Te Ahi at times proved to be slightly stifling for Lil Wayne. She said that

because like I'm one of the older people in the group I didn't want to say a few things and a lot of them are quite (I don't know) effected by their mental health and stuff so I didn't feel like it was suitable to say that. (Participant Interview)

Here, Lil Wayne showed an awareness of her age that contributed to her feeling a sense of responsibility within Te Ahi and care for other members. It is further evidence of the strong relationships within the group but highlights a potential consequence that could decrease the authenticity of youth perspectives shared within a group setting.

In sum, an analysis of the interview data showed how different types of relationships contributed towards young people's voice being amplified through the YPAR project. Young people indicated that support was a key characteristic of the relationships they had with both their peers and the leaders and both helped them feel able to share their perspective. The relationships they had with leaders were based on a perception of feeling cared for and a knowledge that the leaders were there to help guide and support. They also credited the encouragement they received from their peers and a sense that they would not be judged if they chose to share as a contributing factor for their confidence to share and this grew the more they got to know the rest of the group.

\subsection{Creating a Participatory Space}

As well as a strong supportive relationship with the leaders, the young people acknowledged the role that the leaders had in holding the space for them to share their perspectives and were able to identify certain parts of the project that helped make them feel comfortable sharing and thus amplified their perspectives within the YPAR project. The idea of holding a space acknowledges the role that the adults played in facilitating young people's participation by reducing the effect of barriers and interrupting systems of power that work to limit young people's ability to participate (Gallagher, 2008). Within this theme, the young people credited the leaders' tendency not to push their own ideas onto the group, the openness of other participants, the variety of engagement activities, the time given to develop ideas and even the lack of adults as aspects of the project that contributed to the young people's ability to share their perspectives. These factors are all impacted in some way by decisions the leaders 
made to attempt to reduce power dynamics that are traditionally in play that work to reduce the authenticity of youth voice. Critical literature has shown how these power dynamics are particularly impactful and complex within in school/institutional environments (Bernstein, 2000). In the following section I outline how this participatory space was achieved and characterised.

\subsubsection{Reduced Leader Direction}

Five young people mentioned that they appreciated how the leaders didn't force ideas onto the group but instead encouraged the group to share their own opinions. This sentiment was captured when Chantelle suggested that "you guys (the leaders) didn't push anything on us. that's what really helped it wasn't like being told by a teacher this is what you have to do or this is what you have to say." By mentioning teachers, Chantelle contrasts the project with her experience at school which sounded more controlled. Em also described the project by contrasting it to her experience working with adults in the past:

you guys (the leaders) were actually letting us have our opinion because I know some people are like 'what do you think of this?' and we're like 'oh we hate it' and they're like 'ok cool we'll do it anyway.' So, there wasn't that. We actually did get to help shape with what it was and we got that opportunity. (Participant Interview)

Both Em and Chantelle described how the leaders helped to hold a participatory space through an explicit decision not to force their opinions onto the group. However, Charlotte's perspective explored how the leaders created a space that reduced the effect of implicit pressure for the young people to perform to the leaders' expectations (Arnot \& Reay, 2007). Arnot and Reay's research draws upon both a Foucauldian (1977) understanding of power within institutions and Bernstein's (2000) idea of the 'acoustic of the school' to discuss how participatory projects are at risk of replicating rather than dismantling these institutions of social control. The participant talked about how this project and space was different:

The group was really chill so it wasn't like even, even if you're like sitting round a big table with authority figures that's like that's the sort of thing that makes you think "what if I say something that doesn't you know align with what they want?! (Participant Interview by Charlotte) 
Although adults' pressure and expectations can be unstated, Charlotte's perspective shows how creating an informal environment even, in this instance, through the lack of a "big table" helped to create distance between this project and projects and assignments in which she has felt pressure to perform a particular way. Felix reaffirmed this appreciation for a relaxed environment when he said

I reckon, yeah, the whole circle set up definitely made it easier just cos everyone's facing everyone and there wasn't like an overwhelming pressure to share. So, like, if I looked at a piece of data and I've just got nothing I could just sit back and just maybe build off someone else's idea and help them. (Participant Interview)

\subsubsection{Other Participants' Openness}

The openness of other participants also played a significant role in creating a participatory space. As many as ten young people communicated that they felt more able to share when they saw other members of the group sharing. Bubbles identified how the leaders and the YPAR process, helped to facilitate this at the start of each session with a 'what's on top' activity when she stated:

I honestly think the 'what's on tops' were really helpful in the sense that they kind of, without having to like speak up, you got the chance to do it regardless cos it went in a circle and like everyone got to speak and everyone did speak and it also kind of let people know like how that person was feeling that day and how to handle you know them as a person. Yeah, I found the 'what's on tops' quite helpful. (Participant Interview)

Other young people commented on other participants' openness and suggested that it made them feel more comfortable to be open themselves:

Charlotte: everyone else would say what they thought and so it was a lot easier to do that. (Participant Interview)

Keir: I think it was the fact that everyone was also so open to sharing and then like our leaders like you, and the other leaders that we had helping us were also like so open and welcoming, and yeah, it was really like, it was set up in 
an environment where it was easy to be open and to be truthful. (Participant Interview)

Lil Wayne: Definitely the other people sharing made me a lot more comfortable with saying but also, I'm quite confident with that kind of stuff anyways. But still other people being honest about their own experiences and stuff made me comfortable sharing other things. (Participant Interview)

These perspectives speak to the value of normalising openness and participation within the group setting. Charlotte identified that this was not the case from the very beginning and "everyone become(ing) a lot less reserved" was something that "develop(ed) over time." (Participant Interview). Other participants spoke less about feeling more comfortable sharing and more about the domino effect of hearing other's opinions which would spark ideas that they would then be able to share themselves. Felix commented on how the sessions "quickly turned into like a bounce back thing because one person would share and then someone would work off that idea and it just turned into this big network of ideas - just bouncing off each other." (Participant Interview) Chantelle also noted how "in settings like this it's quite open to feed off other people" (Participant Interview).

When asked what made him feel most comfortable sharing, Clive responded "definitely when Em shared the same opinions as me" (Participant Interview). Clive was the only participant to state that his ability to share was enhanced by having the same perspective as another participant but it is worth examining the implications of this particular idea. It suggests that there may have been times when Clive did not feel comfortable to share if he did not have it confirmed to him by another member of the group that his contribution would be a valuable one. Bubbles (whose first language was Te Reo Māori) and Sarah also spoke about this pressure to not be wrong:

Bubbles: I didn't entirely know what to say like I didn't want to be wrong because again like, big English words, like I didn't get them like I didn't get all of them. And I just didn't want to sound dumb I guess so I just kind of yeah just waited for someone else to say it and I was like "cool cool cool" yeah.

Sarah: there was some fear that whatever I say might be wrong so I was like I don't want to say it to them. (Participant Interviews) 
While we have previously examined Charlotte's appreciation of the project's informality, and how that decreased the pressure for young people to have to say the "right thing," here Clive, Bubbles and Sarah, provide evidence to suggest that this pressure still existed and may not only be enforced by the adult leaders but other young people within the group. This speaks to the complexity of the unstated hierarchies that exist between young people themselves as well as young people and adults (Gallacher \& Gallagher, 2008).

\subsubsection{Variety of Sharing Activities}

A third factor that contributed to the creation of a participatory space were the variety of sharing activities shaped by the project design that the leaders employed to draw out perspectives and ideas from young people. When asked which activities helped enable their participation the young people provided a range of answers. This suggests that different young people felt comfortable sharing in different ways and thus by choosing different sharing activities, leaders attempted to ensure that a participant's discomfort with a particular form of sharing did not reduce the impact of their voice when it came to shaping the project. Shelly for example, articulated that she felt most comfortable "just writing down rather than speaking out loud... I think that's less scary and also everyone gets to share their opinion rather than just a few people." In contrast, Ben "felt more comfortable sharing in little group activities. That's mainly part of my introverted nature" (Participant Interviews). My observation notes add weight to this idea that different sharing activities allowed for different young people's ideas to shape the project. On November the $6^{\text {th }} 2019$, for example, I wrote:

Some young people responded well to writing down their thoughts but others left their sheets blank... The individual work sheets acted as a prompt for the group discussion. Some who didn't write anything down were able to contribute comfortably in the discussion which indicated their preference for this type of sharing style. Others who had written a lot down contributed less in the group discussion. (Observation Notes 06/11/19)

Again, this evidence supports the idea that different young people feel more comfortable sharing their perspectives in different ways. Stamaloa extended on this idea when she suggested that she personally appreciated different sharing activities at different stages of the project 
I think it was a mix of all of them. Like after the first few meetings that were just like talking like and then we got into post-its and writing like I felt more comfortable. Oh, at the start I felt more comfortable writing mostly and then as we started talking and doing Post-It-Notes. (Participant Interview)

As well as the need to consider the ways in which different young people feel able to share within the meetings, Stamaloa's perspective illuminates the need to consider how an individual young person's preference or comfort with various activities may change as the project and the relationships they have within the group develop.

\subsubsection{Length of Time}

Some participants also credited the amount of time given to develop ideas as a helpful factor in allowing them to participate and share their perspective. This was identified by Shelly who appreciated the time given to gather her thoughts before being asked to share:

You (the leaders) always gave us a moment to write down our thoughts and stuff but then we would have to say something in the circle - not have to but most of us felt compelled to say something therefore we did say something and I think that was helpful because most people can't just think of something. (Participant Interview)

Chantelle and Stamaloa however, suggested that their appreciation of the time allowed stemmed from a desire for robust conversation and being able to develop a strong idea as a group.

Stamaloa: Having all those sessions developing the theme was really good because there was a lot of debate.

Chantelle: You gave us a lot of like freedom to sort of express what we thought and debate it out and hash it out in the sessions and we'd spend like what? a whole session on one question. and that really helped to sort of get a solid point without external sort of adult influences coming in and warping our perspectives. (Participant Interviews)

Here Chantelle suggests that the time given for conversation and debate, allowed the group to develop an unadulterated youth perspective but also touches on another factor that 
young people suggested helped amplify their voices. There were times when not enough time was given to a particular topic as illuminated by Clive's (16) suggestion that if he:

didn't want to say something it's because people might have already moved on from the topic. So, if it was going a bit fast you know and then you missed your chance to say something. You wouldn't want to say it again because it would sound pretty random.

Clive's critique of the process in this instance provides further evidence to suggest that allowing enough time is an important factor when it comes to encouraging young people's voices within a participatory space and this didn't always happen.

\subsubsection{Lack of Adults}

The lack of adults involved in the project was mentioned by a number of participants in their interviews. The leaders were relatively young adults between the ages of 23 and 31 and there were only three or four at each meeting so the number of young people always outnumbered the 'adults' or leaders. "It was good because there were three adults for what? Like initially 20 kids?" (Chantelle Participant Interview) Ben (17) said that "lots of people that were coming which were mainly my age and school students and that sort of helped me talk a little bit more rather than it being, I don't know, thirty- or forty-year-olds" (Participant Interview). Chantelle's comment suggests that the mere fact that young people outnumbered adults in the project helped to reduce the power dynamic between adults and participants. This was expanded on by Felix (17) who speculated that "if it was just adults doing it, they wouldn't have come up with half the stuff we did" while Em (17) "suggested that if it was done by adults, they probably wouldn't have asked the right questions. And they, we wouldn't have got some of the answers that we did" (Participant Interviews). Em and Felix's assertion that adults would have done things differently had they been involved in the project is an acknowledgement of the deep knowledge that young people have about their own lives and experiences (Torre \& Fine, 2006). This also suggests that this knowledge provides a strong mandate for the inclusion of young people to research and provide answers on issues facing young people. When asked what could have made the project more influenced by young people Clive (16) suggested:

maybe if we'd written the entire thing (survey) and then someone just went over and spell checked or something like that, yeah, that would have been 
interesting to see what happened cos that might have that might have changed

a little bit because maybe what we thought would be the order was maybe

what adults would think was different. (Participant Interview)

This critique sets up an interesting consideration of different factors that influenced the YPAR project. In Section 4.5, I highlighted the importance of progress and momentum for the young people's sustained involvement and the sessions spent writing the survey questions threatened to reduce the momentum. The group had a number of discussions about the sorts of questions that needed to be in the survey but when it became clear to the leaders that getting these ideas into set questions was proving to be difficult for the group, they decided to use the ideas to write the survey before asking for the young people's feedback. Faced with this dilemma we chose to prioritise momentum and progress in this instance, over youth led initiative alone, because we still believed that the questions had been influenced by youth perspectives both before and after they were written and because of the impact that we believed that the loss of momentum and progress would reduce sustained involvement and therefore the amplification of youth perspectives in the long run. Had the priority been on ensuring that young people were the ones directly writing the questions, the project may have stalled and resulted in young people opting out of the project due to a lack of progress. This is not a reflection on the ability of young people to do this work but rather an acknowledgement of the leaders' role within this project to manage pace and progress due to young people's limited time due to school and other commitments.

Increasing the size and diversity of the group was one area where young people thought that the project could have improved. Ben for example suggested that "more people would be better, different perspectives and that would help informs better ideas" (Participant Interview). This point was furthered by Bubbles who indicated that "even though we both are rich and poor we both have, can have bad mental health so I think that could be cool. A larger diversity in the group." While many young people raised the perspective that increased diversity of voices would increase the validity and rigidity of the project, others suggested that increased numbers within the group could also have a negative effect. Felix for example stated that "we could have got a bigger more diverse group but then again we already had a pretty diverse group and if we had a bigger group it probably would have been harder to have that friendship kind of thing so I don't know". Keir also noted: 
"it would just come down to like getting a bigger group of people but even though that would be harder because, like bigger group of people, more like minds but just to like get a wider range of like peoples characteristics kind of thing but that would be the only thing." (Participant Interview)

Here the young people present another dilemma for would be YPAR researchers: If strong relationships and momentum are desirable factors within a YPAR project but so too is the size and diversity of the group, how might a facilitator balance these two factors? And what further initiatives or activities would they need to employ to ensure that the size and diversity of the group did not impact on its ability to develop a successful project? It also sets up the question around the homogeneity of youth voice and whether a melting pot of ideas really achieves the best outcomes when it comes to amplification of youth voices or whether researchers would be better served working with less diverse groups to ensure that different perspectives come to light through different projects.

From this analysis it becomes clear that creating a space that fosters participation and sharing is a key element that helps to amplify youth voices within a YPAR project. Young people articulated that they needed to feel comfortable and able to share and identified ways that the leaders helped to enable this such as the variety of sharing activities, the leaders' tendency to encourage the participants' ideas and the time given to develop ideas. The participants also credited their peers' openness and support as important factors that enabled them to feel comfortable sharing authentically and truthfully. While amplifying youth voices was the goal of the project, the young people raised questions about diversity and their lack of direct involvement in all aspects of the project that illuminated the various dilemmas the leaders faced and decisions they made that may seem contrary to this goal. An apparent prioritisation of group harmony and progress in this project at times, is an example of how the leaders asserted their power within the group (Gallagher, 2008). Whether this prioritisation worked to amplify or constrain youth voices is unclear but the fact that some participants raised this as an area where they felt like they could have been more involved highlights the need to research that prioritises full participation over progress and momentum.

\subsection{Culmination of YPAR Project}

While I stopped collecting regular data after the report writing phase of the project in March 2020, the project attracted a lot of interest from local government and youth 
organisations that BGI had connections to. As discussed in Section 4.2, the young people had the opportunity to present at the Involve youth development conference, made submissions to Wellington City Council and also launched their report at Parliament buildings to over 200 youth development professionals, young people and decision makers including the Mayor and City Councillors, the Children's Commissioner and a number of Members of Parliament. A reflection after the launch event showed how the young people felt about sharing their findings in this manner and asked what effect it had on them and on wider Wellington youth. When asked how they felt after the launch stage of the project, the young people reflected on two key ideas. First, was a sense of pride and achievement that they felt. This was evident from Lil Wayne's reflection where she based her pride on the "time and effort we put in" as well as "the work that we have all done to get to this point" (Post Launch Questionnaire). Felix too, felt a sense of achievement that was based on his expectations of what was possible at the start of the project. He stated "I never would have thought our group would present at Parliament when we first met more than a year ago" (Post Launch Questionnaire). Here, Felix reflects on the group's achievements while also hinting at a greater theme of inaccessible adult spaces. Presenting at Parliament was not something that he felt was possible despite living in Wellington and relative geographical proximity to the Parliament buildings he had compared to young people from other parts of the country. Charlotte, seemed to merge these two sentiments when she reflected on "how far the group has come as it can be easy to forget about all of the work that has come before this moment" (Post Launch Questionnaire). She credits both the hard work of the group while also touching on the growth of the group which enabled them to deliver a successful event at Parliament.

The second response by young people after presenting their findings was the connection that they had with other participants. When asked how she felt, Em responded saying "that it's been nice to do it with a group of people I adore," while Stamaloa stated that "it was honestly such a blessing to meet and work with a talented and humble group of individuals." Despite the question not intending to lead young people to consider the relationships they held with each other, the number of people who expressed some form of gratitude for the other participants highlights just how significant this factor was for the group.

The young people were also asked about what the launch meant for youth voices of wider Wellington. The participants believed that the event in itself worked to bring attention to young people's voices but also as something that could inspire or break down barriers for other young people who want to have their voices heard. Chantelle highlighted the fact that 
“young people in Wellington's voices were amplified and heard by people in positions of power/people who have the capacity to help create change" while Sarah was "sure a lot of the big authorities that showed up to the launch do hold some ability to create that change" (Post Launch Questionnaire). These perspectives indicate that young people believed by sharing their findings with the right people and people with power, their voices would be taken into account in decision making.

Em's reflection that "from talking with young people that attended the launch I can tell it has inspired them to use their voice more and has made them want to join the conversation" and Stella's suggestion that she "see(s) our projects inspiring others to speak up and actioning their own projects" highlight the perceived value and domino effect of seeing young people sharing their voices and perspectives. Participants felt that they provided an example of young people being able to speak at Parliament and that this would show others that it is possible for them too. Every young person suggested that the project had increased their desire, ability or confidence to make their voice heard. Clive for example stated that making his voice heard now "feels a lot more plausible and possible" while Felix had this to share:

Before joining this project, I felt as though my voice was insignificant to the greater workings of Wellington. Because I couldn't vote, I felt I had no direct way to influence the government and the decisions they made. After joining Te Ahi however, I felt that youth voices were something the Government wanted to hear, but didn't have the pathways to reach those voices. Through Te Ahi, I became part of a pathway which made youth voices and opinions heard. (Post Launch Questionnaire)

These reflections speak to the growth and increased self-efficacy of the these particular participants while others such as Em and Raihaan stated that they already had this desire but this project "fuelled the desire more" (Post Launch Questionnaire).

It is clear that this launch event which represented a culmination of 18 months' worth of work for the group, was something that the young people identified as amplifying their own perspectives as well as the perspectives of wider Wellington youth. The very event was an example of young peoples' voices leading the project process because it was the participants who raised the idea of the launch and suggested Parliament as a venue. I must admit that the very suggestion made me nervous because I was unsure of how feasible this idea was and did not want the group to be demotivated should it not eventuate (see Wood, 2016). However, this in itself sets up an interesting consideration of the young peoples' 
ability to conceive of something that myself as an adult might not have considered possible and potentially offers another explanation for why young people at times struggle to have their perspectives affect decision making.

\subsection{Chapter Summary}

This chapter outlined various factors that worked to amplify youth voices within this project. The very nature of the project allowed for young people's voices to impact and guide both internal processes and focus as well as wider decision making that lay outside of the project itself. The relational nature of the project again proved to be a contributing factor that allowed young people the confidence to share their perspectives without fear of judgement. Further to this were various factors that contributed to creating a participatory space that reduced some of the barriers to participation that young people traditionally face. Participants identified the leaders' commitment to allowing the young people's perspective to lead the project, the length of time given to various phases the variety of sharing activities and even the lack of adults involved as factors that enabled them to feel comfortable sharing their perspective.

These factors contributed to the amplification of young people's voices within the project but participants also speculated that their very involvement in the project worked to extend the survey's reach. They identified that the knowledge that they brought to the sessions especially with regards to data collection helped bring their survey to a wider range of young people and thus the voices of those who do not usually have the chance to have their say were amplified through the very action of being included. Furthermore, the group also identified the opportunity to present their findings at Parliament as a factor that worked to amplify their perspectives and the perspectives of other young people.

As is evident from the previous chapter there are similarities between the aspects of the project that encouraged sustained involvement and those that helped to amplify youth perspectives. The strong relationships young people formed for example, were a significant factor in encouraging the participants' sustained involvement and also as this chapter describes, enabled them to share their views and perspectives. Sustained involvement also contributed to the strength of these relationships because the more the young people came, the more they were able to get to know the other members in the group. This helps to illuminate the reflexive connection between sustained involvement and strong group relationships and positions the two as contributing factors for the amplification of youth 
voices which I explore in greater depth in the following chapter as well as the impact of relationships, adult involvement and processes within the project. 


\section{Chapter 6: Discussion}

\subsection{Introduction}

In Chapters Four and Five, I outlined various factors that contributed to young people's sustained involvement and explored how their voices were amplified or constrained through and as a result of this involvement in the project. This chapter will discuss these findings in greater depth first by exploring the importance of relationships. In this chapter I explore an interdependent relationship between themes which emerged in Chapters Four and Five whereby the sustained involvement of youth participants within the project enabled a greater amplification of their voices and in turn, the realisation that their voices were recognised increased the chances of sustained involvement. Second, I will consider the intergenerational interaction within the YPAR project and the roles and exchange of power between young people and adults and the implications of this for project. Finally, I discuss the implications for youth participation models as well as the implications this study has for the literature and further research.

\subsection{Importance of Relationships}

My study showed that relationships were a key factor that not only motivated sustained involvement within the project but also enhanced the amplification of youth voices. There were three relationships that emerged within the findings chapters that significantly impacted this project. These were the participants' relationship with each other, the participants' relationship with the leaders and the participants' relationship with BGI as an organisation. While, somewhat predictably, young people expected support and respect throughout the project, there were also differences in what they expected of their relationships with their peers and with the adults involved. For example, as described in Section 4.3, young people expected their relationship with the adult leaders to be defined by guidance and mentoring, while their relationship with their peers were based around acceptance and a lack of judgement. The distinction here helps to build the case for youth adult partnership within YPAR because of the different role that young people expected adults to play within the project. It also adds weight to evidence from Camino's (2000) study that highlighted young peoples' desire for the guidance and structure that working with adults helps to bring to a project. The significance of intergenerational interaction is discussed further in Section 6.4. 
Similarly, the young people identified how distinct features of each of these relationships that contributed differently to the project. That is, relationships in general helped to sustain young people's involvement and amplified their voices, but the different relationships they held contributed differently within these two outcomes. One benefit associated with the participants' existing relationships with each other, for example, was the fact that it helped extend the reach of the recruitment. Many young people chose to bring along a friend that they thought might also be interested in the project. Some participants identified that this option made them feel more comfortable joining the project themselves. This is consistent with an example from an Italian study that found that friendships among peers helped increase engagement and participation within a youth organisation (Guarino et al., 2020). Furthermore, as described in Section 5.2, young people also felt it was easier to share their opinion within the group once they developed a closer relationship with other group members. This was identified by the participants themselves as well as illuminated in my own observation notes. This adds some adds nuance to the YPAR literature by suggesting that benefits of peer relationships within projects are not only limited to factors identified in the literature such as academic success (Poulin \& Denault, 2013) or increased involvement in the project (Guarino et al., 2020), but also shows how peer relationships enhance the ability and comfort to share authentic perspectives.

The leaders' relationships with the young people also contributed to the outcomes of sustained involvement and amplified youth perspectives. Knowing the participants well gave leaders insights which enabled them to draw out young peoples' perspectives by knowing when to prompt, when to hold silence, when to encourage or even when to talk to a participant individually. Each of these insights gave the participants further opportunity for their perspective to influence the project's direction. Some participants reflected on how the leaders and BGI as an organisation made them feel cared for which also encouraged them to keep attending sessions and stay involved with the project. As pointed to in Section $4.3 \mathrm{a}$ great deal of emphasis was placed on ensuring that young people felt cared for and this is a feature of a positive youth development context within which the project was based (Eccles \& Gootman, 2002).

As well as the participatory benefits of relationships, there are ethical implications for prioritising relationships within YPAR. Because of the extended nature of the project, consent had to be continuously negotiated and one of the ways that this was handled was making it clear that young people had no obligation to turn up to the sessions if they did not wish to be involved any longer or less so during different phases of the project (see Section 
3.6). A focus on relationships therefore, helped to create a project that young people wanted to be involved in rather than obligated and thus helped to ensure there were enough young people at each session to enable the project to progress.

The centrality of relationships throughout this project led me to consider how these relationships enabled a dynamic space of agentic possibility for young people involved. While this wasn't always achieved, there were factors which helped to create a participatory space where participants felt supported to contribute and stay involved (see Section 5.3). This space didn't eradicate all barriers, but nonetheless opened up a space where young people received greater potential to participate and maintain their involvement. I suggest that strong relationships with peers and adults were foundational to all of the five elements identified in Chapter 5 that combine to contribute towards a relational participatory space. Figure 6.1 illustrates this in a diagrammatic way and collapses findings from Chapter 4 and 5 to identify that each of these elements were enhanced by the relational foundation upon which the project was built and that this also helped to support and sustain elements. What follows is a brief description of each element within the model and how it is based on findings within this study

\section{Figure 6.1: Model of Relational Participatory Space}

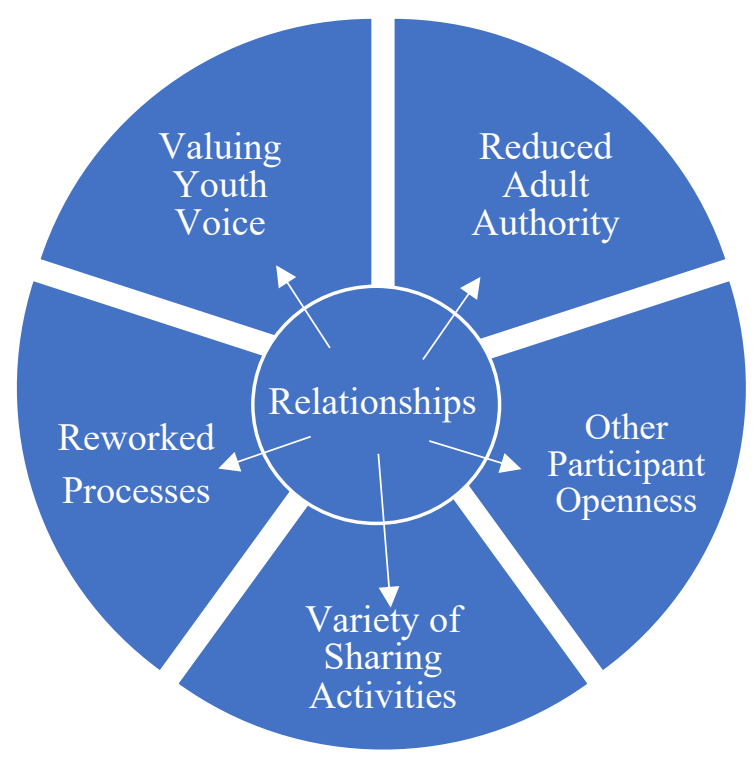

First, the idea of 'reduced adult authority' in Figure 6.1 draws upon findings from Section 5.3.1 (reduced leader direction) and Section 5.3.5 (lack of adults). Both of these 
factors were identified and appreciated by the young people within the project. This element was about reworking young people's expectations around systems of power between themselves and the adult leaders and who had the ability to be able to share and lead. Having less adults than young people involved in the project was one way that this adult authority was diminished and the relationships helped to establish the young people as equals within the project. 'Valuing youth voice' was another important element that appeared to contribute to a relational participatory space. This element draws on findings from Sections 4.4.3 and 5.3 to highlight how young people felt more able to share if they believed that their contributions and perspectives were valued both by the leaders and by their peers. This in turn contributed to the 'openness of other participants' which was another significant element within the model. This element was based on findings from Section 5.3.2 which suggested that participants were more inclined to share if others were sharing and contributing too. The fourth element within the model is 'reworked processes' which acknowledges findings such as an appreciation for the time given to various phases within the project, and the perception that the project was 'more chill' and different to other projects they had been a part of. The idea was adapted from Wierenga et al's (2003) Star which critiques the idea of young people merely being inserted into adult-centric engagement processes. The final element of the model that contributed to creating a relational participatory space was the use of a "variety of sharing activities'. This links to the idea of reworked processes because some of the sharing activities were chosen because of their suitability for youth (see Section 3.1.2). As discussed in Section 5.3.3, the young people appreciated being able to share their perspectives in different ways.

By building the case for relationships as a fundamental base for a meaningful participatory space, this study adds further weight to the idea that a YPAR process can be enhanced when utilising strategies informed by PYD. Setting up a model for a relational participatory space may lead some practitioners towards a transactional understanding of relationship -that is, a relationship and trust that is built with a young person merely as a means to accessing information or the deep knowledge that young people hold about their own experience (Cahill, 2007a). Importantly, within PYD, a youth worker's relationship with a young person is not transactional but affirmative and developmental and this helps to reduce the risk of a young people being cast aside if their participation or contribution within a participatory space is not deemed to be valuable. Critical and indigenous methodologies create a further impetus for meaningful rather than transactional relationship building. Freire (1970) calls for emancipatory research that works to set the oppressed free from systems of 
power and Tuhiwai Smith (2012) similarly insists on reciprocity within research or researchers that considers the wellbeing of the research participants and the value added to the community rather than what can be extracted from the community. Positive long-term and meaningful relationships are one way of ensuring that the needs of the community (in this case young people) are prioritised so that their participation is not taken for granted or exploited.

Through these findings, the reflexive link between relationships and the sustained involvement of young people becomes clear. That is, young people build relationships with each other and the leaders which gives them reason to continue their involvement in the project while enabling the relationships to continue to develop and grow. These relationships in turn helps to set up the possibility of an extended participatory project which works to provide further opportunities for the amplification of youth voices. That is, because young people have developed positive relationships with one another, they feel comfortable coming along regularly for an extended period of time and thus, have time to progress their ideas further through the various opportunities afforded to them as they develop and grow in leadership through their involvement within the project. Furthermore, as described above, more time allows the leaders time to build a better understanding of the young peoples' needs and personalities and improve their facilitation of the sessions in light of these insights. Figure 6.2 explains the interconnectedness between these reflexive factors that work to contribute to the participatory process.

Figure 6.2: Reflexive Relationship Between Sustained Involvement, Relationships and Amplified Youth Perspectives.

\section{Relationships}


The central role of relationships also underpinned interactions between young people and adults within this project and in the next section I explore how these intergenerational partnerships affected the project.

\subsection{Intergenerational Interaction In YPAR}

While the prevailing focus of youth participation literature has been on young people themselves, the findings chapters of this study both point to the significance of the adult leaders' contributions within the project both to encourage sustained involvement and amplify youth perspectives (Mannion, 2007; Richards-Schuster \& Timmermans, 2017; Wood et al., 2018). This thesis was underpinned by a critical theoretical framework that informed the YPAR study. This approach attempted to find ways to amplify and emancipate youth voice by exploring processes and practices derived mainly from PYD. The use of these PYD strategies identified the significance of intergenerational interaction as a feature of this process that deserved further examination as it is often under explored and brushed over.

With regards to sustained involvement, for example, seeing the project progress was something that motivated the young people to attend sessions and stay involved with the project (see Section 4.5). The adult leaders had the most capacity to dictate the speed at which the project progressed and utilised relationships and observations to determine the participants' enthusiasm and energy during different phases of the project. Furthermore, youth participants reported that the simple fact that the adult leaders said that they wanted to hear young people's voices and then continued to back this up throughout the process by allowing them to see the impact of their perspectives within the project also encouraged the young people's sustained involvement (see Section 4.4.3 and Section 5.3). The roles of the adults and youth were not however, exactly the same. Table 6.1 presents the different roles of young people and adults within this YPAR project and illustrates the nature of different and shared roles. 
Table 6.1 Roles Undertaken in the YPAR project by Young People and Adults

\begin{tabular}{|c|c|c|}
\hline Role of Young People & Both & Role of Adults \\
\hline $\begin{array}{ll}\text { - } & \text { Story Telling } \\
\text { - } & \text { Sharing Ideas } \\
\text { - } & \text { Encouraging/Inspiring } \\
\text { - } & \text { Identifying points of } \\
\text { connection with } \\
\text { community (e.g., youth } \\
\text { participants of the } \\
\text { survey) } \\
\text { - Analysis and writing } \\
\text { - Communication of } \\
\text { ideas }\end{array}$ & Creating Participatory Space & $\begin{array}{ll}\text { - } & \text { Deep Listening } \\
\text { - } & \text { Evaluating } \\
\text { - } & \text { Managing } \\
& \text { Momentum/Pace } \\
\text { - } & \text { Providing a Platform } \\
\text { - Reworking processes } \\
\text { - Interrupt systems of power } \\
\text { - Valuing Youth Voice }\end{array}$ \\
\hline
\end{tabular}

In part due to the nature of existing power structures, adults (albeit in partnership with young people) tend to hold greater access to networks of power and it was easier for them to access and implement changes to established systems. Therefore, part of adults' role within youth participation can be to provide a platform for young people and utilise the power they are afforded as adults to amplify youth perspectives (see Table 6.1). In this study, adult connections and status helped to provide the group with a platform at: an event at Parliament, a youth development conference and in Wellington City Council Meetings. These were opportunities that many of the group had not experienced before and despite many of them being totally capable of initiating these opportunities for themselves, this study suggests that they may have felt underqualified or uncomfortable going through the processes available (even I felt overwhelmed at times). While these processes are available, the various barriers described in the literature review ensure that they remain inaccessible for every day young people and therefore adults can play a role in opening up doors for young people who are wishing to participate (Harris et al., 2010). Wood et al. (2018) also describe how teachers can play this role in enhancing citizenship experiences for students in schools.

Like other methodologies that stem from the critical theoretical landscape, YPAR seeks to not only illuminate power structures and raise the consciousness of participants (Cammarota \& Romero, 2011), but also to raise the voices of those who are oppressed and dismantle these same power structures (Freire, 1970). The methodology is about bringing about change and the findings from this study indicate that the young people were motivated by this idea of making change. Again, certain young people may be totally capable and willing navigate the various power structures needed to affect change but there are barriers 
that may block or slow their efforts and completely limit others. Because of the potentially disempowering effects of these barriers (Scott et al., 2015) adults can play a role in widening opportunities for youth agency (Abebe, 2019).

Adult involvement as a catalyst for progress is particularly important when considering the ethics of working with young people within the context of a youth development organisation rather than within schools. First, because young people had no obligation to be part of the project and could simply choose not to show up if they became dissatisfied or disengaged, ensuring that young people were sufficiently stimulated by the progress was an effective way of encouraging sustained involvement in the project. This was a role primarily (but not only) played by adults. In this study, adults worked to ensure youth sustained involvement through strategies such as deep listening, evaluating young people's energy levels within sessions and looking to resource them. While researchers might hope for participatory processes in which young people are meaningfully participating in every part of the project, this study shows that some may not wish to be so heavily involved and withdraw at times and then re-engage with high participation levels later. One might argue that good participation practice calls researchers to allow young people to have a say about when they do not wish to participate (Cullen \& Walsh, 2019; Gallagher, 2008). Further research is needed to determine the reasons why young people might not wish to participate and may illuminate further barriers that will help researchers to make changes at a process level to enable young people to participate more easily.

Second, adult involvement can also enable participatory processes to involve the oft forgotten, 'ordinary' young people (Nairn et al., 2006). While, high achievers, or, young people who are celebrated for their ability to navigate adult spaces, may also be able to progress projects without adult intervention, ordinary young people, however, may struggle to progress a project efficiently enough to feel motivated. Therefore, adult involvement again may increase youth participation because it removes the necessity for youth participation to require a monumental effort from a young person to learn, engage with and succeed in an adult dominated arena despite the exclusionary practices and barriers that they face. If these monumental efforts or child-initiated projects are, as is unintentionally suggested through Hart's Ladder, the purest form of participation, researchers may be wary of initiating their own projects for fear of championing something not considered to be best practice. Increasing the accessibility of youth participation in this way, helps to ensure that more young people's rights supported by conventions such as UNCROC by providing opportunities for them to share their perspective on decisions that affect them. 
A further benefit of the adult leaders' involvement within this project was their ability to utilise the power they possess as adults to hold a participatory space within the sessions. The participatory space is one that allows all young people to participate and contribute within the context of the project. As Gallagher (2008) suggests, while power has often been viewed in the literature as something that adults should work to reduce the impact of within participatory projects, it can also be an effective way of interrupting systems of power that have been instilled in young people. He uses the example from within his Masters' research where he felt uncomfortable about asserting his adult prescribed power onto a group of children to ensure that they completed the assigned activity resulting in the activity being disrupted and not completed. He witnessed power relations within the group of young people, in particular, a young boy who refused to do the activity and infringed on a young girl's ability to also do the activity. This presents a question of whether certain displays of power or domination are preferable to others. That is, should adult prescribed power be enacted if it works to ensure that other power systems (such as patriarchal) do not simply take its place? In the context of this study, the leaders utilised a variety of different sharing and facilitation techniques that worked to direct power to those who may not naturally hold it within the group. For example, written and individual reflections were utilised as well as group discussion to ensure those that might not feel as comfortable interrupting systems of power within the group were also given the opportunity to affect decision making. While utilising power in this way results in a project that is not indicative of a totally youth-initiated and implemented project in its purest form, it does work to mitigate against power merely being transferred from myself, as the adult researcher, to, for example, the next oldest white male in the room (Gallagher, 2008). While power may technically be being transferred to a young person in this instance, if that young person is a dominating force that does not allow for the perspectives of other young people to contribute within the project, then the project fails to uphold the emancipatory focus of critical traditions. Adult involvement does not entirely remove this risk but they can help to manage and reduce its effect.

By interrupting and redistributing power, adults can add value to the participatory process in a number of ways. First, it allows adults to evaluate and critique ideas so young people can critically reflect on the implications of their interpretations of various themes within the project. This allows the young people to consider whether their interpretations were merely replicating commonly held adult ideas about a particular theme or whether they were true of their own experience, thus working to increase the authenticity of the youth perspectives. Caitlin Cahill describes this role as within her (2007a) study and links to 
Freire's (1970) idea of raising consciousness of marginalised groups. Second, as shown through the findings and discussed in detail later on in this section, the young people's involvement was actually sustained by the idea that their voices were being listened to. Therefore, sharing power with and providing a platform for these voices is one way of showing young people that their voices will be listened to, which this study suggests will increase their involvement within the context of the project.

Despite this study providing evidence to suggest that youth participation can be enhanced by adult involvement, a critical consideration of this evidence raises the question of whether the need for, or benefit of, adult involvement would be removed if there were wide spread changes to engagement processes and systems to ensure that they work for young people. For example, one of the benefits of adult involvement in this process that worked to amplify youth voices was the opportunities that it afforded the group to share their findings beyond their own circles. While these opportunities inserted young people's voices and perspectives into traditionally adult settings, the gatekeepers of these settings should consider how ordinary young people, who do not necessarily have the backing of adults or organisations, can engage meaningfully within these spaces. If more inclusive and accessible systems at all levels of decision making become the norm, then adults' ability to provide these opportunities for young people is a less than convincing argument for their inclusion in participatory processes.

Similarly, this study provides evidence to suggest that the young people's sustained involvement in the project was influenced by the simple fact that adults and an organisation wanted to hear their perspectives. This was novel enough for some of the participants that they noted it as part of the reason that they wanted to be involved and continue being involved in the project. While this benefit again depends on adult involvement and an active decision to invite young people to participate, I would suggest that its impact would be greatly reduced should processes and systems work so that young people's voices were heard regularly and effectively. As it is, this project benefited from the fact that young people were grateful and excited to be at the decision-making table as this, sadly, is a novel opportunity.

As youth participatory practice develops across different sectors over time these particular benefits of adult involvement may come to have less of an impact on the authentic participation of young people within YPAR. However, they are important factors to consider in the current youth participation climate and may serve as vehicles to more aspirational levels of youth participation within all institutional decision-making processes. Furthermore, the benefits of adult involvement are not limited to those described above. Among other 
factors described previously, intergenerational relationships are an important factor for both youth development (Bowers, Johnson, Warren, Tirrell, \& Lerner, 2015) and as this study shows, participation with YPAR (see Section 6.2).

\subsection{Implications for Youth Participation Models}

While my study, utilised a number of participation models (see Chapter 2) both to inform the development of this project and evaluate the level of participation within the project, the findings illuminated areas within these models where more nuance was required.

For example, the benefit assigned to relationships within participatory processes are alluded to in the language of participation reference models such as Hart's (1992) Ladder, Westhorp's (1987) Continuum and Shier's (2001) Pathway. However, neither intergenerational, nor peer relationships are explicitly mentioned when classifying the various degrees of participation. This is perhaps because the models are concerned with defining and providing a mode of categorisation for participation rather than providing advice on how adults may facilitate participation to each of these degrees. That being said, this study suggests that relationships are an important indicator for the level of participation within a project and should be considered when evaluating participatory projects. This supports Abebe's (2019) claim that western individualism has contributed toward an understanding of participation that neglects the relational and interdependent nature of children and young people.

While this study does not claim to provide the definitive answer, it adds evidence to suggest that relationships are a necessary base from which to build participatory projects. In doing so it supports other models of participation such as Wierenga et al.'s (2003) Star, as well the local to New Zealand Le Va (2016) model and Ngā Uri Ō (Lifehack, 2016) which all feature relationships as a key aspect of participation. However, while Wierenga et al.'s (2003) Star, mentions the nurturing of informal relationships and Ngā Uri Ō (Lifehack, 2016) offers a framework for a relational approach to participation, this study brings to light the need for a model that further emphasises even more deeply the importance of relationships as a both a base point and continual reference point throughout participatory projects.

Relationships in this study were seen to weave through each stage of the participatory project with young people and informed and strengthened the processes, sustained youth involvement and amplified their perspectives. 
Furthermore, many of the participation models discussed in the literature review present adult involvement within the models as an inevitability (Hart, 1992; Shier, 2001; Treseder, 1997), but very few show a particularly nuanced understanding of the role of adult contributions and intergenerational partnerships as factors that can increase the authenticity of youth participation. Hart (1992) and Treseder (1997) for example consider projects in which adults and young people shared power and decisions as effective form of youth participation while Shier (2001) and Wierenga et al. (2003) discuss how adults can deconstruct or rework adult centric processes so they are more inclusive of young peoples' voices as well as resource processes that seek to amplify them. By exploring more deeply what adults actually might do in YPAR, this study offers further evidence to critique the hierarchical and linear nature of Hart's Ladder and other models of participation that seem to hold young people's independent (or free of adults) organisation and action as something to aspire to. While there is value in youth-initiated and developed projects, this study helps to further illuminate a number of positive factors that adult and community involvement can have on youth participation and development.

In sum, this project offers further critique of a western individualist view of youth participation that separates young people from the relational contexts within which they (and all people) exist. It works to illuminates the need for models of participation that centre and celebrate intergenerational and peer-to-peer relationships as catalysts for participation as these relationships are likely to enhance not only youth voice, but also the impact and outcome of a YPAR project. In the final chapter I examine some of the implications and limitations of this study. 


\section{Chapter 7: Conclusion}

\subsection{Introduction}

The aim of this study was to explore processes within an extended YPAR project to identify factors that can enhance youth participatory processes. As expressed in Chapter 1, the (UNCROC given) provision of a child's right to have a say in decisions that affect them has heightened interest in youth participation (Woodhead, 2010) and yet, now, 32 years later, we still do not have wide spread systems and processes that enable youth participation in decision making. This, I argued, set up the need for this study as well as further research in this area so the literature can continue to identify factors that can enable meaningful and authentic youth participation.

This chapter starts by revisiting the research questions presented in Chapter 1 before considering the implications that these findings have for youth participation policy and practice. Finally, it highlights the need for further research in this area to address some of the limitations of this study and move forward the ongoing cause for processes that uphold the rights of children and young people to have a say in decisions that affect them.

\subsection{Revisiting the Research Questions}

This study contributes to a growing body of work that seeks to understand how young people can participate meaningfully in decision making. Specifically, this study focussed on YPAR as one methodology that attempts to hold high young people's perspectives and consider the specific factors and processes that can enhance the authenticity of young people's engagement within YPAR. In Chapter 1 and through the literature review in Chapter 2, I highlighted the evidence for young people's participation being limited by:

a) Adult-centric engagement processes

b) power structures and unstated youth/adult hierarchies

c) a tendency for sporadic, short term youth participation opportunities that do not lead to sustained participation or change

With this in mind I developed a project that sought to respond to these issues and research questions that allowed me to explore the effectiveness of a relational and extended approach to YPAR.

First, I asked what factors sustained youth involved in an extended YPAR project? This question was about enabling an extended YPAR project and the findings from Chapter 4 
illustrated many of the factors which shaped participants' involvement in a YPAR project as well as provide tools for youth participatory researchers to encourage young people's sustained involvement within a project. The findings suggest that the relationships that the young people formed and developed with both their peers and the leaders through this project was a significant factor that encouraged them to stay involved throughout the 18 months. For some the project was a chance to meet and build relationships with those they might not usually interact with while others expressed an appreciation for the opportunity to hang out with their mates outside of school hours. As the project progressed, evidence of the more supportive and caring nature of the relationships the young people shared became clear. This helped to set up the reflexive relationship between relationships and sustained involvement where relationships in encouraging young people to stay involved with the process which in turn strengthened the relationships they shared which then further encouraged them to continue coming to the sessions (see Figure 6.2).

Although relationships can develop naturally, the influence of PYD strategies meant leaders made a decision to prioritise a relational approach to this project (Bowers et al., 2015) through the recruitment of participants that had an existing relationship with BGI youth workers. This was supported through the whakawhanaungatanga phase at the beginning of the project and through activities such as 'what's on top' and even the designated time and space for afternoon tea and unstructured conversation at the beginning of every session. Each of these factors aimed to contribute to a space where relationship building was encouraged and facilitated and the impact of that culture came through as a significant theme across the various data sets.

A second factor that encouraged sustained involvement for the young people was seeing the continual progress of the project and working towards an end goal was something that motivated the young people to continue coming. Some young people wanted to ensure that they were a part of every decision that progressed the research and this led them to not wanting to miss a meeting. While others who had a variety of commitments might miss a meeting here and there but seeing the progress since they last attended was something that motivated them to keep coming back. This combined with the motivation of making a difference supports Cammaerts, Bruter, Banaji Harrison \& Anstead's (2014) study that suggests that young people's participation is influenced by seeing the "direct impact of their involvement" (p. 658).

The third significant factor that influenced young people's sustained involvement in the project was the project's ethos; which included the idea of making a difference as well as 
the mental wellbeing theme, and the youth participatory nature of the project. Evidence of this factor contributing to sustained involvement builds a case for young people's desire and appreciation for their voices being heard and acted on. The young people chose the mental wellbeing theme and appreciated the fact that this choice shaped the whole emphasis of the project. They also appreciated knowing that this would have a real implications that would make a difference for young people in Wellington.

My second research question was: What processes of YPAR can enable and constrain the amplification of youth voices in a youth engagement project? To answer this question, I drew predominantly from the findings described in Chapter 5 and discussed these in more depth in Chapter 6. These chapters show that there were examples of young people's voices being amplified within the context of the project as well as in traditionally adult spaces.

Again, the relationships that young people shared with each other and the leaders was a significant factor that contributed to their ability to share their perspective. Through the model of relational participatory space (see Figure 6.1 and Section 6.4) I describe how relationships can contribute to creating a participatory space that facilitates young people's participation. For example, young people explained that these relationships made them feel more comfortable speaking up within a group setting. These relationships therefore acted as a vehicle for amplification in a number of ways. First, because they allowed for ideas such as truly valuing youth voices, and reduced leader authority to be communicated in a way that young people could believe and therefore act on in confidence. Second, because they allowed this participatory process to overcome or reduce some of the barriers that work to prevent young people from engaging in decision making processes. In this way relationships create a flow on effect that encourages the openness of other participants and creates a culture of sharing and participation within the context of the group (see Figure 6.2.)

Relationships also contributed to adult's understanding of the young people's personalities and needs which informed their ability to both rework the adult centric processes that limit young people's ability to share and include a variety of sharing activities that work for the specific young people in the group. These factors worked to increase the accessibility of the participatory process and allow young people with different capacities to each contribute to and shape the project.

The various opportunities that the young people had as a result of their involvement in this project also worked to amplify youth perspectives. Te Ahi brought the $1200+$ youth perspectives that they collected through their own research project to various adult spaces such as local Council meetings, the INVOLVE youth development conference, and a report 
launch event at Parliament. This represented a monumental effort on behalf of the young people in the group to organise their perspectives in a way that was accessible and recognised by adults. The effort suggests both the difficulty for young people to engage in adult designed engagement processes but also the opportunity that YPAR can provide young people to do so.

This study did also note several constraints that reduced youth voices and involvement. One of them was a tension between the young people's desire for regular visible progress and their full involvement in all phases of the project. At times the leaders made the decision to progress the project by, for example, writing the survey based on the conversations the young people had had, rather than allowing the young people full creative control over the wording. This was a decision that was made because of an observed lack of enthusiasm for writing questions and sets up an interesting question about whether amplifying their perspectives would have been better achieved by enabling them full control over this process or if allowing them to choose their level of participation is an amplification of their perspectives and wishes? A further constraint was noted by young people when they raised the issue of diversity and size of the group. Again, this set up a tension, that was also acknowledged by the young people, that larger numbers may have impacted the young people's ability to form strong connections and yet the lack of diversity may also work to homogenise youth voice. A third constraint was the constraint of the young people's own time. Many of the group had other commitments that meant their involvement ebbed and flowed across the 18 months which limited their ability to contribute to all phases of the project.

\subsection{Implications for Policy and Practice}

One aim of my research was to consider how YPAR can improve youth engagement processes across multiple sectors of society. This is consistent with the emancipatory focus of YPAR as a methodology because by sharing knowledge that can better equip policy makers and practitioners to develop meaningful youth engagement processes, young people's right to have their say on decisions that affect them will be more widely upheld.

This study suggests that young people's relationships with peers and leaders can enhance the authenticity of the perspectives that young people may provide and thus policy makers and practitioners should consider how relationships can be prioritised within youth participatory projects. For practitioners, this means incorporating whakawhanaungatanga into the project process and weaving it throughout. As articulated in Section 6.4, it is important 
that practitioners do not view relationships as a transactional component of the participatory process or merely a means to an end, but rather as a way of prioritising the wellbeing of the young people involved. Incorporating PYD strategies within participation is one way of prioritising relationships and youth wellbeing within the process (Bowers et al., 2015).

For policy makers an understanding of the value or relationships could mean, firstly, exploring how youth participation processes can be undertaken by those with existing relationships with young people. Youth development organisations such as BGI work to maintain such relationships and this can reduce the effect of power structures present in other institutions such as schools that can limit the young people's comfort sharing their perspective (Bernstein, 2000). Secondly, understanding the importance of relationships within participatory processes encourages policy makers to rework expectations around short project timeframes as well as considering how the relatively unquantifiable or unmeasurable outcome of a relationship can be valued as a legitimate outcome or performance measure within a project. Freeman et al. (2003) identify time frames, targets and resources among institutional systems that work as constraints for youth participation. This links to the idea of reworking processes (see Section 6.4) so that youth participation is not measured by the same criteria as adult-focussed participatory projects but rather by the extent to which their participation is enabled through unquantifiable factors such as the development of a relational participatory space.

\subsection{Implications for Further Research}

This study considered a small-scale case and there are a number of limitations that mean the findings are not generalisable. However, it does sheds light on areas for future research. Youth participation practices and literature is still far from providing young people with authentic and meaningful opportunities to have a say on decisions that affect them and thus further research is needed to develop theory and frameworks that uphold young people's right to have their say.

This was a small, 18-month YPAR study. Further research that extends upon this such as a large-scale, mixed-methods study that explores the use of a relational participatory space across a number of YPAR projects would be valuable. The ethics of utilising a control group to test the effectiveness of this approach within participatory processes is dubious because of the wellbeing and developmental benefits associated with youth adult relationships (Bowers et al., 2015). However, future studies could provide evidence to support or critique different 
types of relationships that might enable sustained involvement within a project. Furthermore, my own study focussed on the participants whose involvement was sustained but some participants did pull out of the project for a number of reasons. Further research could work to understand the reasons why young people might not wish to continue with a participatory project. This would help to illuminate further barriers for young people's involvement which could be reduced or responded to in future projects.

My study employed a number of activities and systems that aimed to facilitate relationships developing between the participants as well as with the leaders. However, these initiatives were not evaluated. Further research could also test the effectiveness of these approaches to determine how well they facilitated and sustained relationships within the group. In addition, my closeness to the project meant, at times, my judgements and sense of it were clouded by my own involvement. Whilst this meant I kept close to the action, an external evaluator may also have greater perception in such areas

Finally, a longitudinal study that examines the sustained impact of the YPAR project to gauge to what extent young people's voices contributed to meaningful change would add further evidence to ascertain the effectiveness of an extended YPAR project informed by PYD strategies.

In conclusion I wish to pay respect to the young people and their involvement within this study. Their enthusiasm and energy throughout the project highlighted the appetite that young people have for participating as citizens within society and illuminated the need to increase the range of opportunities that allow all young people to have their say on decisions that affect them. 


\section{References}

Abebe, T. (2019). Reconceptualising Children's Agency as Continuum and Interdependence. Social Sciences, 8(81).

Adams, T. E., Ellis, C., \& Jones, S. H. (2014). Autoethnography : Autoethnography. Oxford, UNITED STATES: Oxford University Press, Incorporated.

Apple, M. W., Au, W., \& Gandin, L. A. (2009). Mapping Critical Education. In The Routledge international handbook of critical education (Vol. Routledge international handbook series, pp. 3-19). New York, NY: Routledge.

Ara Taiohi. (2020). Code of Ethics For Youth Work In Aotearoa New Zealand (3 ed.). Wellington: Korowai Tupu.

Ardoin, N. M., Castrechini, S., \& Hofstedt, M. K. (2014). Youth-community-university partnerships and sense of place: two case studies of youth participatory action research. Children's Geographies, 12(4), 479-496. doi:10.1080/14733285.2013.827872

Arnot, M. (2006). Gender voices in the classroom. In B. Skelton, B. Frances, \& L. Smulyan (Eds.), Sage handbook on gender and education (pp. 407-422). London: Sage.

Arnot, M., \& Reay, D. (2007). A Sociology of Pedagogic Voice: Power, inequality and pupil consultation. Discourse: Studies in the cultural Politics of Education, 28(3), 311-325. doi:10.1080/01596300701458814

Ball, D. (2019) Darroch Ball argues against lowering the voting age to 16/Interviewer: $R$. Bridge. Magic Talk Drive.

Baum, F., MacDougall, C., \& Smith, D. (2006). Participatory action research. Journal of Epidemiology and Community Health, 60(10), 854. doi:10.1136/jech.2004.028662

Baxter, R., Caddie, M., \& Cameron, G. B. (2015). Aotearoa New Zealand's Indigenous Youth Development Concepts Explored in Practice Today. In M. Heathfield \& D. Fusco (Eds.), Youth and Inequality in Education: Global Actions in Youth Work. London, UNITED KINGDOM: Taylor \& Francis Group.

Berg, B. (2009). Qualitative research methods for the social sciences (7 ed.). Boston: Allyn and Bacon.

Bermudez, A. (2012). Youth civic engagement: decline or transformation? A critical review. Journal of Moral Education, 41(4), 529-542. doi:10.1080/03057240.2012.732296

Bernstein, B. (2000). Pedagogy, Symbolic Control, and Identity. Blue Ridge Summit, UNITED STATES: Rowman \& Littlefield Publishers.

Body, A., \& Hogg, E. (2019). What mattered ten years on? Young people's reflections on their involvement with a charitable youth participation project. Journal of Youth Studies, 22(2), 171-186.

Bowers, E. P., Johnson, S. K., Warren, D. J. A., Tirrell, J. M., \& Lerner, J. V. (2015). YouthAdult Relationships and Positive Youth Development. In E. P. Bowers, G. J. Geldhof, S. K. Johnson, L. J. Hilliard, R. M. Hershberg, J. V. Lerner, \& R. M. Lerner (Eds.), Promoting Positive Youth Development: Lessons from the 4-H Study (1st ed.): Springer International Publishing.

Braun, V., \& Clark, V. (2006). Using thematic analysis in psychology. In (pp. 77-101). Qualitative Research in Psychology.

Cahill, C. (2004). Defying gravity? raising consciousness through collective research. Children's Geographies, 2(2), 273-286. doi:10.1080/14733280410001720557

Cahill, C. (2007a). Doing Research with Young People: Participatory Research and the Rituals of Collective Work. Children's Geographies, 5(3), 297-312. doi:10.1080/14733280701445895 
Cahill, C. (2007b). Including excluded perspectives in participatory action research. Design Studies, 28(3), 325-340. doi:10.1016/j.destud.2007.02.006

Cahill, C. (2007c). Positioning Ethical Commitments: Participatory Action Reseach as a Relational Praxis of Social Change. ACME: An International E-Journal for Critical Geographies, 6(3), 360-373.

Camino, L. A. (2000). Youth-Adult Partnerships: Entering New Territory in Community Work and Research. Applied developmental science, 4(sup1), 11-20. doi:10.1207/S1532480XADS04Suppl_2

Cammaerts, B., Bruter, M., Banaji, S., Harrison, S., \& Anstead, N. (2014). The Myth of Youth Apathy: Young Europeans' Critical Attitudes Toward Democratic Life. American Behavioral Scientist, 58(5), 645-664. doi:10.1177/0002764213515992

Cammaerts, B., Bruter, M., Banaji, S., Harrison, S., \& Anstead, N. (2016). Participation of Youth in Elections: Beyond Youth Apathy. In B. Cammaerts, M. Bruter, S. Banaji, S. Harrison, \& N. Anstead (Eds.), Youth Participation in Democratic Life: Stories of Hope and Disillusion (pp. 49-82). London: Palgrave Macmillan.

Cammarota, J., \& Romero, A. (2011). Participatory Action Research for High School Students: Transforming Policy, Practice, and the Personal With Social Justice Education. Educational Policy, 25(3), 488-506. doi:10.1177/0895904810361722

Cerecer, D., Alberto, Quijada, Cahill, C., \& Bradley, M. (2013). Towards a Critical Youth Policy Praxis: Critical Youth Studies and Partiipatory Action Research. Theory into Practice, 52(3), 216-223.

Corbin, J., \& Strauss, A. (2008). Basics of Qualitative Research (3rd ed.): Techniques and Procedures for Developing Grounded Theory. In. doi:10.4135/9781452230153

Cossar, J., Brandon, M., \& Jordan, P. (2014). 'You've got to trust her and she's got to trust you': children's views on participationin the child protection system. Child and Family Social Work, 21(1), 103-112.

Creswell, J. W. (2019). Educational research : planning, conducting, and evaluating quantitative and qualitative research (Sixth edition. ed.). New York, NY: Pearson.

Cullen, O., \& Walsh, C. A. (2019). A Narrative Review of Ethical Issues in Participatory Research with Young People. Young, 1-24. doi:10.1177/1103308819886470

Davidson, C., \& Tolich, M. (2003). Social science research in New Zealand: Many paths to understanding. Auckland: Pearson Education.

Department of the Prime Minister and Cabinet. (2019). Child and Youth Wellbeing Strategy. Retrieved from https://childyouthwellbeing.govt.nz/sites/default/files/2019-08/childyouth-wellbeing-strategy-2019.pdf

Eccles, J. S., \& Gootman, J. A. (2002). Community programs to promote youth development. Washington, DC: National Academy Press.

Fielding, M. (2004). Transformative approaches to student voice: theoretical underpinnings, recalcitrant realities. British Educational Research Journal, 30(2), 295-311. doi:10.1080/0141192042000195236

Finlay-Robinson, S., Baxter, R., \& Dunlop, H. (2019). Youth Participation in Aotearoa: before 2020 and beyond. Kaiparahuarahi, 1(2), 32-68.

Fitzgerald, R., Graham, A., Smith, A., \& Taylor, N. (2010). Children's participation as a struggle over recognition: Exploring the promise of dialogue. In B. Percy-Smith \& N. Thomas (Eds.), A Handbook of Children and Young People's Participation (pp. 294305). Oxon: Routledge.

Fitzmaurice, L. (2016). Towards a participation ecosystem: A literature review on participation in decision-making for children in state care. Journal of Applied Youth Studies, 1(3), 84-95.

Foucault, M. (1977). Discipline and punish. New York: Pantheon Books. 
Freeman, C., Nairn, K., \& Sligo, J. (2003). 'Professionalising' Participation: From Rehtoric to Practice. Children's Geographies, 1(1), 53-70.

Freire, P. (1970). Pedagogy of the oppressed (M. B. Ramos, Trans.). In Pedagogy of the oppressed (30th Anniversary Edition ed., pp. 71-86). New York, NY: Continuum.

Gallacher, L.-A., \& Gallagher, M. (2008). Methodological Immaturity in Childhood Research?:Thinking through 'participatory methods'. Childhood, 15(4), 499-516. doi:10.1177/0907568208091672

Gallagher, M. (2008). 'Power is not an evil': rethinking power in participatory methods Children's Geographies, 6(2), 137-150.

Graham, A., Whelan, J., \& Fitzgerald, R. (2006). Progressing Participation: Taming the Space between Rhetoric and Reality. Children, Youth and Environments, 16(2).

Guarino, A., Cicognani, E., \& Zani, B. (2020). Motivations for Joining and Engaging in Youth Organisations in the Italian Context. In S. Banaji \& S. Mejias (Eds.), Youth Active Citizenship in Europe: Ethnographies of Participation (pp. 37-61). Cham: Springer International Publishing.

Harris, A., Wyn, J., \& Younes, S. (2010). Beyond apathetic or activist youth: 'Ordinary' young people and contemporary forms of participation. Young Nordic Journal of Youth Research, 18(1), 9-32. doi:10.1177/110330880901800103

Hart, R. A. (1992). Children's Participation: From Tokenism to Citizenship. In Innocenti essays (Vol. 4). Florence: UNICEF Innocenti Research Centre.

Hart, R. A. (1997). Children's participation : the theory and practice of involving young citizens in community development and environmental care / by Roger A. Hart

with contributions by Maria Fernanda Espinosa, Selim Iltus, Raymond Lorenzo. London: London : Earthscan.

Hemara, W. (2000). Māori pedagogies : a view from the literature. Wellington, N.Z: New Zealand Council for Educational Research.

Hickey, A., \& Pauli-Myler, T. (2019). The constraints of youth: young people, active citizenship and the experience of marginalisation. Discourse: Studies in the cultural Politics of Education, 40(3), 372-385.

Houghton, C. (2015). Young People's Perspectives on Participatory Ethics: Agency, Power and Impact in Domestic Abuse Research and Policy-Making. Child abuse review (Chichester, England : 1992), 24(4), 235-248. doi:10.1002/car.2407

Johnson, B., \& Christensen, L. (2012). Educational Research: Quantitative, Qualitative and Mixed Approaches (4 ed.). California: Sage Publications.

Lansdown, G. (1995). Taking Part: Children's Participation in Decsion-making London: Institute for Public Policy Research.

Lansdown, G. (2010). The realisation of children's participation rights. In B. Percy-Smith \& N. Thomas (Eds.), A Handbook of Chilrdren and Young People's Participation (pp. 11-23). London: Routledge.

Lather, P. (2006). Paradigm proliferation as a good think to think with: teaching research in education as a wild profusion. International Journal of Qualitative Studies in Eductation, 19(1), 35-57. doi:10.1080/09518390500450144

Lawy, R., \& Biesta, G. (2006). Citizenship-As-Practice: The Educational Implications of an Inclusive and Relational Understanding of Citizenship. British Journal of Educational Studies, 54(1), 34-50. doi:10.1111/ j.1467-8527.2006.00335.x

Le Va. (2016). Pasifika Youth Participation Guide. Retrieved from https:/www.leva.co.nz/wp-content/uploads/2019/10/Pasifika-Youth-Participationguide-A4.jpg

Lifehack. (2016). Ngā Uri Ō. Retrieved from https://lifehackhq.co/nga-uri-o-descendants/ 
Lock, H. (2019, 20/09/19). Teens campaign to lower voting age to 16. Radio New Zealand. Retrieved from https://www.rnz.co.nz/news/national/399244/teens-campaign-tolower-voting-age-to-16

Loveridge, J., \& Bourke, R. (2018). Using Student Voice to Challenge Understandings of Educational Research, Policy and Practice. In J. Loveridge \& R. Bourke (Eds.), Radical Collegiality through Student Voice. Singapore: Springer Nature.

Lundy, L. (2007). 'Voice' Is Not Enough: Conceptualising Article 12 of the United Nations Convention on the Rights of the Child. British Educational Research Journal, 33(6), 927-942. Retrieved from http://www.jstor.org.helicon.vuw.ac.nz/stable/30032800

Malone, K. (1999). Growing Up in Cities as a model of participatory planning and placemaking' with young people. Youth Studies Australia, 18(2), 17. Retrieved from http://helicon.vuw.ac.nz/login?url=http://search.ebscohost.com/login.aspx?direct=true $\& \mathrm{db}=$ aph \&AN $=2009810 \&$ site $=$ ehost-live

Mannion, G. (2007). Going Spatial, Going Relational: Why "listening to children" and children's participation needs reframing. Discourse: Studies in the cultural Politics of Education, 28(3), 405-420.

Matthews, H. (2001). Citizenship, Youth Councils and Young People's Participation. Journal of Youth Studies, 4(3), 299-318. doi:10.1080/13676260120075464

McGinley, B., \& Grieve, A. (2010). Maintaining the status quo?: Appraisingthe effectiveness of youth councils in Scotland. In B. Percy-Smith \& N. Thomas (Eds.), A Handbook of Children and Young People's Participation (pp. 254-261). Oxon: Routledge.

Merriam, S. B. (1988). Case study research in education : a qualitative approach (1st ed. ed.). San Francisco: Jossey-Bass.

Ministry of Education. (2007). The New Zealand Curriculum. Wellington: Learning Media Ministry of Youth Affairs. (2002). Youth Development Strategy Aotearoa. Retrieved from Wellington: http://www.myd.govt.nz/documents/resources-andreports/publications/youth-development-strategy-aotearoa/ydsa.pdf

Ministry of Youth Development. (2019). Funding Guide Youth Development Funding Stream 2019/2020. Retrieved from http://www.myd.govt.nz/documents/funding/final-mydfunding-guide-yd-f20.pdf

Mitra, D. L. (2004). The significance of students: Can increasing "student voice" in schools lead to gains in youth development? . Teachers College Record, 106(4), 651-688.

Nairn, K., Sligo, J., \& Freeman, C. (2006). Polarizing Participation in Local Government: Which Young People Are Included and Excluded. Children, Youth and Environments, 16(2), 248-271.

Nir, T., \& Perry-Hazan, L. (2016). The framed right to participate in municipal youth councils and its educational impact. Children and Youth Services Review, 69, 174183.

Norton, L., \& Sliep, Y. (2019). \#WE SPEAK: exploring the experience of refugee youth through participatory research and poetry. Journal of Youth Studies, 22(7), 873-890.

Ozer, E. J., \& Douglas, L. (2013). The Impact of Participatory Research on Urban Teens: An Experimental Evaluation. American Journal of Community Psychology, 51(1), 66-75. doi:10.1007/s 10464-012-9546-2

Ozer, E. J., \& Douglas, L. (2015). Assessing the Key Processes of Youth-Led Participatory Research: Psychometric Analysis and Application of an Observational Rating Scale. Youth \& Society, 47(1), 29-50.

Pain, R., \& Francis, P. (2003). Reflections on Participatory Research. Area, 35(1), 46-54. Retrieved from http://www.jstor.org.helicon.vuw.ac.nz/stable/20004288

Patton, M., Quin. (2015). Qualitative Research \& Evaluation Methods (4 ed.). Los Angeles: Sage Publications, Inc. 
Poulin, F., \& Denault, A.-S. (2013). Friendships with Co-Participants in Organized Activities: Prevalence, Quality, Freinds' Characteristics and Associations with Adolescents' Adjusment. In J. A. Fredricks \& S. D. Simpkins (Eds.), Organized OutOf-School Activities: Setting for Peer Relationships : New Directions for Child and Adolescent Development, Number 140 (pp. 19-36). New York, UNITED STATES: John Wiley \& Sons, Incorporated.

Richards-Schuster, K., \& Timmermans, R. (2017). Conceptualizing the role of adults within youth-adult partnerships: An example from practice. Children and Youth Services Review, 81, 284-292. doi:10.1016/j.childyouth.2017.07.023

Rodríguez, L. F., \& Brown, T. M. (2009). From voice to agency: Guiding principles for participatory action research with youth. New directions for youth development, 2009(123), 19-34. doi:10.1002/yd.312

Scott, D., \& Morrison, M. (2005). Key Ideas in Educational Research (1 ed.). UK: Bloomsbury.

Scott, M. A., Pyne, K. B., \& Means, D. R. (2015). Approaching Praxis: YPAR as Critical Pedagogical Process in a College Access Program. The High School Journal, 98(2), 138-157. Retrieved from http://www.jstor.org.helicon.vuw.ac.nz/stable/43281046

Serido, J., Borden, L. M., \& Perkins, D. F. (2011). Moving Beyond Youth Voice. Youth \& Society, 43(1), 44-63.

Shier, H. (2001). Pathways to Participation: Openings, opportunities and obligations. Children \& Society, 15(2), 107-117.

Skerrett, M., \& Ritchie, J. (2018). Ara Mai He Tetekura: Māori Knowledge Systems That Enable Ecological and Sociolinguistic Survival in Aotearoa. In A. Cutter-Mackenzie, K. Malone, \& E. Barratt Hacking (Eds.), Research Handbook on Childhoodnature: Assemblages of Childhood and Nature Research (pp. 1-21). Cham: Springer International Publishing.

Spicer, N., \& Evans, R. (2006). Developing Children and Young People's Participation in Strategic Processes: The Experience of the Children's Fund Initiative. Social Policy and Society, 5(2), 177-188. doi:10.1017/S1474746405002861

Te Ahi o Ngā Rangatahi. (2020). What's Next for Mental Wellbeing?: Outlining Opportunities for Youth Led Change. Retrieved from Wellington:

The UN Convention on the Rights of the Child Monitoring Group. (2017). Getting it Right: The Children's Convention in Aotearoa. Retrieved from http://www.occ.org.nz/childrens-rights-and-advice/uncroc/

Tisdall, E. K. M., \& Davis, J. (2004). Making a difference? Bringing children's and young people's views into policy-making. Children \& Society, 18(2), 131-142. doi:10.1002/chi.816

Torre, M., \& Fine, M. (2006). Participatory Action Research (PAR) by youth. In Youth activism: An international encyclopedia (L. Sherrod ed., Vol. 456-462, pp. 456-464). Westport: Greenwood Publishing Group.

Treseder, P. (1997). Empowering Children and Young People: Promoting Involvement in Decision Making. Children \& Society, 21, 31-41.

Tuhaka, C., \& Zintl, J. (2019). Mana Taiohi - the journey the destination. Kaiparahuarahi, $1(2), 5-7$.

Tuhiwai Smith, P. L. (2012). Decolonizing Methodologies : Research and Indigenous Peoples. London, UNITED KINGDOM: Zed Books.

Tukie, A. (2010). More than crubs from the table: A critique of youth paliaments as models of representation for marginalised young people. In B. Percy-Smith \& N. Thomas (Eds.), A Handbook of Children and Young People's Participation (pp. 262-269). Oxon: Routledge. 
Convention on the Rights of the Child, 1577 Cong. Rec. (1989).

Wagaman, M. A. (2015). Changing Ourselves, Changing the World: Assessing the Value of Participatory Action Research as an Empowerment-Based Research and Service Approach With LGBTQ Young People. Child \& Youth Services, 36(2), 124-149. doi:10.1080/0145935X.2014.1001064

Warren, C. A., \& Marciano, J. E. (2018). Activating student voice through Youth Participatory Action Research (YPAR): policy-making that strengthens urban education reform. International Journal of Qualitative Studies in Education, 31(8), 684-707. doi:10.1080/09518398.2018.1478154

Westhorp, G. (1987). Planning for youth participation: A resource kit. Youth Sector Training Council of South Australia.

Wierenga, A., Wood, A., Trenbath, G., Kelly, J., \& Vidakovic, O. (2003). Sharing a New Story: Young People in Decision-Making. Retrieved from Melbourne:

Williams, C., Edlin, J., \& Beals, E. (2010). Commentary 6. In B. Percy-Smith \& N. Thomas (Eds.), A Handbook of Children and Young People's Participation (pp. 281-290). Oxon: Routledge.

Wood, B. (2015). A Genealogy of the "Everyday" Within Young People's Citizenship Studies. In K. Kallio, S. Mills, \& T. Skelton (Eds.), Politics, Citizenship and Rights (pp. 1-14). Singapore: Springer Singapore.

Wood, B. (2016). Excluded citizens? Participatory research with young people from a 'failing' school community. Children's Geographies, 14(3), 310-324. doi:10.1080/14733285.2015.1043515

Wood, B., \& Black, R. (2014). Performing Citizenship Down Under: Educating the Active Citizen. Journal of Social Science Education, 13(4), 56-65. doi:10.2390/jsse-v13-i41413

Wood, B., Taylor, R., \& Atkins, R. (2018). Student Voice, Citizenship and Regulated Spaces. In R. Bourke \& J. Loveridge (Eds.), Radical Collegiality throuhg Student Voice: Educational Experience, Policy and Practice (pp. 179-196). Singapore: Springer Nature.

Woodhead, M. (2010). Foreword. In B. Percy-Smith \& N. Thomas (Eds.), A Handbook of Children and Young People's Participation: Perspectives from theory and practice (pp. xx). New York: Routledge.

Yanar, Z. M., Fazli, M., Rahman, J., \& Farthing, R. (2016). Research ethics committees and participatory action research with young people: The politics of voice. Journal of Emiracal Research on Human Research Ethics, 11(2), 122-128. 


\section{Appendices}

\section{Appendix 1: Observation Protocol}

\section{TE WHARE WX̃NANGA TE UPOKO O TE IKA MÃUI}

Authentic Youth Engagement in Decision-Making Processes: A Youth Participatory Action Research [YPAR] project with Urban Young People

The observation protocol will develop as the research group process becomes more clearly defined by the young people. However, below are a list of the sorts of details that I will observe during this process.

- Attendance at the weekly hui (I will keep a roll)

- Group dynamics (e.g., leadership, confidence) (I will note who is emerging with dominance in the groups - how that evolves or changes over time; strategies I use to try and bring in the wider groups and what impact that has - I will list these observations straight after meetings before I forget.

- Sharing styles of young people (large group, small group, written) - noting which styles seem to work for more youth.

- Success of various facilitation activities. I will document these in my field notes following each session.

- Extent of involvement of each young person (e.g., quieter/louder/active/distant etc)

I will write up these reflections as field notes following each session. Approximately every second week I will also ask participants to provide some reflections on the session through a creative oral process such as describing the meeting using an object in the room or a written post-it note exercise. 


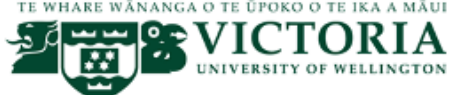

Authentic Youth Engagement in Decision-Making Processes:

A Youth Participatory Action Research [YPAR] project with Urban Young People

\begin{tabular}{|c|c|}
\hline Intro & $\begin{array}{l}\text { 1. Describe how you found being involved in this research } \\
\text { group. } \\
\text { a. PROMPT: what did you appreciate about being } \\
\text { involved? } \\
\text { b. PROMPT what did you find challenging about being } \\
\text { involved? }\end{array}$ \\
\hline Motivation & $\begin{array}{l}\text { 2. What motivated you to be a part of the research group? } \\
\text { 3. What motivated you to regularly attend meetings? } \\
\text { a. PROMPT: You didn't have to keep coming but you } \\
\text { chose to why was that? } \\
\text { b. PROMPT: You had some trouble attending } \\
\text { regularly, can you explain more about this? }\end{array}$ \\
\hline $\begin{array}{l}\text { Sharing } \\
\text { Perspectives }\end{array}$ & $\begin{array}{l}\text { 4. Think about times you shared your perspective either written } \\
\text { or out loud. What helped you feel comfortable sharing? } \\
\text { a. PROMPT: were there particular activities that we } \\
\text { used in the meetings that you thought worked well? } \\
\text { Could be improved? } \\
\text { 5. Were there times where you didn't share your perspective? } \\
\text { If so, what prevented you from saying/writing something or } \\
\text { sharing your opinion? } \\
\text { 6. How did you find relating to the others in the group - did this } \\
\text { help or hinder your active participation? } \\
\text { a. PROMPT: did this change over time? }\end{array}$ \\
\hline Amplification & $\begin{array}{l}\text { 7. Describe how much you think the project was shaped by } \\
\text { youth perspectives? } \\
\text { a. Follow up: what enabled this? } \\
\text { b. Follow up: how could the project have been more } \\
\text { influenced by the group? }\end{array}$ \\
\hline Closing & $\begin{array}{l}\text { 8. Is there anything else you would like to add that we haven't } \\
\text { discussed? } \\
\text { In closing state intention to get to participants a summary of } \\
\text { the discussion and full report will be available later. }\end{array}$ \\
\hline
\end{tabular}

Thank you... 
Appendix 3: Post Launch Reflection Sheet

How do you feel after getting to this stage of the project?

What does this mean for wider Wellington young people's voices?

To what extent has this process impacted your desire/ability to make your voice heard now and in the future? 


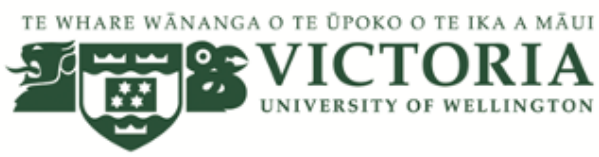

\section{Authentic Youth Engagement in Decision-Making Processes: A Youth Participatory Action Research [YPAR] project with Urban Young People}

My name is Eddy Davis-Rae and I am a Masters Student at the Faculty of Education at Victoria University of Wellington. This letter is to invite you to participate in research which will work towards my Masters in Education thesis.

\section{What is the aim of the research?}

Many people have started to realise that it is important to include young people's ideas when making decisions. However, many adult decision makers find it difficult to engage with young people. The purpose of this research project is to find out what helps young people provide their perspectives on important issues.

The research is part of my Master's Thesis in the Faculty of Education and the findings will be written up in a final report, and may be in academic journals and in conference presentations. This research has been approved by the Victoria University Human Ethics Committee [HEC No. 0000027762]

\section{How can you help?}

You have been invited to participate because you are a young person between the ages of 15 and 19 and are passionate about helping to make Wellington a better place for young people. If you agree to take part you will be part of a research design group. You will be asked to contribute 1-2 hours at a weekly hui during term time. The hui will take place weekly during term time at BGI (3 MacDonald Crescent, Te Aro, Wellington) from 4-5:30pm and there will be approximately 10 meetings per term.

At these hui we will:

- Brainstorm issues facing young people

- Learn about different research methodologies.

- Develop our own research question

- Strategise to maximise the number of young people we can reach

- $\quad$ Share food, have fun and make friends.

- Putting ideas/projects discussed at the hui into action!

During these hui I will be taking notes about how the session goes and how you all engage with the various activities especially focusing on how the sessions help you provide your perspective. I will also give you a chance to give quick feedback on some of the sessions by using post-it notes or verbally. At the end of the year, you will be invited to take part in a one-on-one interview where I will ask you how you found this process and which activities you found useful or unhelpful. This interview will be voice recorded. 
You can still be part of this design group but not part of the research if you wish.

What will happen to the information you give?

I will not name you in the report and will give you the option of choosing a code name so you can't be identified. Only my supervisor and I will read the research notes and interview transcripts.

All data collected will be stored in a locked filing cabinet and all electronic information will be password protected. All data will be destroyed five years after completion of the research.

What will the project produce?

The information from my research will be used in my Masters of Education thesis and in report to BGI and/or academic publications and conferences.

\section{If you accept this invitation, what are your rights as a research participant?}

There is no obligation to be involved in the research and there are no implications for your involvement with BGI if you choose not to participate. You can choose to be involved in a) the focus group and/or b) the interview or neither of these.

If you do decide to participate, you have the right to:

- choose not to answer any question;

- ask for the recorder to be turned off at any time during the interview;

- withdraw from the study before December 28, 2019 without giving a reason;

- ask any questions about the study at any time.

If you are under 16 years, I will need your parent's consent for you to participate in this research. If you are willing to be involved, can you please sign the form below and get your parent's consent as well. Your parents are very welcome to contact me if they require further information - my details are supplied below.

I will be very happy to provide a summary of the findings of the research to you/your parents and you can request a copy of the final report or a summary document on the consent sheet attached.

I appreciate you taking time to consider this request.

Warm regards,

Eddy Davis-Rae

Masters Student

Faculty of Education,

Victoria University of Wellington

Email: davisedwa@myvuw.ac.nz

If at any time you have any ethical concerns about this study, contact my supervisor, Dr Bronwyn Wood, Senior Lecturer, School of Education (telephone: +64 4463 9611); email: bronwyn.wood@vuw.ac.nz

or

the Victoria University HEC Convenor: Dr Judith Loveridge. Email hec@vuw.ac.nz or telephone +64-4-463 6028 . 


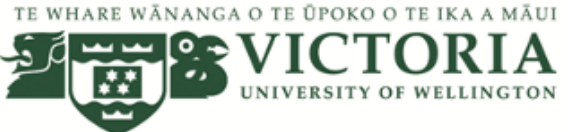

\section{Authentic Youth Engagement in Decision-Making Processes: A Youth Participatory Action Research [YPAR] project with Urban Young People \\ Consent to research design group/interview}

This consent form will be held for 5 years.

Researcher: Eddy Davis-Rae, Faculty of Education, Victoria University of Wellington.

- I have read the Information Sheet and the project has been explained to me. My questions have been answered to my satisfaction. I understand that I can ask further questions at any time.

I consent to participating in:

○ The design research group/reflections

on process

○ The interview

I understand that:

- $\quad$ I may withdraw the information I provide from this study at any point before 28 December, 2019 and any information provided will be destroyed.

- I understand that data provided in this study will be stored in a locked cabinet or on a password-protected computer to ensure that it is safe.

- The identifiable information I have provided will be destroyed on $28^{\text {th }}$ December 2024

- I won't be named or identified in the research and I can provide a code name for myself.

- Any information I provide will be kept confidential to the researcher and his supervisor

- I understand that the results will be used for a MEd thesis, a final report and academic publications and presented to conferences.

- I understand that organisational consent has been provided by BGI and the organisation will be named in the reports

- I would like to receive a copy of the final report

Yes

No

Signature of participant:

Name of participant:

Date:

Contact details: 


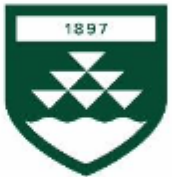

VICTORIA UNIVERSITY OF

\begin{tabular}{l|l}
\hline TO & Edward Francis Davis-Rae \\
\hline FROM & $\begin{array}{l}\text { Associate Professor Judith Loveridge, Convenor, Human Ethics } \\
\text { Committee }\end{array}$ \\
\hline
\end{tabular}

\begin{tabular}{l|l}
\hline DATE & 17 September 2019 \\
\hline PAGES & 1
\end{tabular}

\begin{tabular}{l|l}
\hline SUBJECT & $\begin{array}{l}\text { Ethics Approval } \\
\text { Number: } 27762 \\
\text { Title: YPAR with Wellington Teens }\end{array}$ \\
\hline
\end{tabular}

Thank you for your application for ethical approval, which has now been considered by the Human Ethics Committee.

Your application has been approved from the above date and this approval is valid for three years. If your data collection is not completed by this date you should apply to the Human Ethics Committee for an extension to this approval.

Best wishes with the research.

Kind regards,

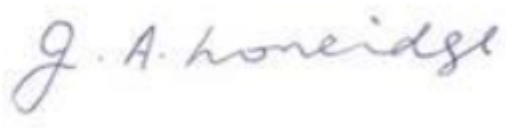

Judith Loveridge

Convenor, Victoria University of Wellington Human Ethics Committee 